\title{
Potential Behavior of Depleted Uranium Penetrators under Shipping and Bulk Storage Accident Conditions
}

J. Mishima M. A. Parkhurst

R. I. Scherpelz

D. E. Hadlock

March 1985

Prepared for

the U.S. Department of the Army under a Related Services Agreement with the U.S. Department of Energy

Contract DE-AC06-76RLO 1830

Pacific Northwest Laboratory Operated for the U.S. Department of Energy by Battelle Memorial Institute 


\title{
DISCLAIMER
}

This report was prepared as an account of work sponsored by an agency of the United States Government. Neither the United States Government nor any agency thereof, nor any of their employees, makes any warranty, express or implied, or assumes any legal liability or responsibility for the accuracy, completeness, or usefulness of any information, apparatus, product, or process disclosed, or represents that its use would not infringe privately owned rights. Reference herein to any specific commercial product, process, or service by trade name, trademark, manufacturer, or otherwise, does not necessarily constitute or imply its endorsement, recommendation, or favoring by the United States Government or any agency thereof. The views and opinions of authors expressed herein do not necessarily state or reflect those of the United States Government or any agency thereof.

\author{
PACIFIC NORTHWEST LABORATORY \\ operated by \\ BATTELLE \\ for the \\ UNITED STATES DEPARTMENT OF ENERGY \\ under Contract DE-AC06-76RLO 1830
}

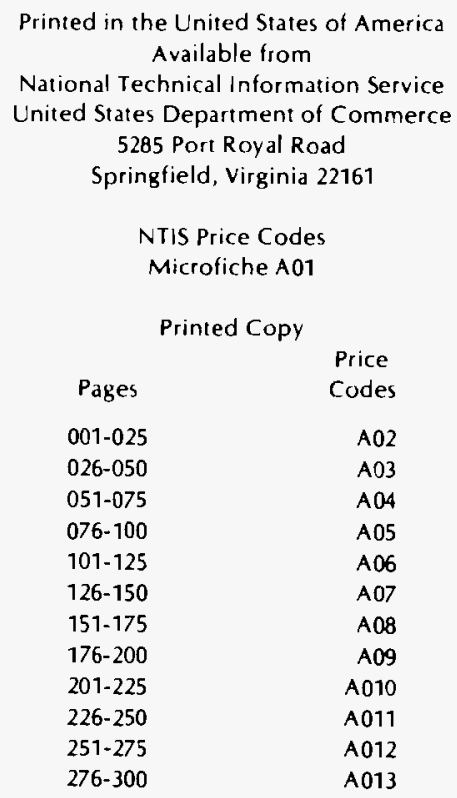


PNL-5415

UC-41

\section{2}

POTENTIAL BEHAVIOR OF DEPLETED URANIUM PENETRATORS UNDER SHIPPING AND BULK STORAGE ACCIDENT CONDITIONS

J. Mishima

M. A. Parkhurst

R. I. Scherpelz

D. E. Hadlock, Project Manager

February 1985

Prepared for Tank Ammunition Section Munitions System Division Large Caliber Weapons System Laboratory Army Armament Research and Development Center under a Related Services Agreement with the U.S. Department of Energy Contract DE-AC06-76RLO 1830

Pacific Northwest Laboratory

Richland, Washington 99352 



\section{$\underline{\text { ABSTRACT }}$}

An investigation of the potential hazard from airborne releases of depleted uranium (DU) from the Army's M829 munitions was conducted at the Pacific Northwest Laboratory. The study included: 1) assessing the characteristics of DU oxide from an April 1983 burn test, 2) postulating conditions of specific accident situations, and 3) reviewing laboratory and theoretical studies of oxidation and airborne transport of DU from accidents. Results of the experimental measurements of the DU oxides were combined with atmospheric transport models and lung and kidney exposure data to help establish reasonable exclusion boundaries to protect personnel and the public at an accident site. 


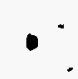

$\bullet$

- 


\section{EXECUTIVE SUMMARY}

In accordance with the Department of Defense's hazard classification test requirements, the Army Armament Research and Development Center conducts a testing program of its large caliber munitions. This hazard classification testing includes tests of the explosive hazards associated with various munitions under accident conditions, and transport classes are assigned to the munitions based on the test results. The Army tests the behavior of these rounds so that an exclusion area could be established around an accident site to protect Army personnel and members of the general public.

Previous tests have focused on the potential explosive hazards and penetrator ejections resulting from fires during transport or bulk storage of the munitions. More recently there has been a great deal of interest in the radiological and toxicological hazards to downwind populations from the possible airborne release of depleted uranium. The need to further investigate the potential hazard from airborne releases was evident after tests with the M829 rounds showed that, under severe fire conditions, the penetrators remained in the fire and were oxidized to powder rather than being ejected undamaged from the fire.

A study (documented in this report) to investigate the potential hazard from airborne releases was conducted with two objectives. The first objective was to characterize the depleted uranium oxide samples taken from an April 1983 external heat test for particle size, morphology, and lung fluid solubility. The second was to conduct a literature search on the uranium oxidation rates, the characteristics of oxides generated during the fire, the airborne release as a result of the fire, and the radiological/toxicological hazards from inhaled uranium oxides.

Results of the DU oxide sample analysis showed that about $1 \%$ of the uranium oxide had a least linear diameter $<10 \mu \mathrm{m}$. Particles $<10 \mu \mathrm{m}$ are generally considered in the respirable range. A more sensitive measure of respirable size is the measurement of the fraction that is <10 $\mu \mathrm{m}$ in aerodynamic equivalent diameter (AED). From $0.2 \%$ to $0.65 \%$ of the samples 
measured <10 $\mu \mathrm{m}$ AED. The particle size and the morphology indicated that a maximum of $0.6 \%$ by weight $(0.6 \mathrm{wt} \%)$ of the DU oxide was in the respirable size fraction and could become airborne.

Measurement of the solubility of the DU oxide in simulated interstitial lung fluid demonstrated that $96.5 \%$ of the sample had not dissolved within 60 days. The sample for this analysis was small because only the <10 $\mu \mathrm{m}$ AED fraction was used, but it provided sufficient evidence to conclude that the uranium in the sample should be classified as being $100 \%$ in the $Y$ class for calculations of retention and dose using the ICRP lung model. The $Y$ class includes compounds with dissolution half-times in the lung of more than 100 days.

In the literature search, laboratory and theoretical studies of DU oxidation and release from accidents that result in fire are summarized. The reaction rates, swelling and thermal stress, and variations in these and other properties are discussed as well as the compounds produced, their particle size, morphology and solubility.

Downwind transport of airborne DU from the accident site is evaluated in terms of plume characterization and plume movement. Models used to calculate particle entrainment and atmospheric transport are reviewed, and their capabilities are analyzed. The application of the atmospheric transport calculations to the hazard analysis starts with first identifying whether the main hazard to workers or the public downwind of the accident is likely to be radiological or toxicological in nature. Establishing this requires the knowledge of chemical form, solubility, and particle size of the uranium produced by the fire, or the use of worst-case assumptions. The chemical toxicity is the critical limit for soluble uranium compounds, and the critical organ is the kidney. Insoluble compounds present a hazard primarily to the lungs. Chronically exposed occupational workers are 1 imited to $0.2 \mathrm{mg} / \mathrm{m}^{3}$ for a $40-\mathrm{hr}$ week or $0.6 \mathrm{mg} / \mathrm{m}^{3}$ for occasional short-term exposures (ACGIH 1983). Exposures to $20 \mathrm{mg} / \mathrm{m}^{3}$ for soluble uranium compounds or $30 \mathrm{mg} / \mathrm{m}^{3}$ for insoluble ones are designated as being the maximum levels that a person could be subjected to for 30 minutes without impairing escape or causing irreversible health effects (Mackison, Stricoff and Partridge 1978). 
The exposure limits for toxicity are more conservative than most of the radiological limits and thus protect from either type of insult. None of the limits, however, are directly applicable to the accident situation, so derived limits to determine exclusion boundaries are reviewed and their assumptions are examined. The derived limits are applied to results from the characterization study and are used to estimate the fraction of inhaled DU deposited and retained in the lung versus the fraction that is transported to the kidney. Although it is not clear that DU in the M829 penetrators would consistently produce the same relative amount of respirable aerosol, the use of actual test results coupled with the atmospheric transport and lung and kidney exposure data allows calculation of exposure levels and provides pertinent input to the determination of reasonable exclusion boundaries that will protect personnel and the general public. 

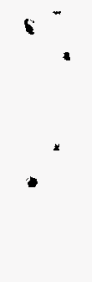

3

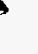

- 


\section{ACKNOWLEDGMENTS}

The authors wish to acknowledge the guidance and direction provided by the project manager, R. F. Sayer, of the Tank Ammunition Section, Large Caliber Weapons Systems Laboratory; and the in-depth technical review provided by R. W. Fliszar, of the Compliance and Technical Support Division, Safety Office. We also wish to thank M. Cross for word processing and A. Marshall for editing. 


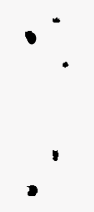

-

. 


\section{CONTENTS}

ABSTRACT

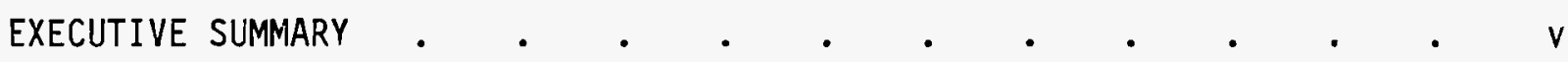

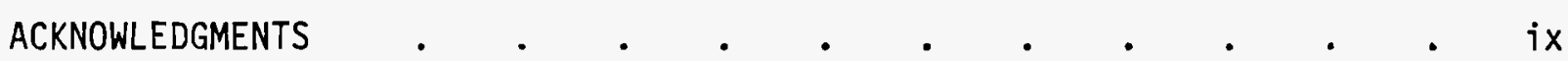

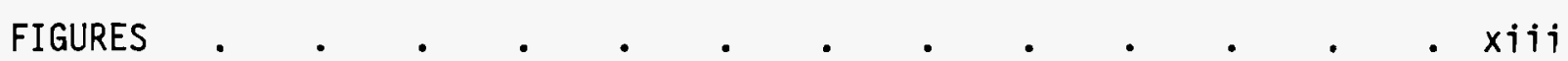

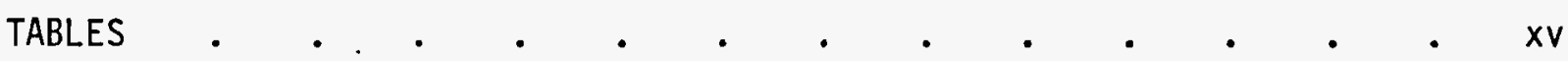

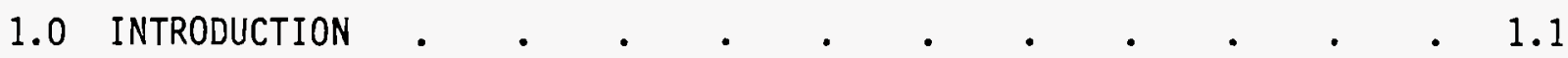

2.0 CHARACTERISTICS OF DU OXIDES FROM EXTERNAL HEAT TESTS OF

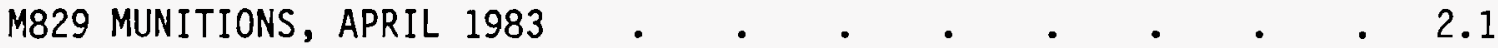

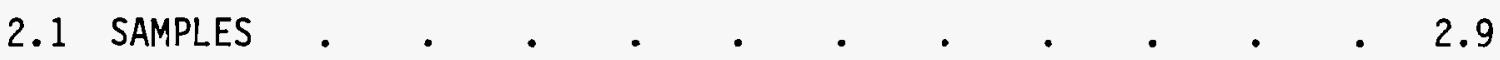

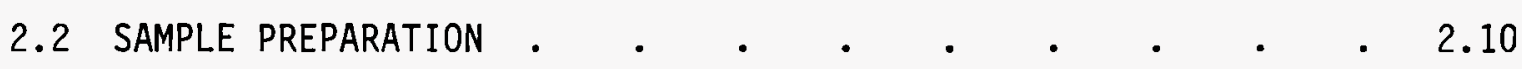

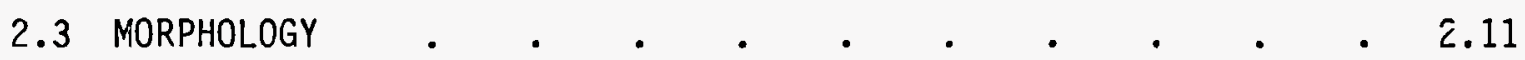

2.3.1 Fraction $<20>10 \mu \mathrm{m}$ LLD, Sample \#1 . . . . 2.11

2.3.2 Fraction $<10 \mu m$ LLD, Sample \#1 . . . . . . $\quad$. 2.14

2.3.3 Fraction <10 $\mu \mathrm{m}$ LLD, Composite Sample . . . . 2.14

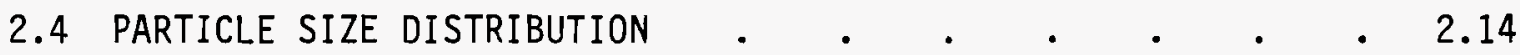

2.4.1 Size Distribution by Sieve Analysis . . . . 2.20

2.4.2 Size Distribution by Liquid Sedimentation . . . 2.20

2.5 SOLUBILITY IN INTERSTITIAL LUNG FLUID $\quad$ • $\quad$ • $\quad$ • $\quad$ • 2.25

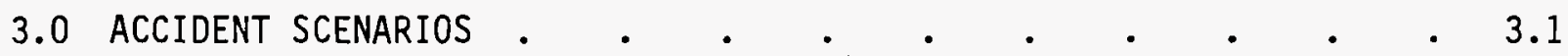

3.1 SHIPPING ACCIDENT - TRUCK ACCIDENT WITH FIRE . . . . $\quad 3.1$

3.2 BULK STORAGE ACCIDENT - FIRE IN AN IGLOO OR
STRADLEY MAGAZINE

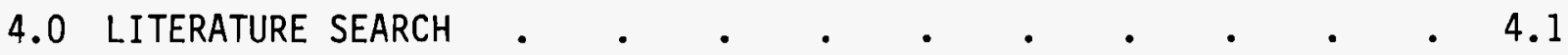

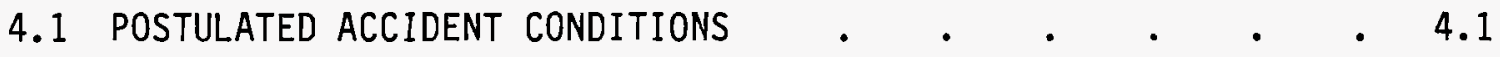


4.1.1 Analysis of Fires Involving DU Munitions . • 4.1

4.1.2 Fires Where Wood is the Principal Fuel . . . 4.4

4.2 BEHAVIOR OF DEPLETED URANIUM (DU) UNDER ACCIDENT

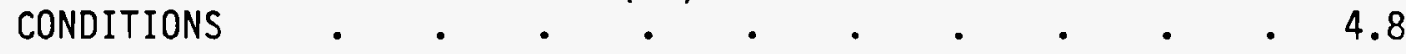

4.2.1 Uranium Compounds and Reaction Rates ..$\quad$. $\quad$. 4.9

4.2.2 The Characteristics of DU 0xides Generated by Fires - 4.18

4.2.3 Particle Size of the Oxides Formed From a Fire . . 4.20

4.2.4 Airborne Release of Uranium Under Postulated
Accident Conditions $. \quad . \quad . \quad . \quad . \quad . \quad . \quad 4.28$

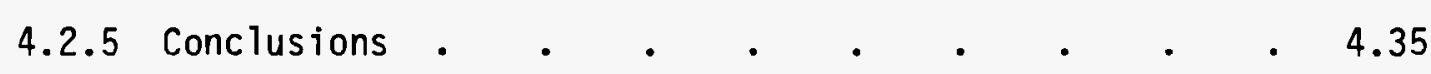

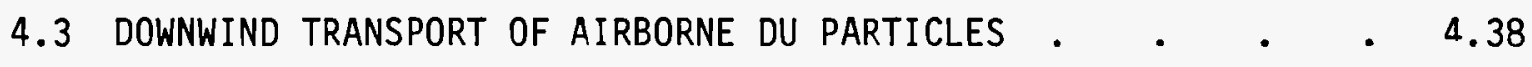

4.3.1 Models for Initial Plume Characterization . . . 4.39

4.3.2 Nearfield Atmospheric Transport . . . . . . 4.43

4.3.3 Effects of Complex Terrain and Rough Surfaces • • 4.44

4.3.4 Calculation of Downwind Atmospheric Transport . $\quad 4.45$

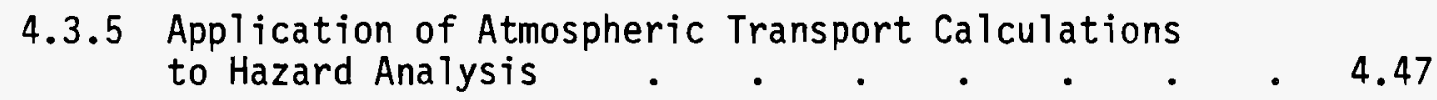

4.4 POTENTIAL INHALATION HAZARD FROM AIRBORNE RELEASES

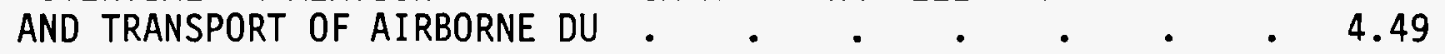

4.4.1 Identification of the Limiting Hazard . • . . 4.50

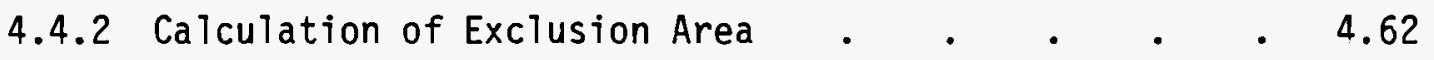

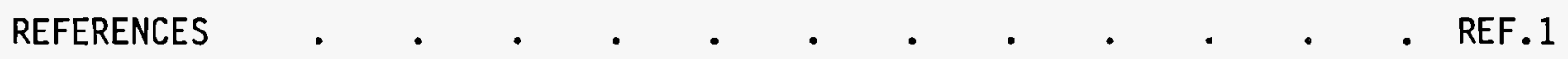

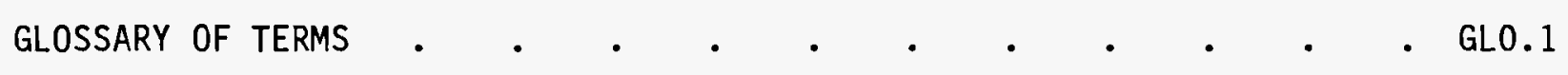




\section{FIGURES}

2.1 Test Munitions Secured to Test Stand . . . . . . 2.2

2.2 Ammunition Test Stand and Temperature Sensing Elements . . 2.3

2.3 Positions of Individual Heat Sensors . . . . . . . 2.3

2.4 Containment Enclosure and Post-Test Air-Sampling System $\quad$ - $\quad 2.4$

2.5 Containment Test Tray Prior to Ignition of Fire . . • • 2.4

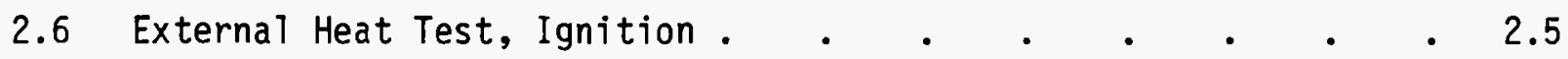

2.7 External Heat Test, Initial-Growth-Phase Fire . . . . 2.5

2.8 April 1983 External Heat Test, Time vs Temperature . . . 2.6

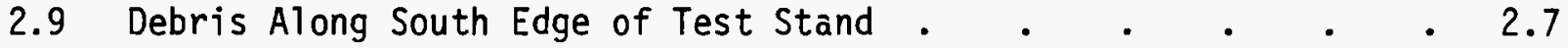

2.10 Remnant DU Core at Eastern Edge of Test Stand . . . . 2.8

2.11 Remnant DU Core at Northwest Corner of Test Stand . • . 2.8

2.12 SEM 100X. Particle Size Analysis Sample - Fraction $<20>10$ um LLD - Field \#1, Overall View . . . . . . 2.12

2.13 SEM 1500X. Particle Size Analysis Sample - Fraction $<20>10 \mu \mathrm{m}$ LLD - Field \#1, Typical Size and Shape of Particles

2.14 SEM 5000X. Particle Size Analysis Sample - Fraction $<20>10$ um LLD - Field \#1, Particle Morphology . . . . 2.15

2.15 SEM 500X. Particle Size Analysis Sample - Fraction $<10 \mu \mathrm{m}$ LLD - Field \#1, Typical Size and Shape of Particles . . 2.16

2.16 SEM 5000X. Particle Size Analysis Sample - Fraction $<10 \mu \mathrm{m}$ LLD - Field \#1, Particle Morphology . . . . . . 2.17

2.17 SEM 1500X. Composite Sample (\#6, \#7 and \#18) - Fraction $<10 \mu \mathrm{m}$ LLD - Field \#1, Typical Size and Shape of Particles . . 2.18

2.18 SEM 5000X. Composite Sample (\#6, \#7, and \#18) - Fraction $<10$ m LLD - Field \#1, Particle Morphology . . . . . 2.19

2.19 Size Distribution by Liquid Sedimentation - Fraction $<10 \mu \mathrm{m}$ LLD, Sample \#11e and Composite . . . . . . 2.25

2.20 Size Distribution of DU Oxide From Apri1 1983 Burn Test . • 2.26 


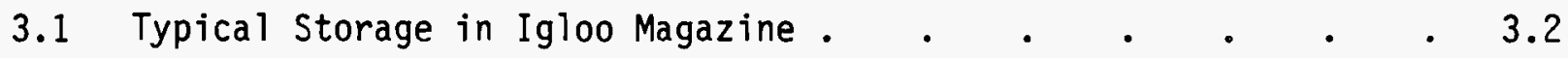

3.2 Typical Storage in Stradley Magazine . . . . . . . . . 3.3

4.1 Dependence of Uranium Ignition on Specific Area . . . . 4.11

4.2 Overall Oxidation Rate versus $1 / T$ for Various Specimen Sizes $\quad 4.13$

4.3 Oxidation Rate of Uranium in Air . $\quad . \quad$. $\quad . \quad$. $\quad . \quad$. 4.14

4.4 Variation of Oxidation Rate at $600^{\circ} \mathrm{C}$ with Oxygen Content of Gas Stream . $\quad . \quad . \quad . \quad . \quad . \quad . \quad . \quad . \quad .45$

4.5 Oxidation of Uranium in Carbon Dioxide ..$\quad$. $\quad . \quad$. $\quad$. 4.16

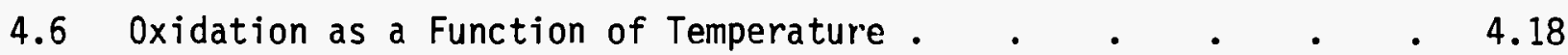

4.7 Phases in Pellets Oxidized in Air at Various Temperatures . . 4.19

4.8 Size Distribution of Oxides From Uranium Oxidizing in Air . $\quad$. 4.23

4.9 Size Distribution of Oxide From Uranium Oxidizing in Carbon

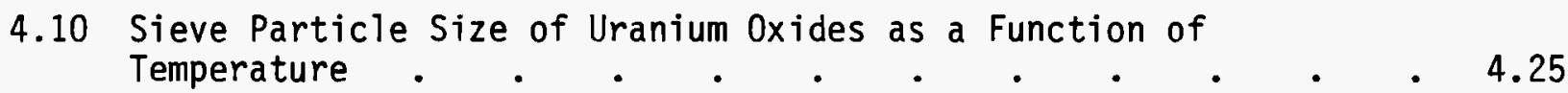

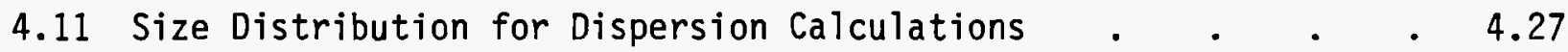

4.12 Respirable Size Fraction of Airborne Particles . . . . $\quad$ • 4.28

4.13 Aerosol Mass as a Function of Temperature . . . . . . . 4.31

4.14 Respirable Mass as a Function of Temperature $\quad$ e . . . $\quad$. 4.32

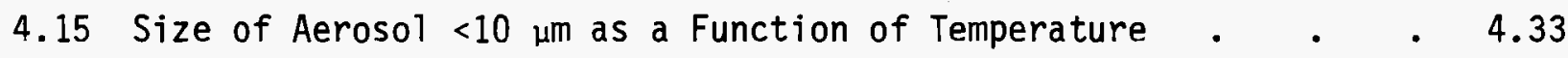

4.16 Particulate Threshold Friction Speed . . . . . . 4.36

4.17 Variation of Inhalation Dose with Particle Size . . . . 4.53

4.18 Particle Size Related to Dose $\quad$. $\quad$. $\quad$. $\quad$. $\quad$. $\quad$. 4.54

4.19 Schematic of Removal Pathways . . . . . . . . . . . 4.55

4.19 Variation of Inhalation Dose with Particle Size . . . . . 4.66

\begin{tabular}{l} 
4.20 Assumptions Used in McMillan (1979) to Derive Control \\
Boundary Limits... \\
\hline
\end{tabular}

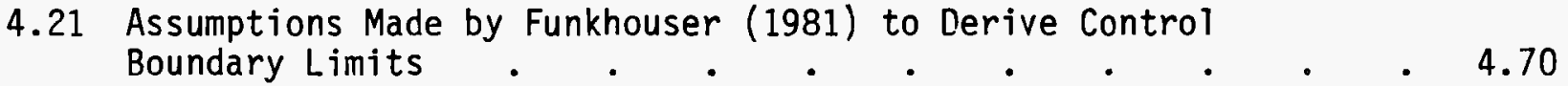


4.22 Transport and Inhalation of Depleted Uranium Based on M829 Field Test Fire

\section{$\underline{\text { TABLES }}$}

2.1 Samples From the April 1983 External Heat Test "C" . . $\quad 2.9$

2.2 Sieve Analysis Results - Particle Size Analysis,

Sample \#1

2.3 Sonic Sieve Analysis Results, Sample \#1le . . . . . . 2.21

2.4 Sieve Analysis Results, Composite Sample . . . . • . 2.22

2.5 Range of Sonic Sieve Fractions, Composite Sample . . . . 2.23

2.6 Comparison of Sieve Size Distributions . . . . . . . 2.24

2.7 Comparison of Experimental Values of $F$ With Those

Expected for $\mathrm{T}=100$ Days . . . . . . . . 2.27

4.1 Table from Schnizlein et al. 1959 . . . . . . . . 4.11

4.2 Penetrator 0xidation . . . . . . . . . . . . 4.17

4.3 Burn \#4, Final Penetrator Weights . . . . . . . 4.17

4.4 Data Relating to the Form and Composition of the Oxide
and Oxidation Kinetics of Sheet Specimens . . . . 4.21

4.5 Results of X-Ray Diffraction of DU Oxide Powders . . . . 4.22

4.6 Particle Size Distribution of DU Oxide Aerosol Used in

Dispersion Prediction Calculations for a Fire Involving

DU Munitions . . . . . . . . . . . . 4.26

4.7 Uranium Airborne Releases . . . . . . . . 4.29

4.8 Isotopic Composition of Depleted Uranium in
M735A1, M774, and M829 Penetrators . . . . . 4.51

4.9 Recommended Limits for Uranium and Uranium Oxide Exposures . . 4.59

4.10 Summary of Chronic Exposure Limits . • • • . . 4.60

4.11 Regulatory and Recommended Exposure Limits . . . . . 4.60

4.12 Calculated Emergency Exposure Limits . . • • • • • 4.66

4.13 Calculated $\mathrm{mg} / \mathrm{kg}$ Limits . . . . . . . . . . . 4.67 


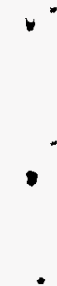

? 


\subsection{INTRODUCTION}

In accordance with the NATO Standard National Agreement, the U.S. Army tests new and modified packaged munitions and explosives to determine their potential transportation and storage hazards. The munitions are subjected to specific conditions simulating an accident or fire and the types and degrees of hazard for a given weapon are assessed. The munitions are then classified based on their explosive or toxic nature and their propensity for causing personnel injuries or property damage during transport or storage (DOD 1982).

Various factors must be addressed to evaluate the potential hazard to personnel or populations near the site of an accident. Nearby individuals could be subjected to blast effects from the detonation of the propellent or explosives in the rounds; these hazards are specifically considered in the current tests. Munitions incorporating depleted uranium (DU) pose an additional potential hazard from the radiation released during transport and from the possible dispersion of DU under some extreme conditions; the direct radiation hazard is covered by current Department of Transportation/Nuclear Regulatory Commission restrictions. Potential downwind hazards from airborne toxic or radiological releases during accidents, however, have not been evaluated in detail because tests on most cartridges showed that there was little possibility of such releases.

The Pacific Northwest Laboratory assisted the Army during the hazard classification tests on the M774 (Gilchrist, Parker and Mishima 1978) and the M829 (Hooker et al. 1983). The tests with the M774 indicated that little potential existed for the airborne release of depleted uranium (DU) from the penetrators during a fire because all of the DU penetrators were ejected from the high temperature area and sustained little damage that could result in the oxidation of the DU (Gilchrist, Parker and Mishima 1978).

When the M829 rounds were tested in a fire however, the cartridge cases did not confine the pressure, and all the DU remained in the high temperature area and was oxidized (Hooker et al. 1983). The external heat tests were performed twice for the M829 with substantialiy the same results. In the repeat of the external heat test, performed in April 1983, the residual 
material from the fire was collected and little, if any, DU was 1ost. Since the existing hazard classification tests do not address the possible radiological/toxicological hazard, the study that is documented in this report was necessary. The objective of this study is to accumulate and interpret the data on the potential radiological/toxicological hazard to the downwind population from the possible airborne release of DU during and following fires during transport and bulk storage of M829 rounds.

To pose a radiological/toxiological hazard to the downwind population, the DU must be relocated from the accident site. The relocation of the unchanged DU metal penetrator was assessed in the previous tests. The DU must be sufficiently subdivided before it can be carried by the prevailing winds and be considered an additional hazard. The DU particles must be under 20 micrometers aerodynamic equivalent diameter (AED) to be carried significant distances downwind, and must be less than 10 micrometers AED (a conservative estimate of the respirable fraction) to be an inhalation hazard. Metallic DU can be subdivided if the metal is oxidized. Thus, fires are the most severe accident conditions leading to the airborne release of DU.

To ascertain a particular fire's effects upon the DU, the fire's temperature, duration, atmosphere, etc. must be considered. This requires a scenario based upon the conditions anticipated for the accident. Once a conservative but generally realistic accident scenario has been formulated, the response of the DU to these postulated accident conditions can be evaluated. The two most important factors in estimating the hazard are the amount of metal oxidized and the characteristics of the oxide produced.

The quantity and characteristics of the material made airborne under the accident conditions define the initial hazard. The changes in concentration and characteristics of the material as it is carried by the wind define the hazards posed to individuals located along the path of the cloud. The degree of hazard to any individual is the effect to the body and organs from inhalation of the airborne material, because material inhaled and deposited within the body can pose both toxicological and radiological hazards.

This discussion includes the characteristics of the DU oxide from the April 1983 external heat test, possible accident scenarios, and a literature 
search. The DU oxide's morphology, particle size distribution, and solubility in simulated interstitial lung fluid were determined from experimental measurements. The literature search (primarily from 1979 on) is a comprehensive but not exhaustive review of uranium oxidation/oxidation rates, characteristics of the oxides generated during fires, airborne release of uranium under fire conditions, models to define the transport of airborne material, and radiological/toxicological hazards from inhaled uranium oxides. 
. 


\subsection{CHARACTERISTICS OF DU OXIDES FROM EXTERNAL HEAT TESTS OF M829 MUMITIONS, APRIL 1983}

Samples of oxidized penetrators were collected during the April 1983 external heat test "C" conducted at the Nevada Test Site (Hooker et a1. 1983). The test consisted of enveloping 12 M829 packaged rounds, banded together (Figure 2.1), in a hot fire. The munitions were placed on a prefabricated test stand $2.5 \mathrm{ft} \mathrm{H} \times 2 \mathrm{ft} W \times 3.5 \mathrm{ft} L$ made of 3 -inch ang?e iron (Figure 2.2). Six stainless-steel-clad thermocouples were positioned under the test stand to record the temperature that the penetrators were subjected to during the fire (Figure 2.3).

The test stand rested upon a $30 \mathrm{ft} \times 30 \mathrm{ft}$ square tray made of 1/4-inch steel with 3 -inch high sides attached to the outer edges. The tray was to aid in the recovery of the fire-generated materials from the test. Receptacles were placed around the outer edge of the tray to support the plastic sides erected after the initial high temperature phase of the fire abated (Figure 2.4). The center $10 \mathrm{ft} \times 10 \mathrm{ft}$ square of the tray was depressed an additional 5 inches to provide more insulation for that portion during the fire. The entire tray was filled with locally obtained sandy soil.

Large pieces of wood (railroad ties) were stacked under and around the munitions to form a crib-like configuration (Figure 2.5). The entire stack was wetted with fifty-five gallons of fuel and ignited (Figure 2.6). The fire burned vigorously during the first three hours (Figure 2.7 ) reaching temperatures in the $800^{\circ}$ to $1100^{\circ} \mathrm{C}$ range with 1 ocal highs up to $1200^{\circ} \mathrm{C}$ (Figure 2.8 ).

A11 12 rounds "cooked off" during the first hour of the burn. Observations following the initial period indicated no significant relocation of the materials. Portions of four penetrators were visible (Figures 2.9, 2.10, and 2.11). Weather conditions and the internal temperatures within the residues delayed the collection of residual materials for approximately two days. 


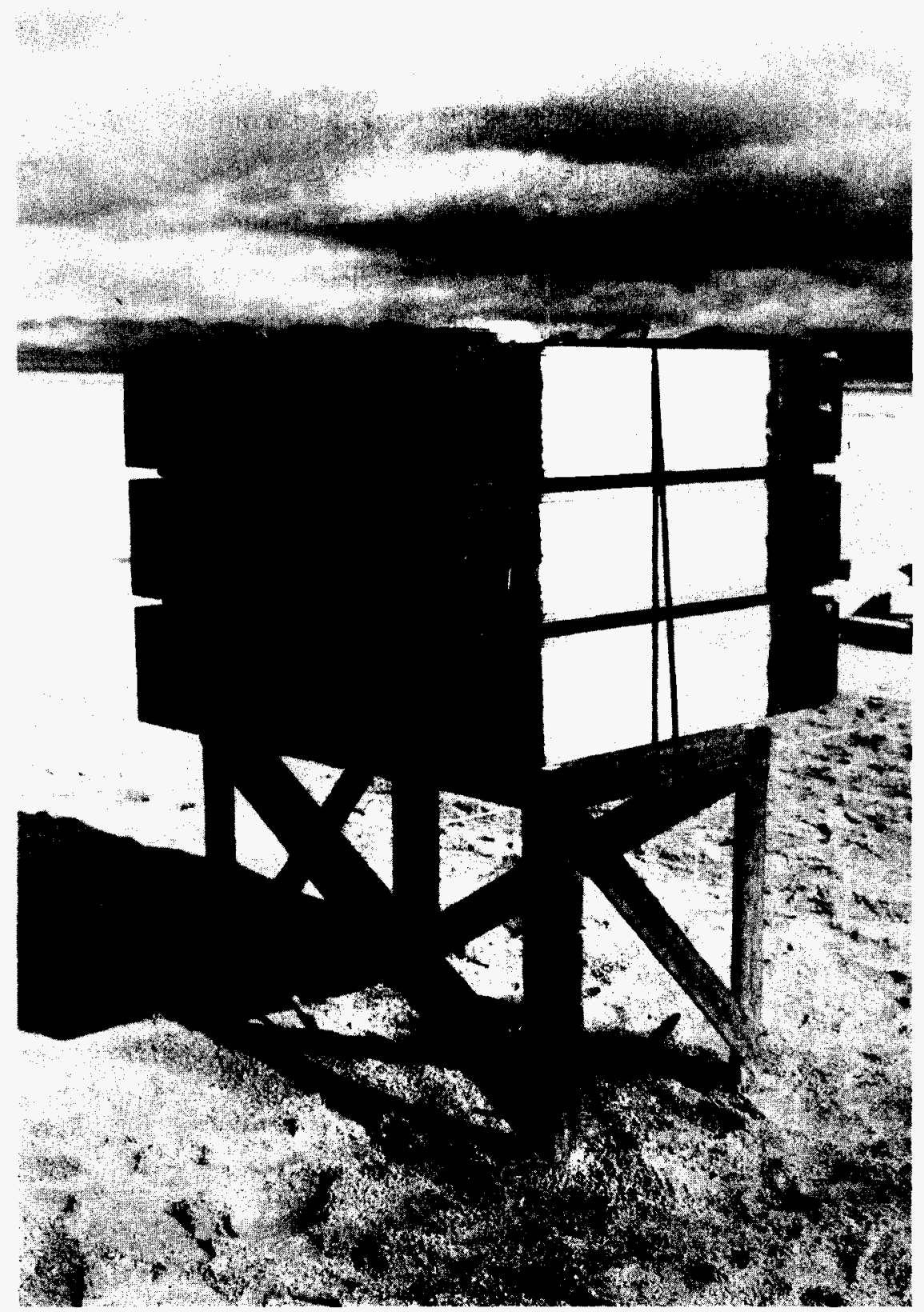

FIGURE 2.1. Test Munitions Secured to Test Stand 


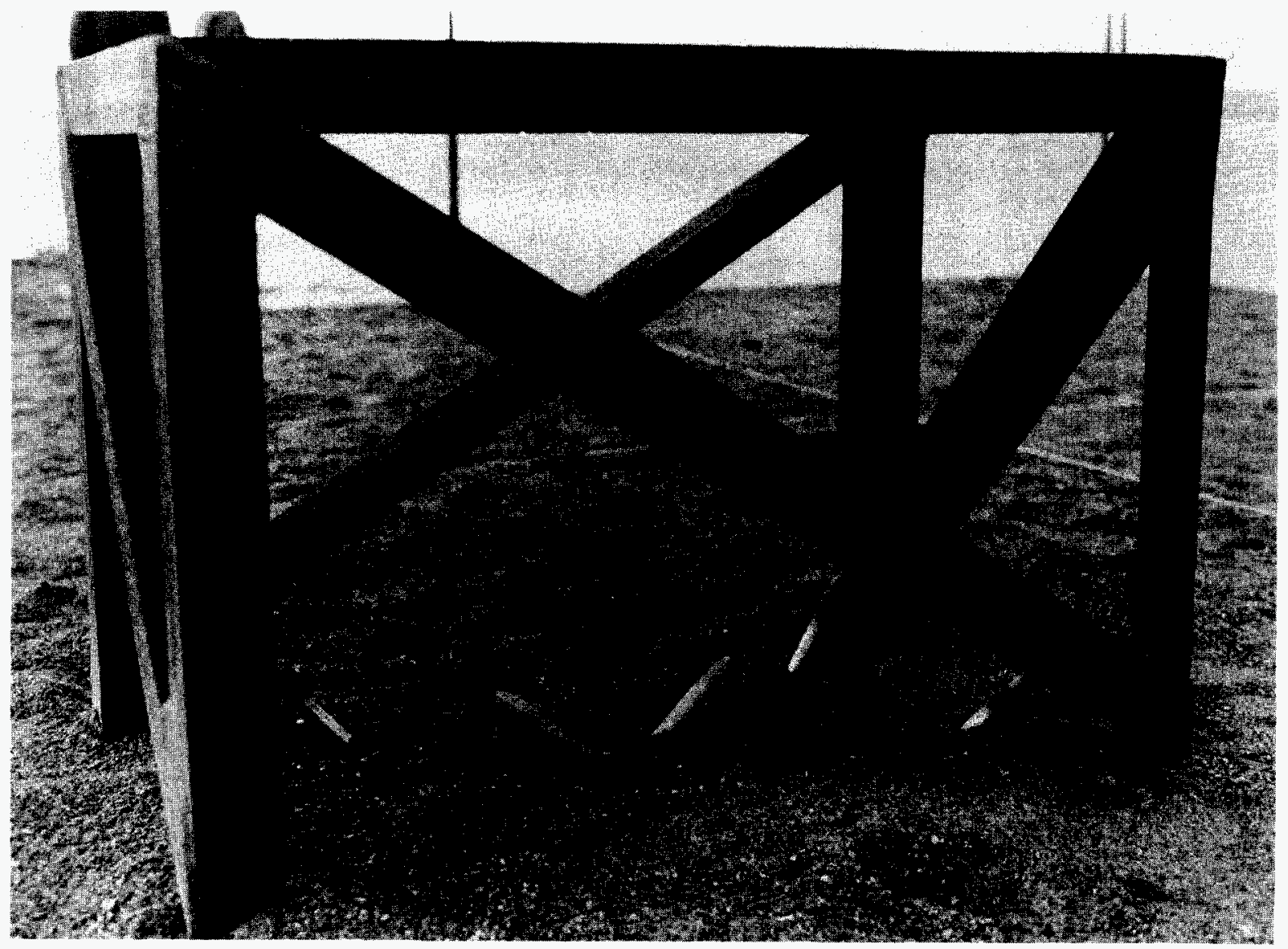

FIGURE 2.2. Ammunition Test Stand and Temperature Sensing Elements

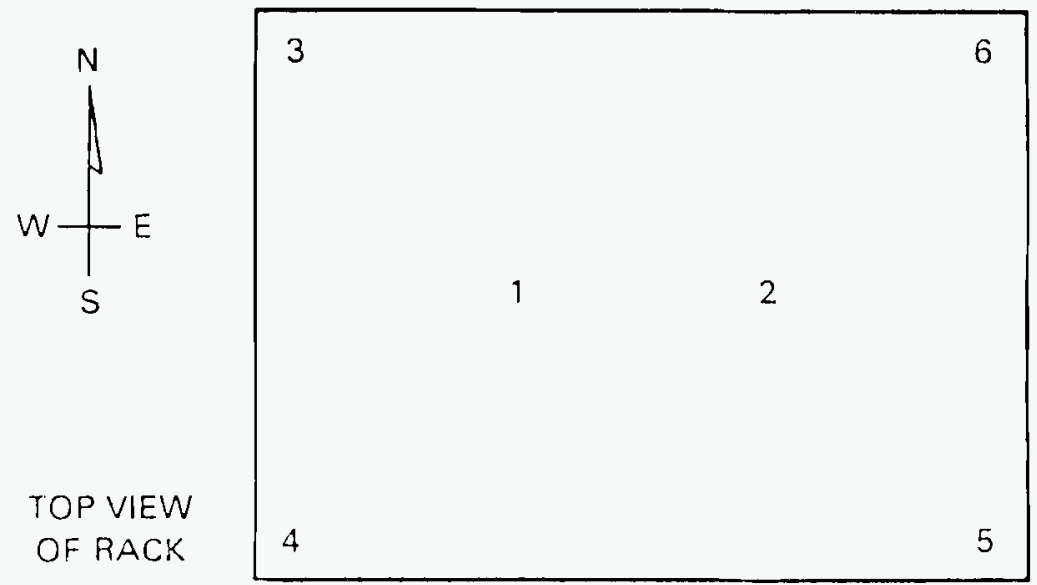

FIGURE 2.3. Positions of Individual Heat Sensors 


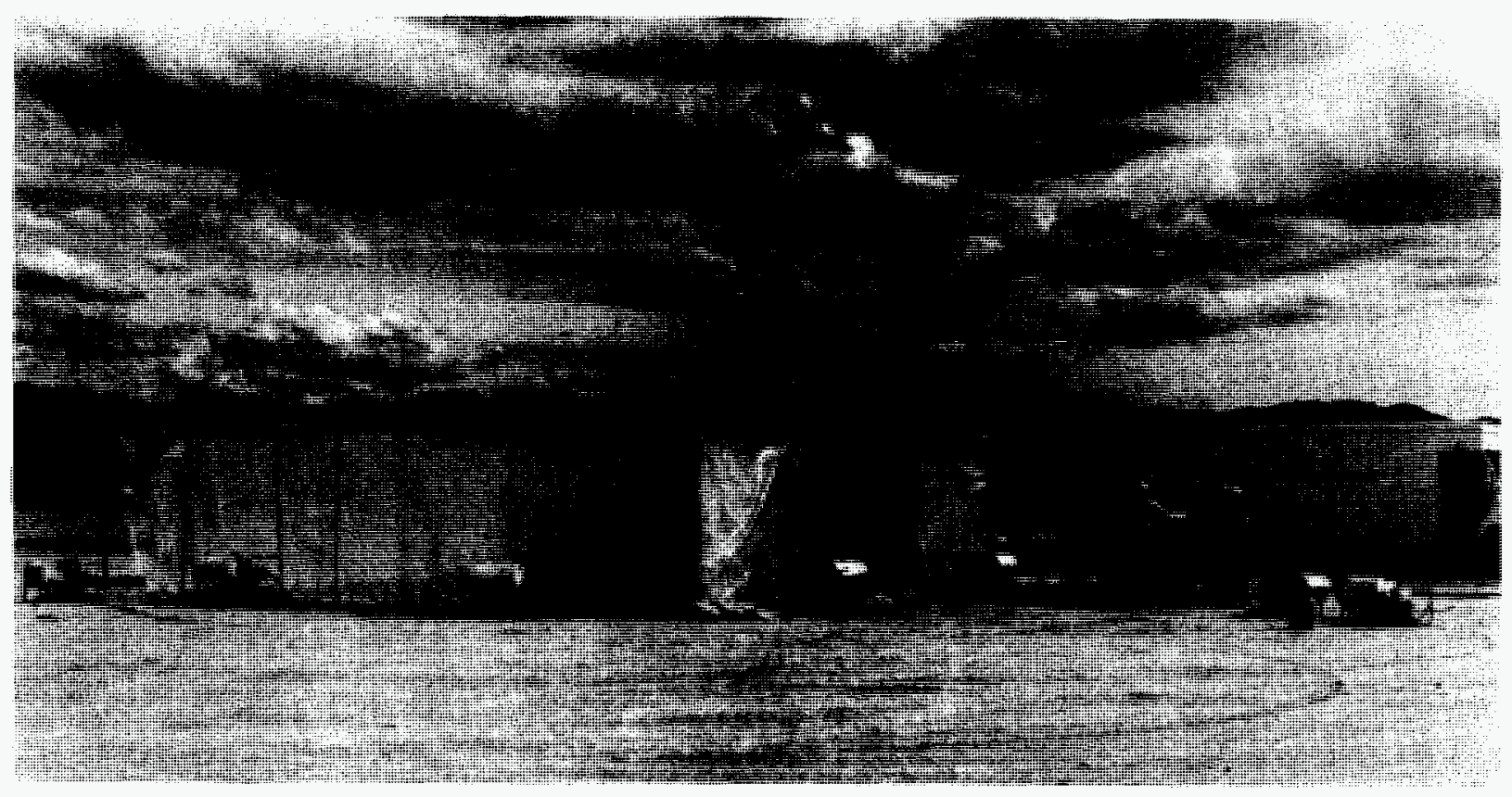

FIGURE 2.4. Containment Enclosure and Post-Test Air-Sampling System

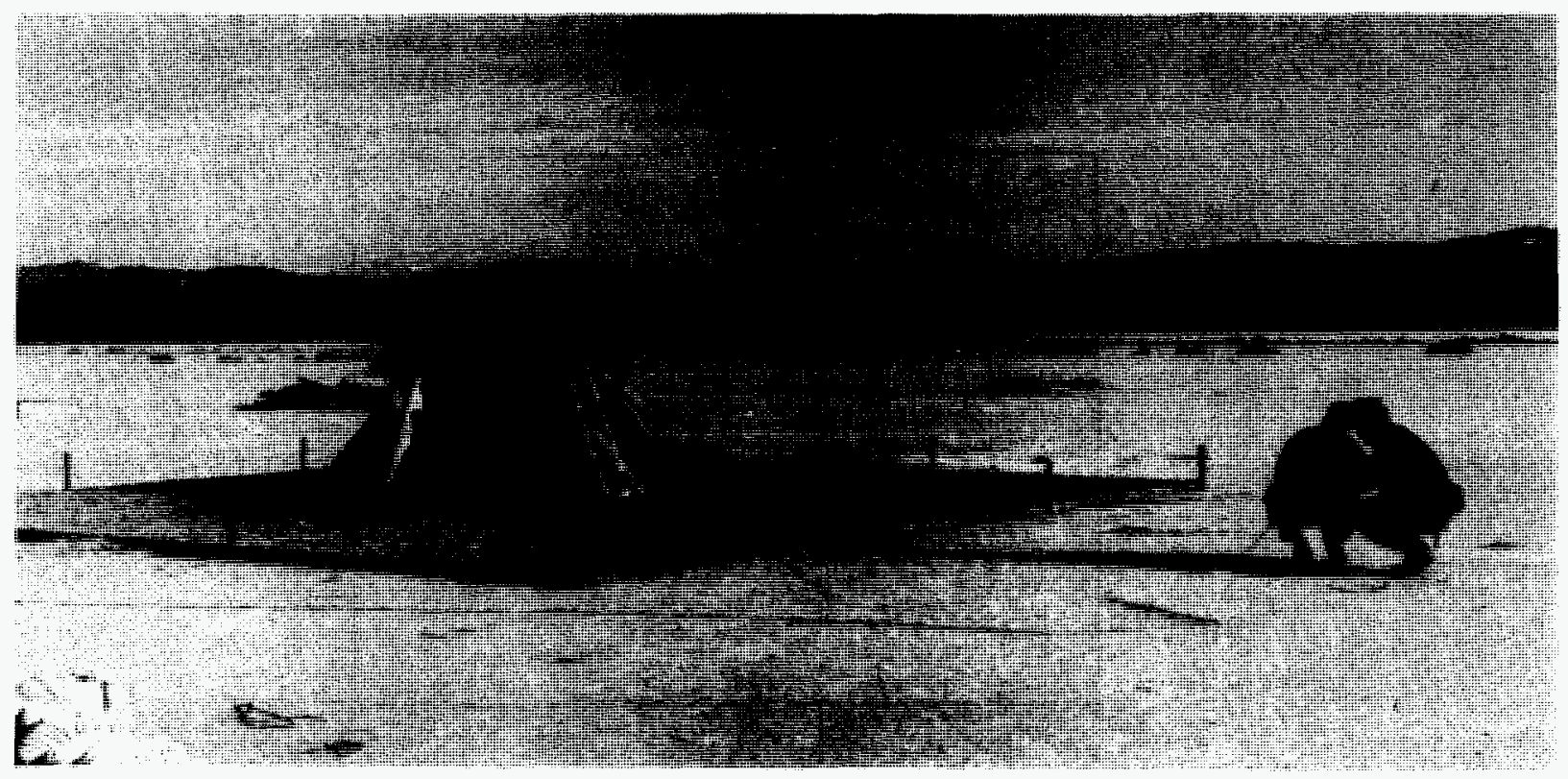

FIGLRE 2.5. Containment Test Tray Prior to Ignition of Fire 


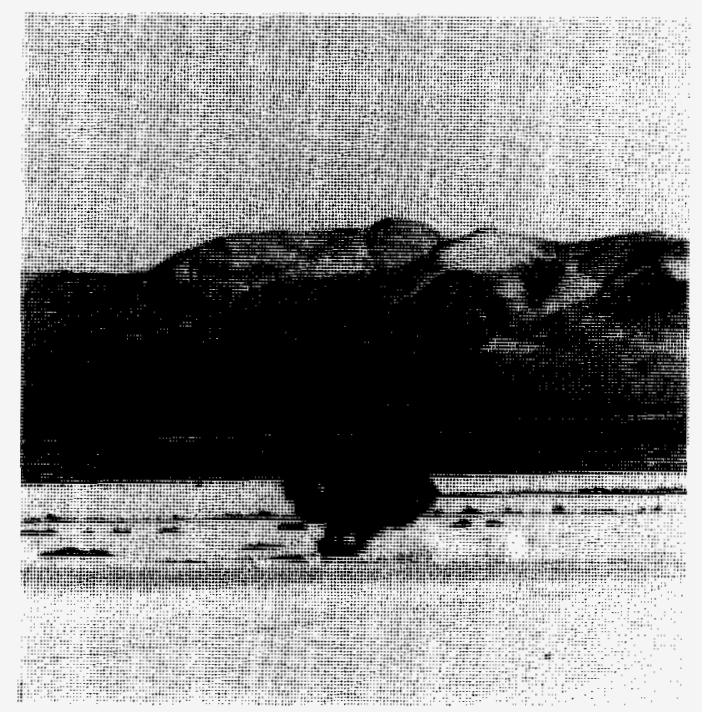

FIGURE 2.6. External Heat Test, Ignition

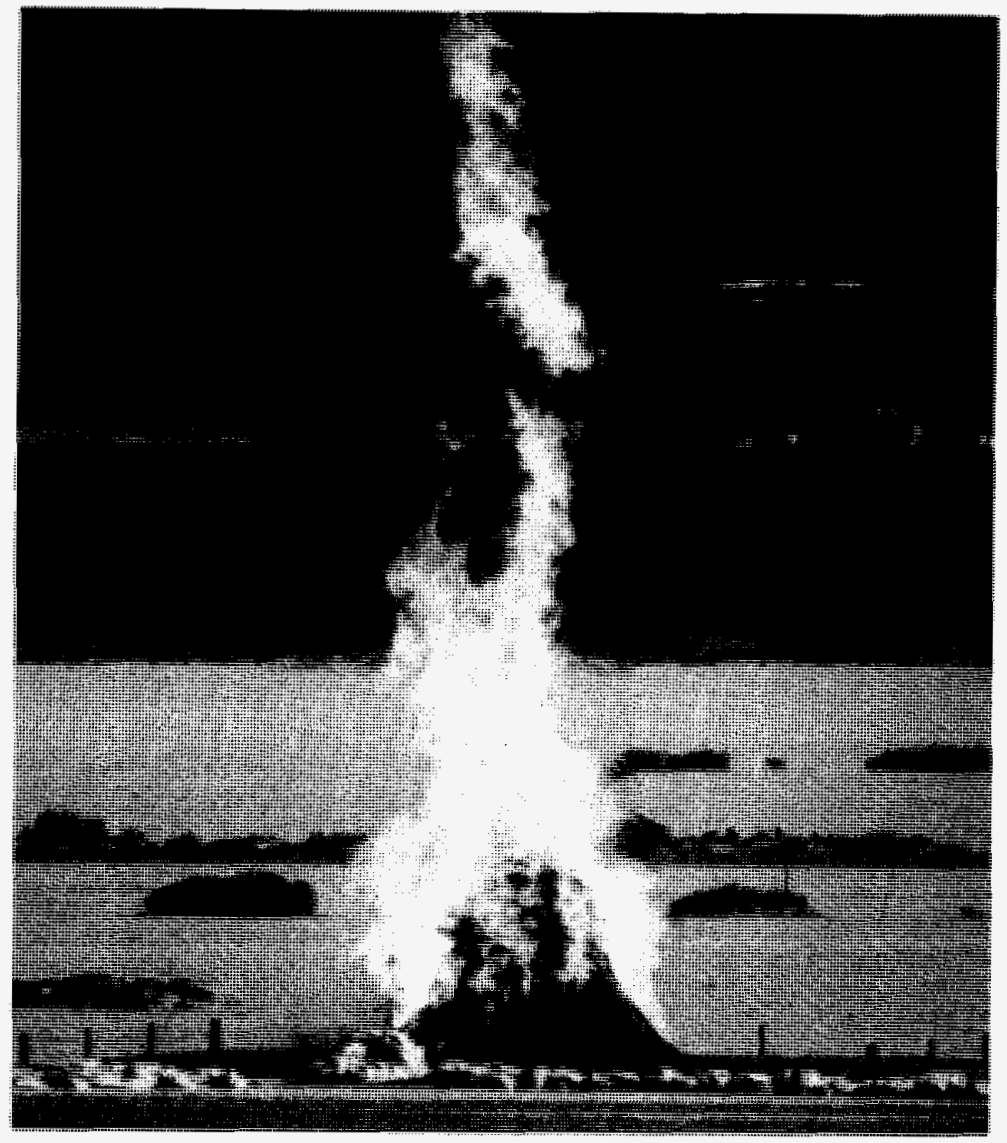

FIGURE 2.7. External Heat Test, Initial-Growth-Phase Fire 


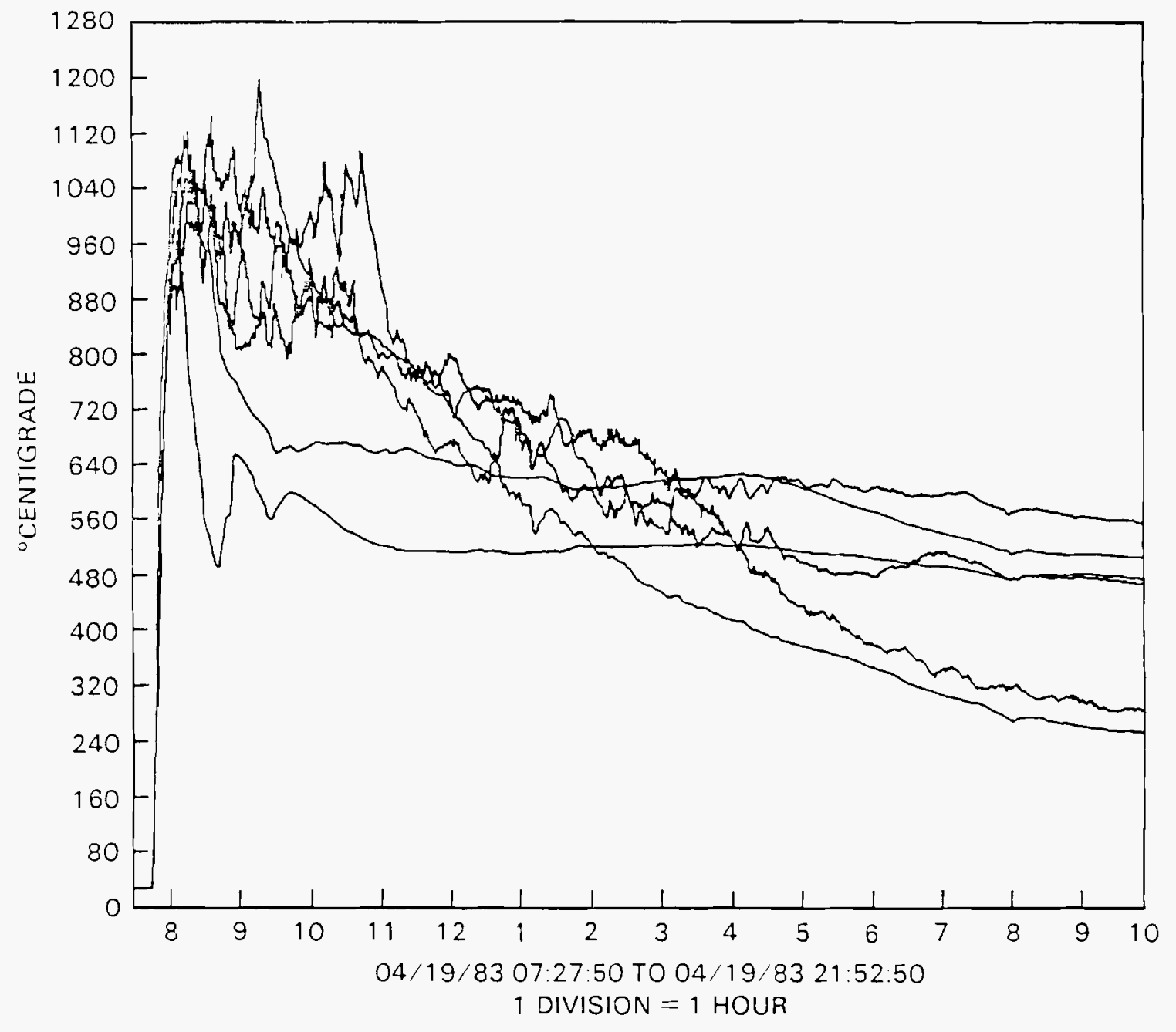

FIGURE 2.8. April 1983 External Heat Test, Time vs Temperature (Data from Six Heat Sensors, see Figures 2.2 and 2.3) 


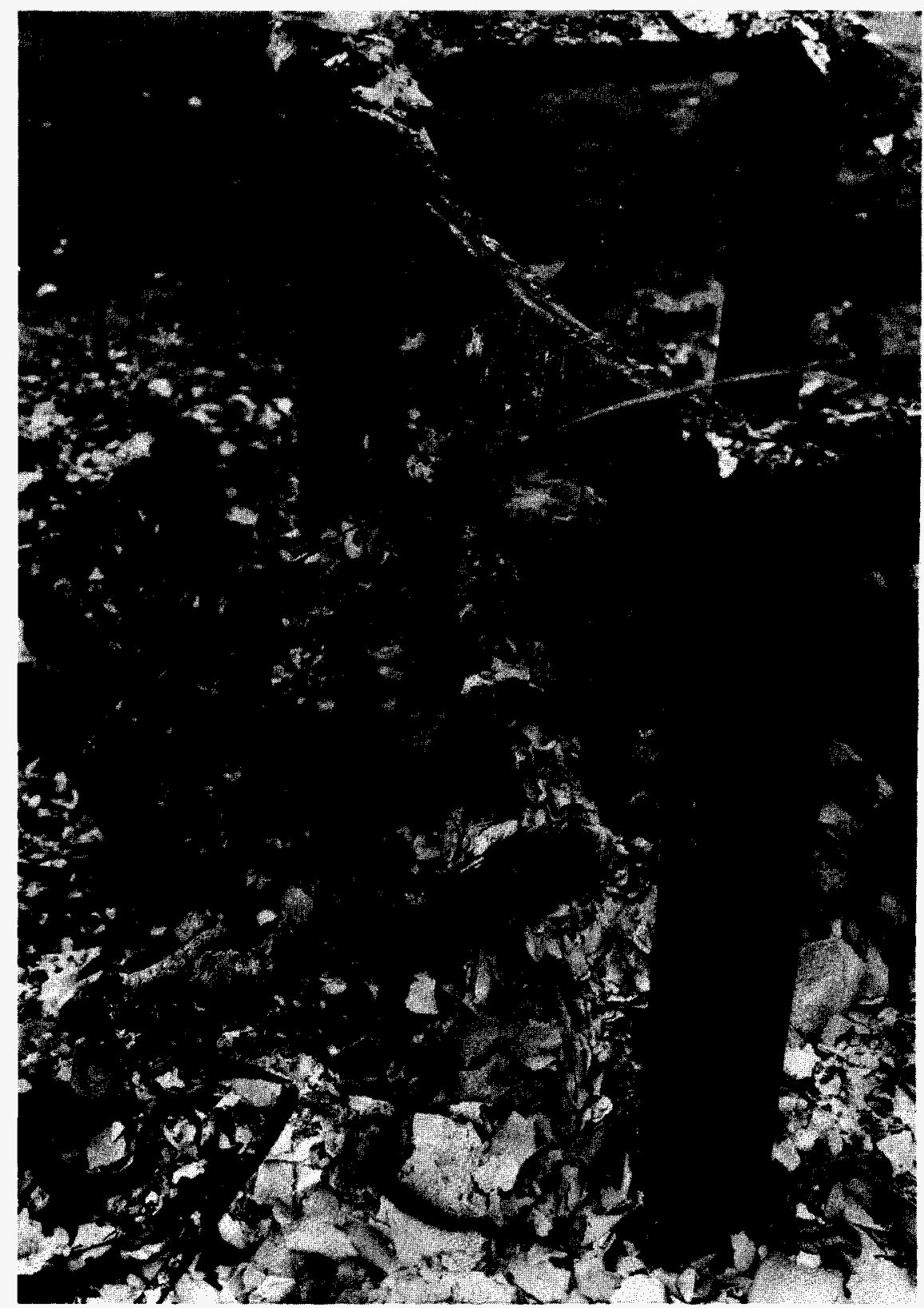

FIGURE 2.9. Debris Along South Edge of Test Stand 


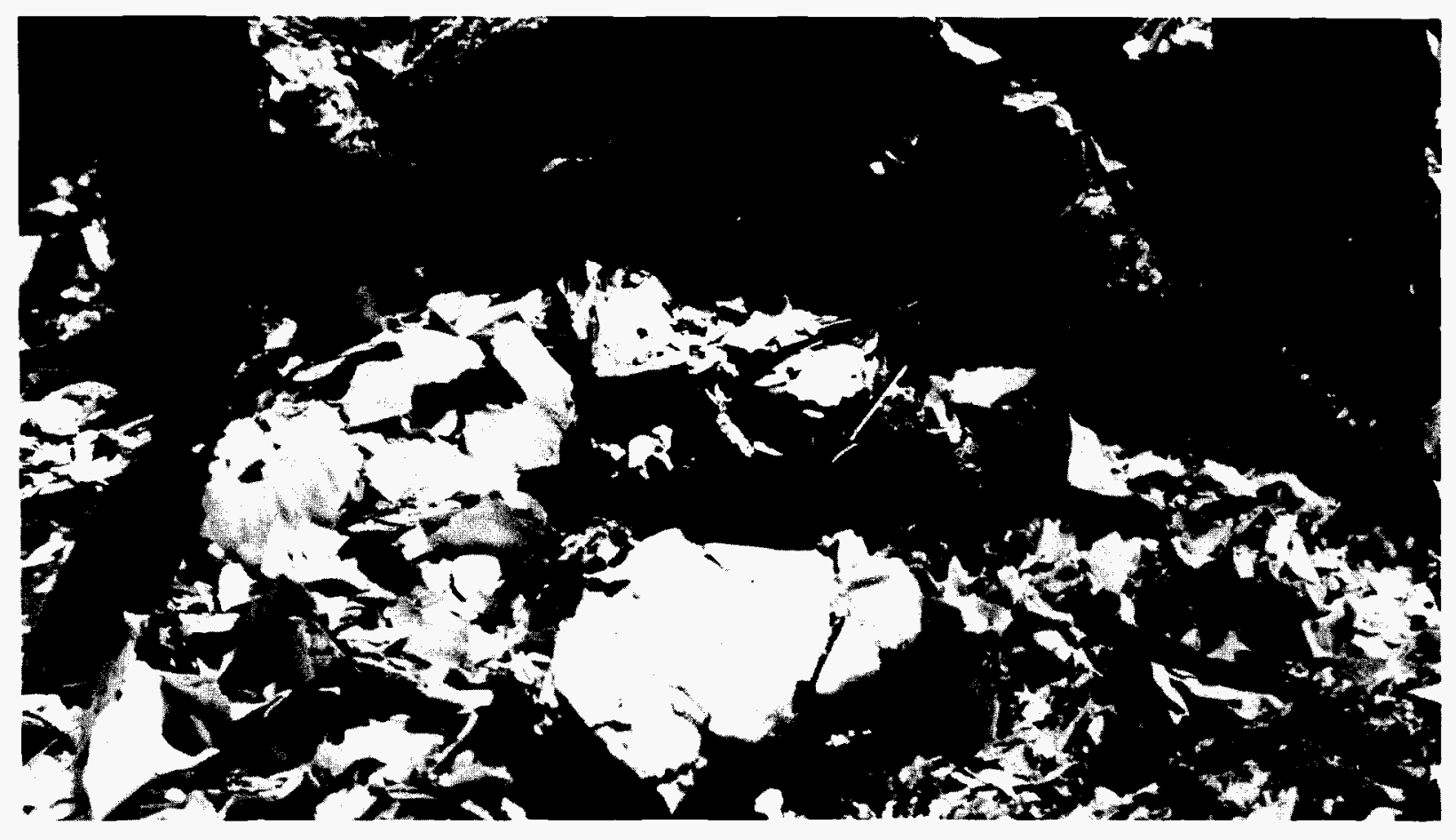

FIGURE 2.10. Remnant DU Core at Eastern Edge of Test Stand

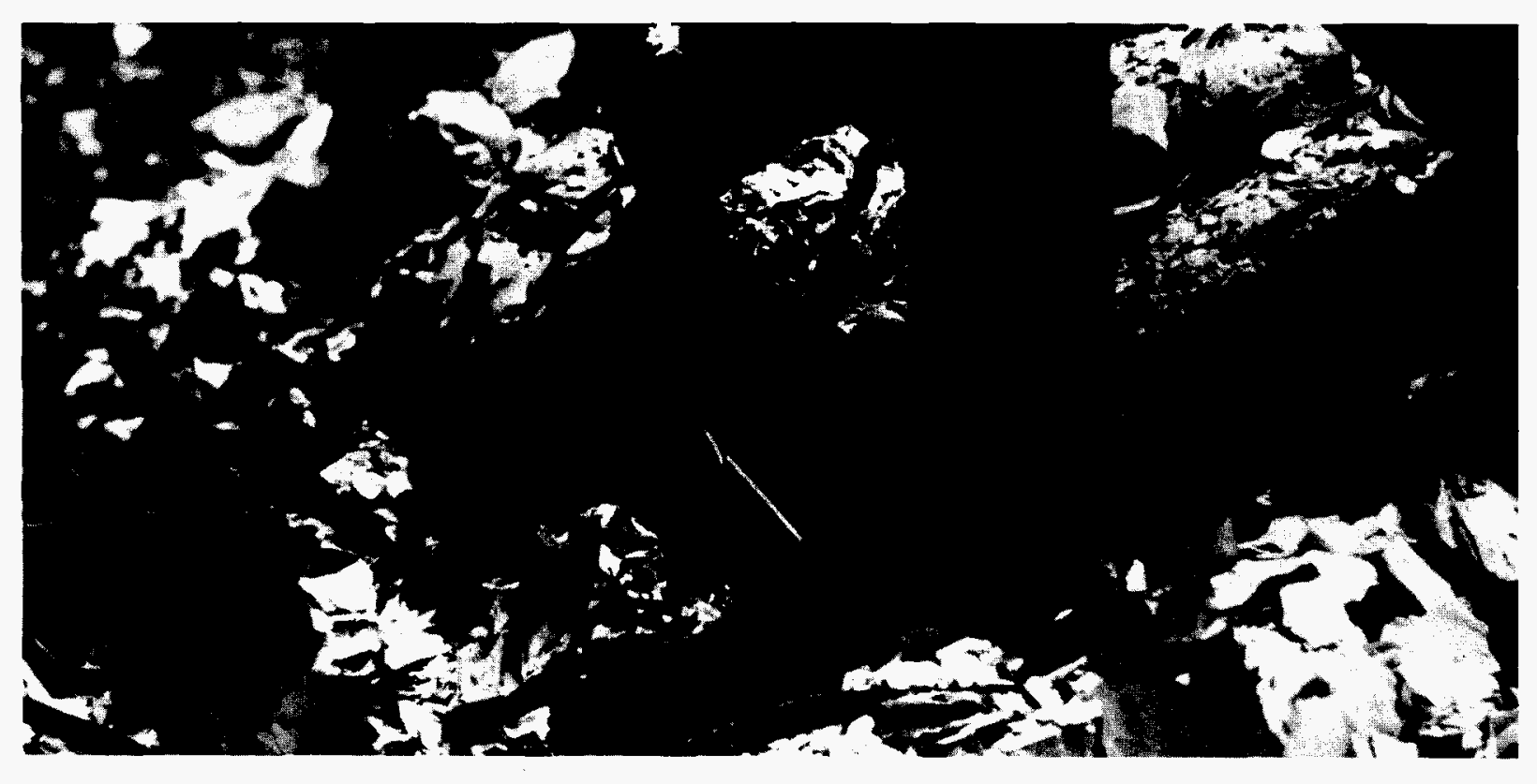

FIGURE 2.11. Remnant DU Core at Northwest Corner of Test Stand 


\subsection{SAMPLES}

A11 the suspected uranium-bearing materials were collected for measurement of the their uranium content. An initial rough segregation was made using hand-held GM counters. A single, relatively uncontaminated sample from the oxidized penetrator located at the eastern edge of the test stand was selected for particle size analysis. The remainder of the materials collected were uranium-fire residue (charcoal, melted aluminum, etc.) or uranium-soil mixtures containing varying concentrations of uranium, and the unoxidized remnants of the penetrators.

The samples obtained are tabulated in Table 2.1. Some samples are not listed because the rough field test showed they had an insignificant amount of

TABLE 2.1. Samples From the Apri1 1983 External Heat Test "C"

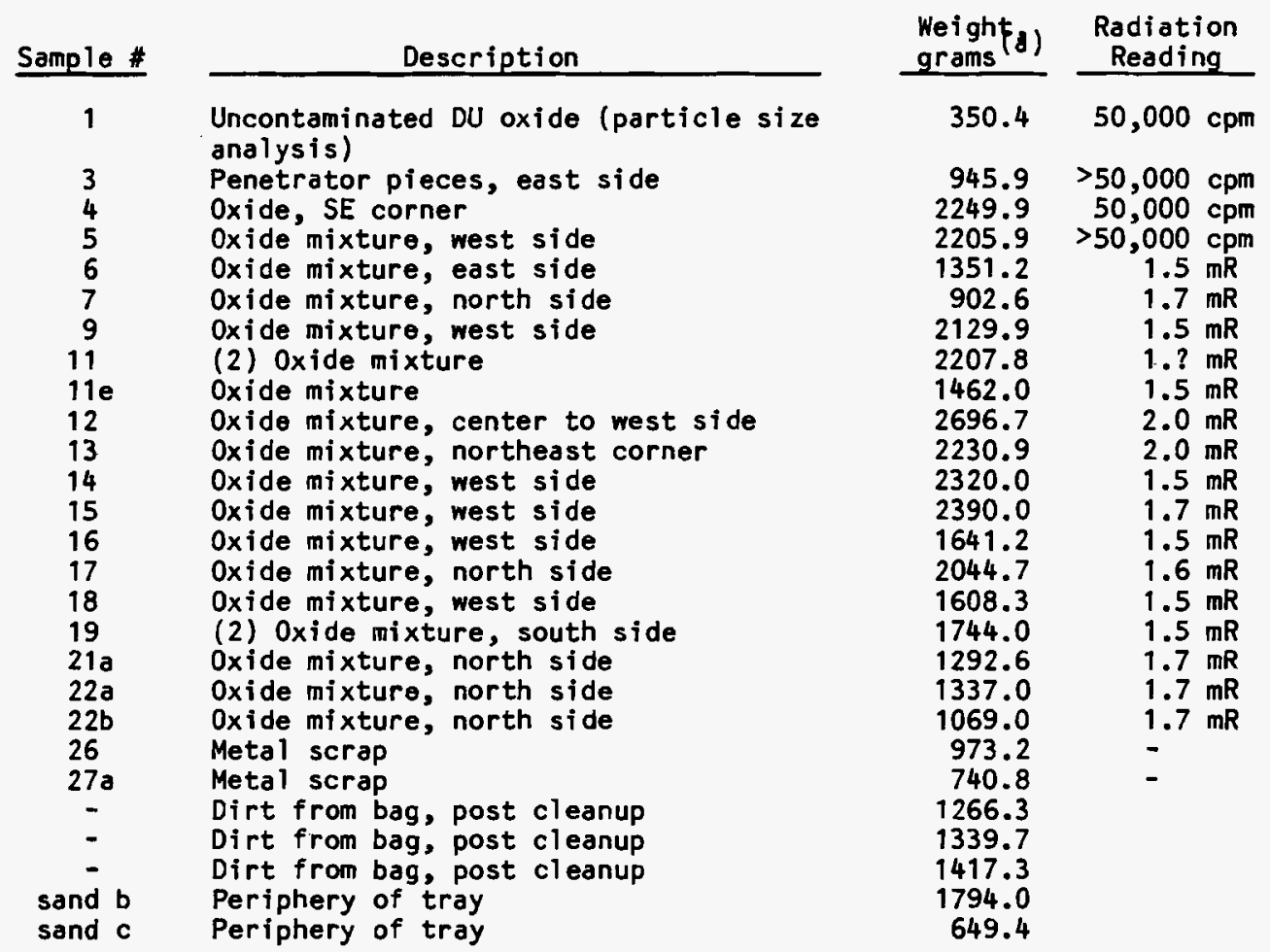

(a) Weight includes the plastic sack containing the sample. 
DU and the final measurements showed that very little of the DU was lost. Sample \#1 (the least contaminated DU oxide sample) was initially chosen for analysis. The quantity available in sample \#1, $216.1 \mathrm{~g}$ (total weight excluding the plastic sack), was insufficient for all required analyses, so material from sample \#1le was added for the particle size analysis by liquid sedimentation.

It was subsequently decided that the size distribution should not be based upon a single sample. Therefore, three samples (\#6, \#7, and \#18) were composited and treated as a single sample for another size analysis and morphology.

\subsection{SAMPLE PREPARATION}

All samples were initially segregated by size to determine their size distribution and to provide samples in the proper size range for further analysis. The samples were weighed and sieved using two Tyler sieves - \#140 (105 $\mu \mathrm{m}$ least linear diameter (LLD)) and \#325 (44 $\mu \mathrm{m}$ LLD). The fractions remaining on each sieve and passing through the \#325 sieve were recovered and weighed. The percentage of material in each fraction was determined by comparing it to the total mass recovered. The fraction < $44 \mu \mathrm{m}$ LLD was placed on a stack of 20-um and $10-\mu \mathrm{m}$ sonic sieves. Material passing through the 10- $\mathrm{m}$ sieve was collected in a fines collector. Again the amount of material in each fraction was determined by comparison with the total mass recovered. Some of the material <10 $\mu \mathrm{m}$ LLD from sample \#1 was air elutriated into a cascade impactor consisting of a 0 (stage cut-off $11 \mu \mathrm{m}$ AED) and a 1 stage (stage cut-off $9.2 \mu \mathrm{m} \mathrm{AED).} \mathrm{The}<9.2$ - $\mu \mathrm{m}$ material was collected on a membrane filter and submitted for measurement of its solubility in interstitial lung fluid. An aliquot of the <10- $\mu m-L L D$ fraction and an aliquot of the fraction $<20>10 \mu \mathrm{m}$ LLD were submitted for scanning electron microscopy to ascertain sample morphology. The latter fraction was also used to determine the size separation of the DU oxide by sieving.

The <10-um-LLD material from sample \#lle and the composite were submitted for measurement of the particle size distribution by liquid sedimentation, and an aliquot of the composite was submitted for determination of its morphology. 


\subsection{MORPHOLOGY}

A scanning electron microscope (SEM) was used to determine the morphology of the DU oxide particles in the two samples (\#1 and composite). Two methods of sample preparation were used. The first was for uniform particles in the 10-um size range. The second was for smaller particles, in the micron and. submicron range, with a significant shape variation.

Method 1. The particles were distributed on a glass slide, picked up on a piece of double-backed sticky tape, and placed directly on the mount. The mounted particles were then carbon coated with a vacuum evaporative process and examined in the SEM.

Method 2. A small quantity of particles was dispersed in alcohol and agitated in an ultrasonic bath. A uniform mixture of particles and liquid was removed with an eye dropper and deposited upon a 0.1-um millipore filter, $1 / 2$ inch in diameter, previously mounted with doublebacked sticky tape to an aluninum mount. The sample was then carbon coated with a vacuum evaporative process and examined in the SEM.

The uranium particles were imaged using the secondary electrons generated by scanning a 25-keV electron beam across the particles. (A detailed description of the image formation can be found in Goldstein et al. 1977.)

\subsubsection{Fraction $<20>10 \mu \mathrm{m}$ LLD, Sample \#1}

Figure 2.12 is a $100 \mathrm{X}$ magnification of a single field. The photo indicates that good separation was obtained between particles greater than and less than $10 \mu \mathrm{m}$ LLD. Figure 2.13 is a $1500 \mathrm{X}$ magnification of a portion of the previous field and shows the presence of a few particles $<10 \mu \mathrm{m}$ LLD. Whether these particles were present in the original sample or resulted from the agitation during sieving is not known. The individual particles appear to have a striated, layered appearance with one surface less clearly defined (appear to be the rounded ends of the layer). 


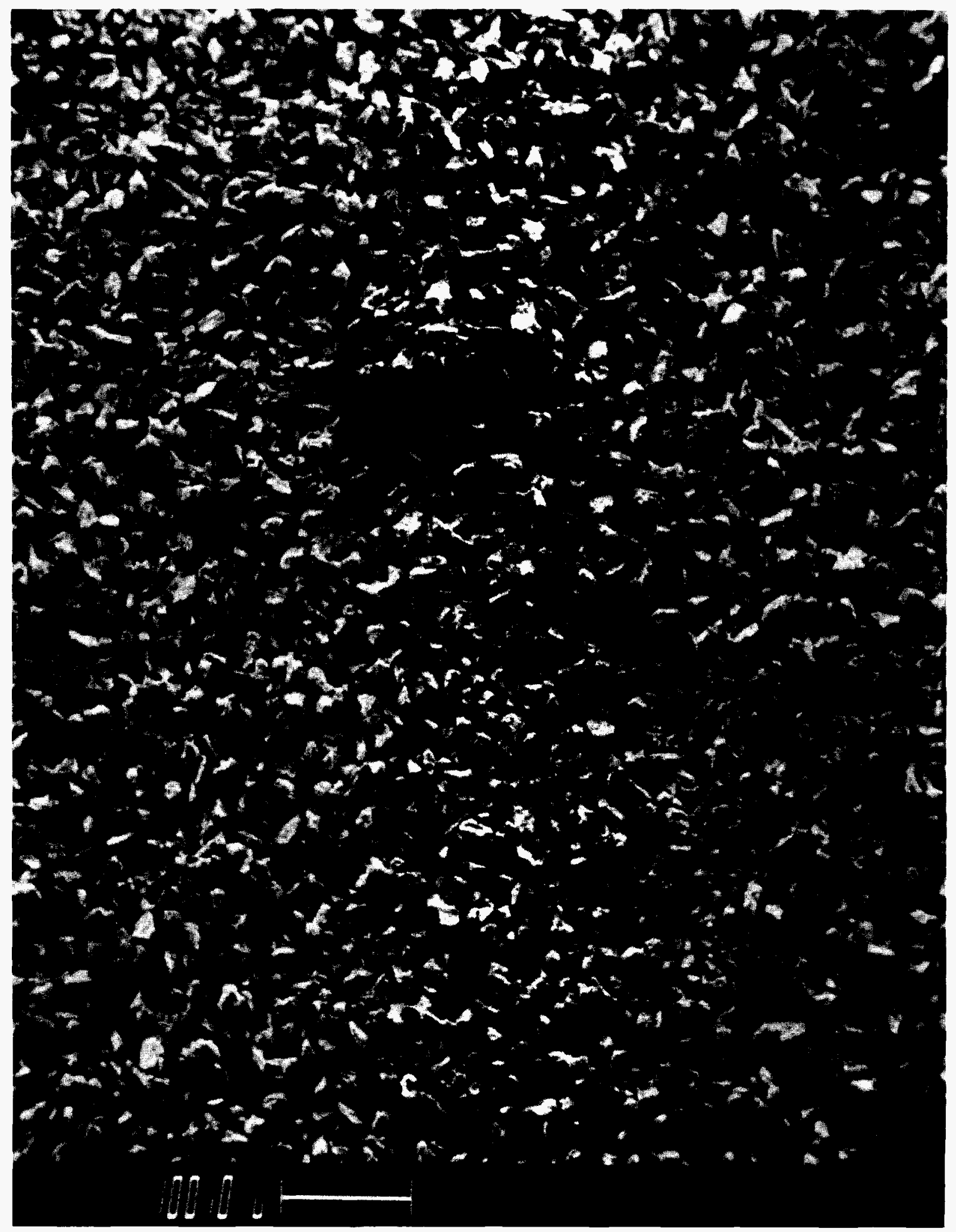

FIGURE 2.12. SEM 100X. Particle Size Analysis Sample - Fraction $<20>10 \mu \mathrm{m}$ LLD - Field \#1, Overall View 


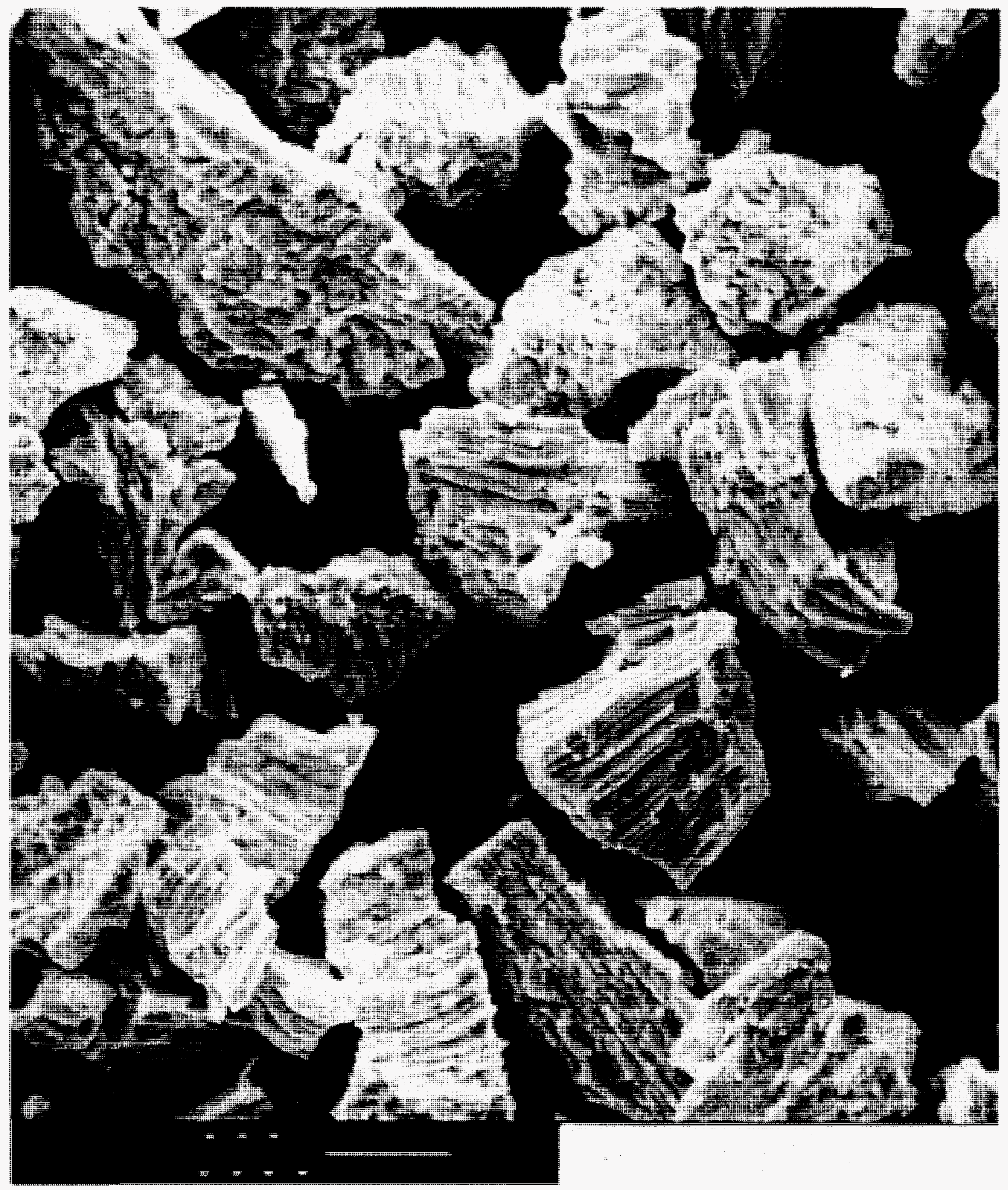

FIGURE 2.13. SEM 1500X. Particle Size Analys is Sample - Fraction $<20>10 \mu \mathrm{m}$ LLD - Field \#1, Typical Size and Shape of Particles 
Figure 2.14 is a single particle from the field at 5000x magnification and shows more clearly the structure of the particles. Notice the presence of a number of submicron particles on the surface of the particle. It is not known whether the submicron particles are attached, lying on the surface, or superimposed on the image of the larger particle.

\subsubsection{Fraction $<10 \mu \mathrm{m} \mathrm{LLD,} \mathrm{Sample} \mathrm{\# 1}$}

A field at 500x magnification of this fraction is shown in Figure 2.15. There appear to be a few particles that exceed $10 \mu \mathrm{m}$ LLD in the field but only one dimension of the particle needs to be $<10 \mu \mathrm{m}$ LLD for the particle to pass through the screen. The amorphous-appearing particle in the lower left quadrant may be a soil particle. Electron microprobe analysis of similar particles in the composite sample indicated an elemental composition primarily of Si with $\mathrm{Al}, \mathrm{Mg}, \mathrm{Ca}, \mathrm{Fe}, \mathrm{Zn}$, and $\mathrm{K}$. Figure 2.16 is a $5000 \mathrm{X}$ magnification of a portion of the previous field. The individual particles have the same appearance as those in the previous fraction including the presence of submicron particles.

\subsubsection{Fraction $<10 \mu \mathrm{m} \mathrm{LLD,} \mathrm{Composite} \mathrm{Sample}$}

The 1500X magnification of a field from this sample (Figure 2.17) clearly shows the presence of two distinct types of particies - a dark, glassyappearing particle and a lighter particle with an appearance similar to the DU oxide particles in the previous two samples. (The carbaceous particles would not be detected due to their low density.) Figure 2.18 is a 5000X magnification of a single particle in the field and shows that the surface structure and morphology of the lighter particles is indeed similar to the DU oxide particles in the two previous samples. The surface appears to be more lumpy and less layered than the particles in sample $\# 1$ and may be due to a higher degree of oxidation (sample was taken from residue in the interior of the major mass of burned material and may have been heated at higher temperatures, for a longer period, and with greater oxygen availability than sample \#1).

\subsection{PARTICLE SIZE DISTRIBUTION}

The particle size distribution was investigated by sieve analysis and by liquid sedimentation. The results of these two methods were combined to estimate the particle size distribution of the sample material. 


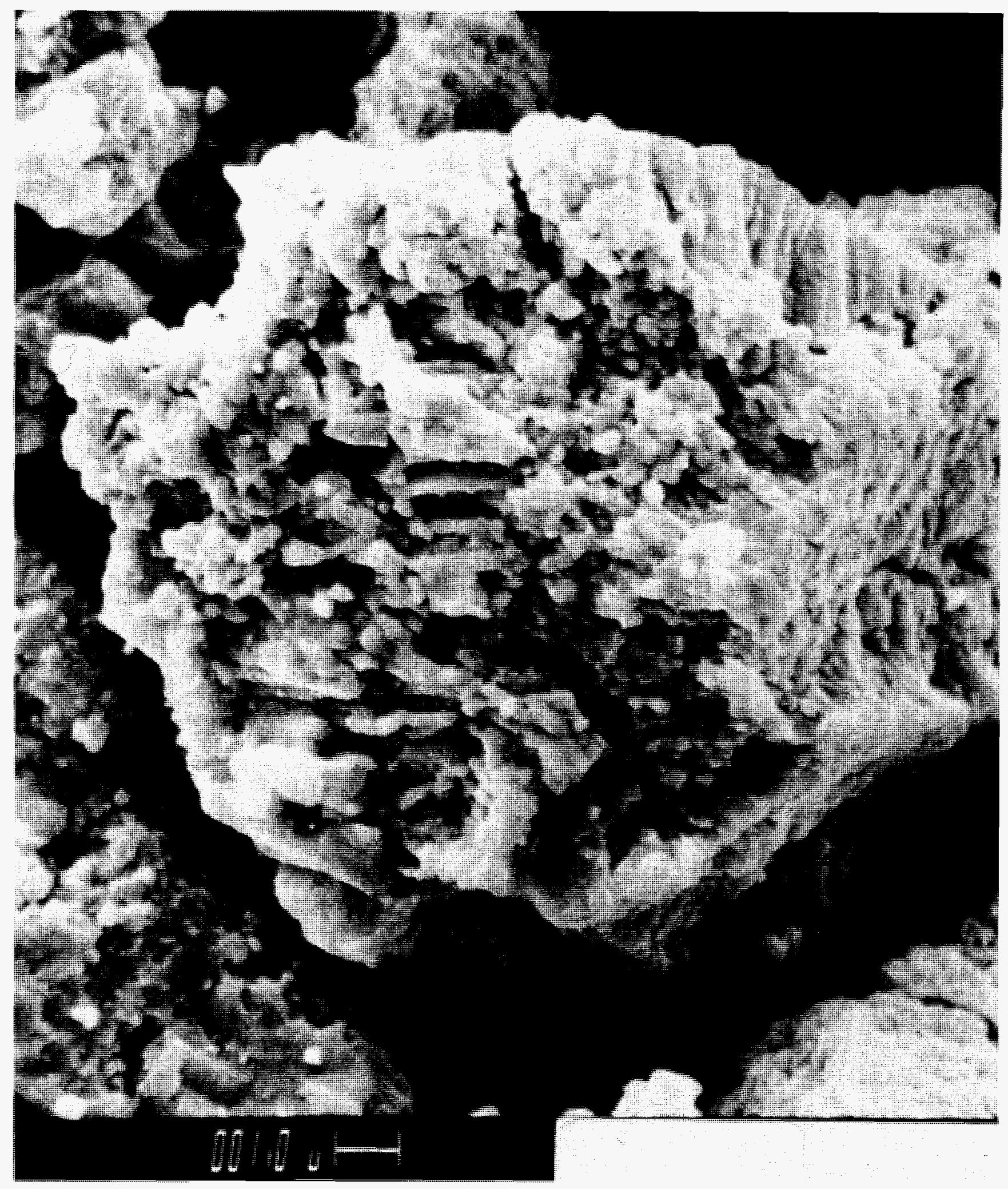

FIGURE 2.14. SEM 5000X. Particle Size Analysis Sample - Fraction $<20>10 \mu \mathrm{m}$ LLD - Field \#1, Particle Morphology 


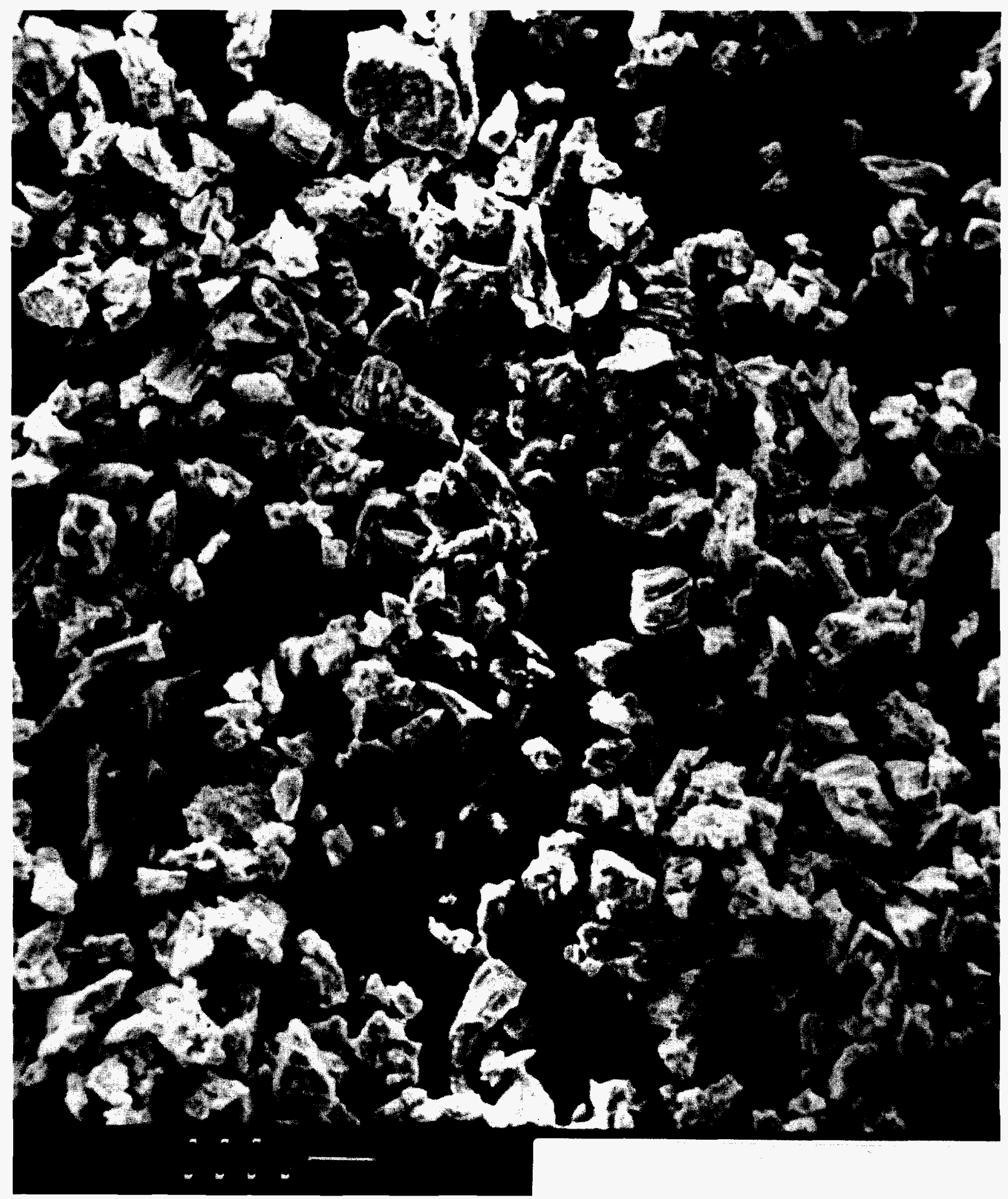

FIGURE 2.15. SEM 500X. Particle Size Analysis Sample - Fraction $<10 \mu \mathrm{m}$ LLD - Field \#1, Typical Size and Shape of Particles 


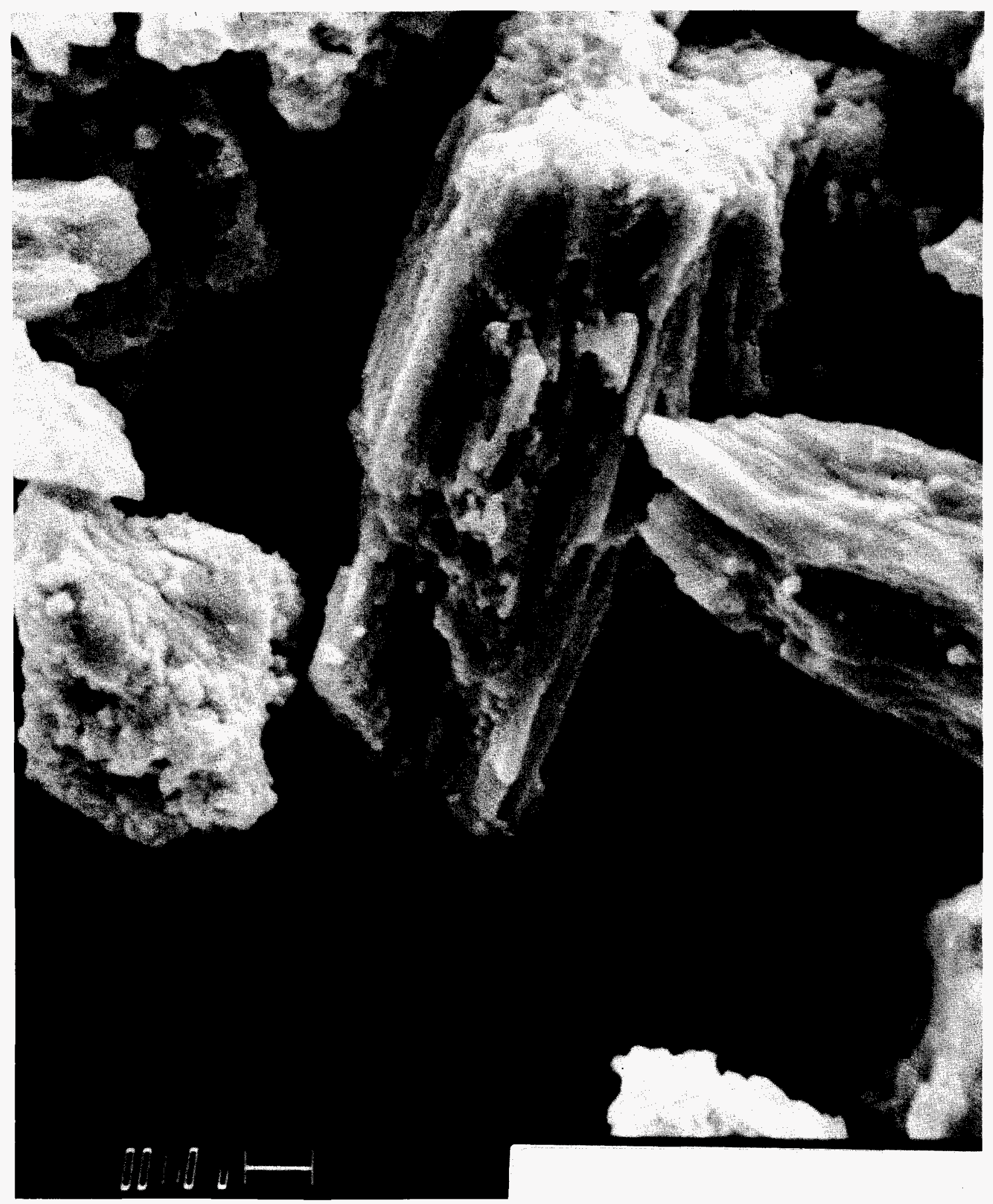

FIGURE 2.16. SEM 5000X. Particle Size Analysis Sample - Fraction $<10 \mu \mathrm{m}$ LLD - Field \#1, Particle Morphology 


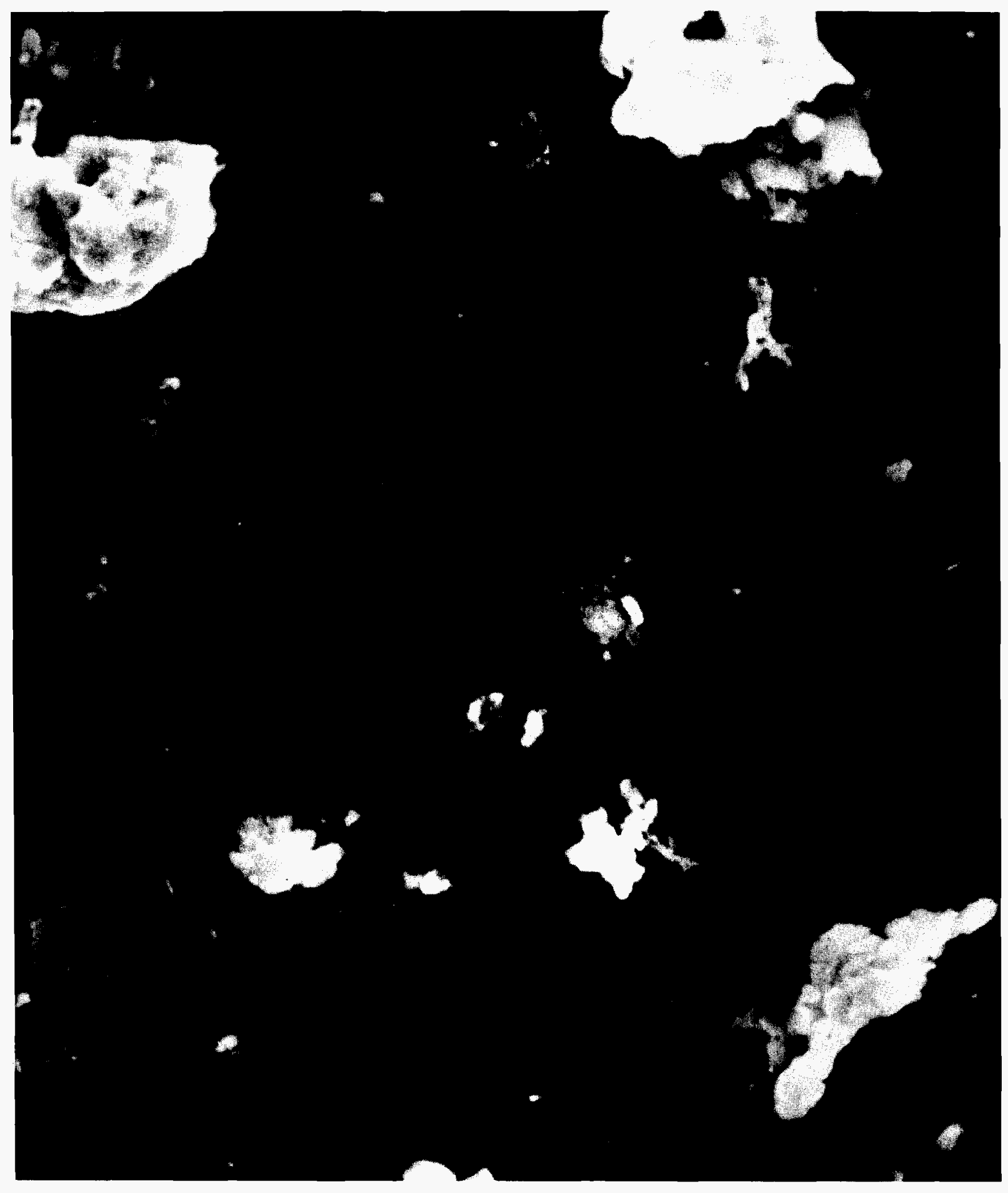

FIGURE 2.17. SEM 1500X. Composite Sample (\#6, \#7, and \#18)Fraction <10 um LLD - Field \#l, Typical Size and Shape of Particles 


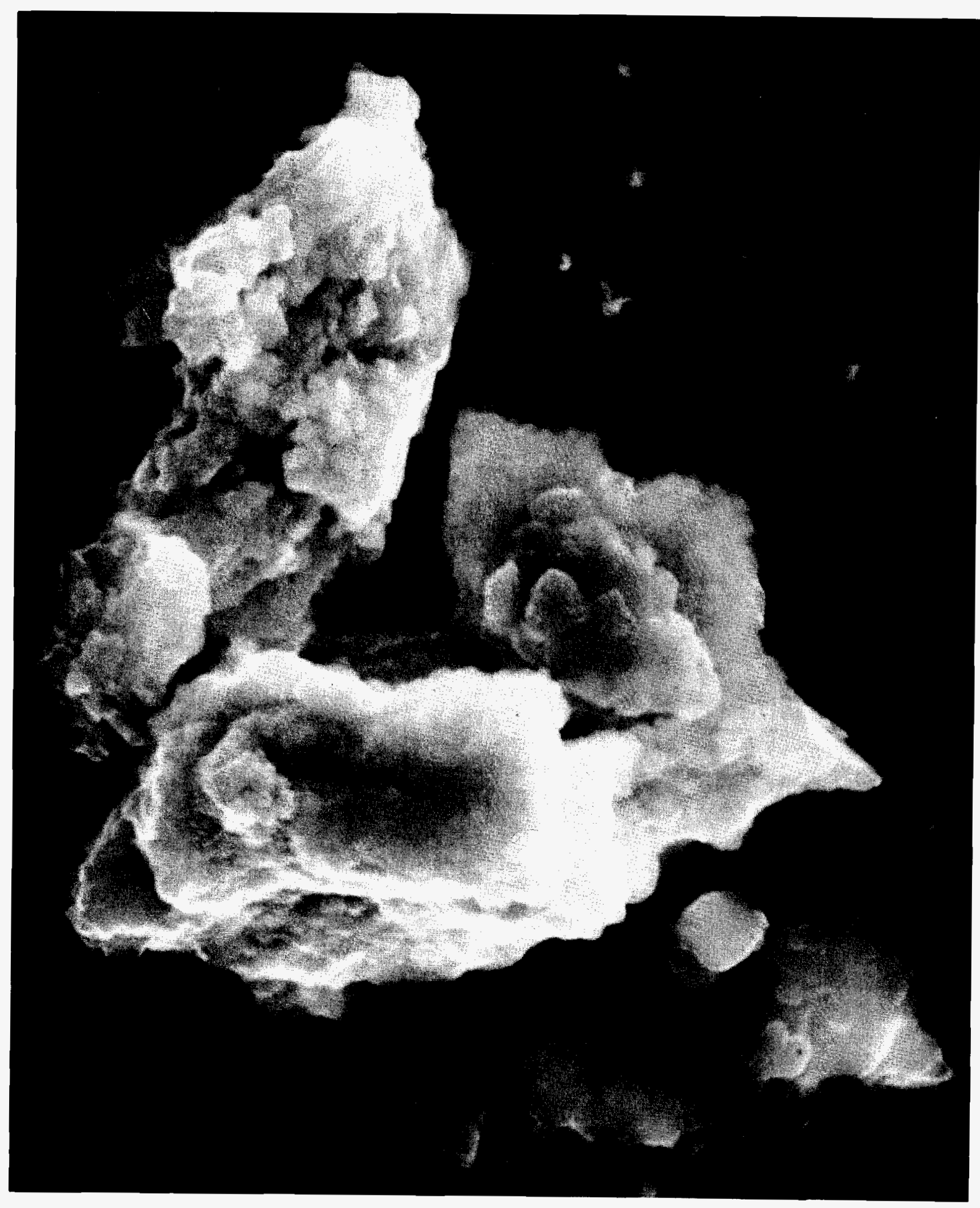

FIGURE 2.18. SEM 5000X. Composite Sample (\#6, \#7 and \#18)-Fraction $<10 \mu \mathrm{m}$ LLD - Field \#1, Particle Morphology 


\subsubsection{Size Distribution by Sieve Analysis}

The basic procedure for determining the size distribution of a powder by sieve analysis was outlined in the sample preparation section. A weighed amount of the material to be analyzed is placed in the upper pan of a series of sieves. The floor of each pan is a screen with mesh openings of a carefully controlled size and the pans are designed to nest in one another. The sieves are stacked in order of decreasing size openings; the top of the stack is sealed with a lid and the floor of the bottom pan is solid. The powder is bounced on the screens either manually, mecharically, or acoustically so that all particles with one side smaller than the dimensions of the opening pass through the screen. The Tyler sieves (approximately 9 inches in diameter and 2-inches deep) are larger and can hold more material than the sonic sieves (approximately 3 inches in diameter by 1 -inch deep). Thus, the entire weight of most samples could be sieved in one run using the Tyler sieves but only 2 grams could be used for each sonic sieve run.

The results of the sieve analyses for samples \#1, \#1le, and the composite (\#6, \#7, and \#18) are shown in Tables 2.2, 2.3, and 2.4, respectively. Since only a limited fraction (approximately $4 \%$ ) of the tota 1 material < 44 um LLD was used for the subsequent sonic sieve analysis, Table 2.5 shows the range of values found for the three fractions. The greatest range is found for the $<10-\mu m-L L D$ fraction with a spread of approximately $20 \%$. A similar range is found for the fraction $>10<20 \mu \mathrm{m}$. The consistency in the results indicates appreciable uniformity in the samples. The size distributions for all three samples are shown in Table 2.6. The values for the lesser size ranges were derived by assuming the fraction $<44 \mu \mathrm{m}$ LLD was distributed as the fraction recovered in the subsequent analyses.

\subsubsection{Size Distribution by Liquid Sedimentation (SediGraph ${ }^{\circledR}$ )}

The liquid sedimentation instrument determines the particle size distribution of a sample by using a finely collinlated $X$-ray beam to assess the particle concentration remaining at decreasing sedimentation distance as a function of time. The results are in Stoke's or equivalent spherical (sphere

(3) Micromeritics Instrument Corporation (MICROME), Norcross, Georgia. 
TABLE 2.4. Sieve Analysis Results, Composite Sample

\section{Tyler Sieve Analysis}

Initial weight

Mass $>105 \mu \mathrm{m}$

Percent $>105 \mu \mathrm{m}$, initial

Percent $>105 \mu \mathrm{m}$, recovered

Mass $<105>44 \mu \mathrm{m}$

Percent $<105>44 \mu \mathrm{m}$, initial

Percent $<105>44 \mu \mathrm{m}$, recovered

Mass $<44 \mu \mathrm{m}$

Percent $<44 \mu \mathrm{m}$, initial

Percent $<44 \mu \mathrm{m}$, recovered

Weight recovered

Percent recovered
Sample Number

\begin{tabular}{|c|c|c|}
\hline$\# 18$ & $\$ 7$ & $\# 6$ \\
\hline $1464.4 \mathrm{c}$ & $760.8 \mathrm{gg}$ & 1198.7 \\
\hline 595.7 & $383.1 \mathrm{~g}$ & 539. \\
\hline $40.7 \%$ & $50.4 \%$ & \\
\hline $\begin{array}{r}41 . \\
440 . \varepsilon\end{array}$ & $230.8 \mathrm{a}$ & 411.30 \\
\hline 30.1 & 30.3 & $34.3 \%$ \\
\hline $30.7 \%$ & $31.4 \%$ & $34.5 \%$ \\
\hline $399.1 \mathrm{~g}$ & $120.5 \mathrm{~g}$ & $240.2 \mathrm{~g}$ \\
\hline $\begin{array}{l}27.2 \% \\
27.8 \%\end{array}$ & $15.8 \%$ & $20.0 \%$ \\
\hline $1435^{\circ}$ & $\begin{array}{l}10.4 \% \\
734.4 \mathrm{~g}\end{array}$ & $\begin{array}{c}20.2 \% \\
1191.4 \mathrm{~g}\end{array}$ \\
\hline 98. & $96.5 \%$ & $99.4 \%$ \\
\hline
\end{tabular}

Sonic Sieve Analysis (Samples from the composite of the $<44-\mu m$ portions of Samples \#18, \#7, and \#6)

\begin{tabular}{|c|c|c|c|c|c|}
\hline $\begin{array}{l}\text { Initial } \\
\text { Wt }(g) \\
\end{array}$ & $\begin{array}{l}\text { Recovered } \\
\text { Wt }(\mathrm{g}) \\
\end{array}$ & $\begin{array}{c}\text { Percent } \\
\text { Recovered }\end{array}$ & $\begin{array}{c}>20 \mu \mathrm{mm} \\
(\mathrm{g})^{-}\end{array}$ & $\begin{aligned} &>10<20 \mu \mathrm{m} \\
&(\mathrm{g}) \\
&\end{aligned}$ & $\begin{array}{c}<10{ }^{\mu m} \\
(\mathrm{~g})^{\mathrm{m}}\end{array}$ \\
\hline 4.1672 & 4.1943 & 100.6 & $\begin{array}{l}2.7511 \\
(65.6 \%)\end{array}$ & $\begin{array}{l}1.0944 \\
(26.1 \%)\end{array}$ & $\begin{array}{l}0.3488 \\
(8.3 \%)\end{array}$ \\
\hline 4.0702 & 3.9953 & 98.2 & $\begin{array}{l}2.6586 \\
(66.6 \%)\end{array}$ & $\begin{array}{l}0.9568 \\
(23.9 \%)\end{array}$ & $\begin{array}{l}0.3799 \\
(9.5 \%)\end{array}$ \\
\hline 4.1507 & 4.0614 & 97.8 & $\begin{array}{l}2.6942 \\
(66.3 \%)\end{array}$ & $\begin{array}{l}0.9627 \\
(23.7 \%)\end{array}$ & $\begin{array}{l}0.4045 \\
(10.0 \%)\end{array}$ \\
\hline 2.0069 & 1.9292 & 96.2 & $\begin{array}{l}1.2823 \\
(66.5 \%)\end{array}$ & $\begin{array}{l}0.4380 \\
(22.7 \%)\end{array}$ & $\begin{array}{l}0.2089 \\
(10.8 \%)\end{array}$ \\
\hline 6.1527 & 5.9936 & 97.4 & $\begin{array}{l}3.9636 \\
(66.1 \%)\end{array}$ & $\begin{array}{l}1.3822 \\
(23.1 \%)\end{array}$ & $\begin{array}{l}0.6478 \\
(10.8 \%)\end{array}$ \\
\hline 6.1228 & 5.9795 & 97.7 & $\begin{array}{l}3.9301 \\
(65.8 \%)\end{array}$ & $\begin{array}{l}1.4023 \\
(23.4 \%)\end{array}$ & $\begin{array}{l}0.6471 \\
(10.8 \%)\end{array}$ \\
\hline 2.0900 & 1.9430 & 93.0 & $\begin{array}{l}1.2882 \\
(66.3 \%)\end{array}$ & $\begin{array}{l}0.4404 \\
(22.7 \%)\end{array}$ & $\begin{array}{l}0.2144 \\
(11.0 \%)\end{array}$ \\
\hline
\end{tabular}




\section{TABLE 2.5. Range of Sonic Sieve Fractions, Composite Sample}

Size Range

Percent $<10 \mu \mathrm{m}$ LLD

$$
\begin{aligned}
& 22.6 \% \times 0.083=1.88 \%(2)^{(a)} \\
& \times 0.095=2.15 \%(2) \\
& X 0.100=2.26 \% \text { (1) } \\
& X 0.108=2.44 \% \text { (3) Mean: } 2.28 \%(b) \\
& X 0.108=2.44 \% \text { (3) Median: } 2.44 \% \\
& X 0.108=2.44 \% \text { (3) Range: } 1.88-2.49 \% \\
& \times 0.110=2.49 \%(1)
\end{aligned}
$$

Percent $>10<20 \mu \mathrm{m}$ LLD

$$
\begin{aligned}
& 22.6 \% \times 0.261=5.90 \%(2) \\
& \times 0.230=5.20 \%(2) \\
& X 0.237=5.36 \% \text { (1) Mean: } 5.38 \% \\
& X 0.227=5.13 \% \text { (3) Median: } 5.22 \% \\
& X 0.231=5.22 \% \text { (3) Range: } 5.13-5.90 \% \\
& \times 0.234=5.29 \%(3) \\
& \times 0.227=5.13 \%(1)
\end{aligned}
$$

Percent $>20<44 \mu \mathrm{m}$ LLD

$$
\begin{aligned}
& 22.6 \% \times 0.656=14.8 \%(2) \\
& \times 0.664=15.0 \%(2) \\
& X 0.663=15.0 \% \text { (1) Mean: } 14.9 \% \\
& \times 0.665=15.0 \% \text { (3) Median: } 14.9 \% \\
& X 0.661=14.9 \% \text { (3) Range: } 14.8-15.0 \% \\
& \times 0.658=14.9 \%(3) \\
& \times 0.663=15.0 \%(1)
\end{aligned}
$$

(a) $22.6 \%$ (percentage of the entire composite sample that is $<44 \mu \mathrm{m}$ LLD) $\times 0.083$ (fraction of the <44 $\mu \mathrm{m}$ portion that is $<10 \mu \mathrm{m} L L D)=1.88 \%$ (percentage of the total composite sample that is $<10 \mu \mathrm{m}$ ) (2) (number of sonic sieve runs with this result).

(b) $2.28 \%$ (mean of the percentages of the entire composite sample that are $<10 \mu \mathrm{m}$ LLD). 
TABLE 2.6. Comparison of Sieve Size Distributions

Sieve Size, LLD

$>105 \mu \mathrm{m}$

$<105>44 \mu \mathrm{m}$

$<44 \mu \mathrm{m}$

$<44>20 \mu \mathrm{m}$

$<20>10 \mu \mathrm{m}$

$<10 \mu \mathrm{m}$
Percentage of Sample in Each Size
$\# 1 \quad$ \#11e

55.6

45.2

29.9

(14.5)

28.9

32.2

11.5

$(22.6)$

14.9

2.1

5.4

0.9

0.9

2.3

of the same material that would have the same terminal velocity) diameter in micrometers $(\mu \mathrm{m})$. The size distribution is given graphically using the cumulative mass fraction ( $\log$ of the difference in transmitted $X$-ray (tungsten $L$ line) intensity) versus the equivalent spherical diameter.

Pure suspension fluid is initially circulated in the instrument and, after it is allowed to remain undisturbed for a specified period of time, is used to zero the instrument. A dilute, deflocculated (homogenous) suspension is used in the same manner with readings taken at predetermined decreasing settling depths to give readings for a series of diameters as a function of time. The size distributions for the <10-um-LLD fractions for samples \#11e and the composite are shown in Figure 2.19. Assuming a material density of 10.9 for the uranium oxide, it appears that there are no particles $>8 \mu \mathrm{m}$ SED (spherical equivalent diameter) in sample \#11e. This is not unexpected since most of the particles in the sample appear relatively cubic in shape. Sample \#1le appears to be a factor of 5 to 7 finer than the composite.

Figure 2.20 is a plot of the size distribution of all the material. The plot is based on the assumption that all the material is homogeneous with a density of $10.9 \mathrm{~g} / \mathrm{cm}^{3}$. The sieve data is assumed to be an extension of the liquid sedimentation results. The plot indicates that the fraction $<10 \mu \mathrm{m}$ AED (a conservative estimate of the "respirable fraction") ranges from 0.6 to $0.2 \mathrm{wt} \%$. The fraction $<3 \mu \mathrm{m}$ AED (a more realistic estimate of the "respirable fraction") ranges from 0.25 to $0.1 \mathrm{wt} \%$. The shapes of the distributions at 


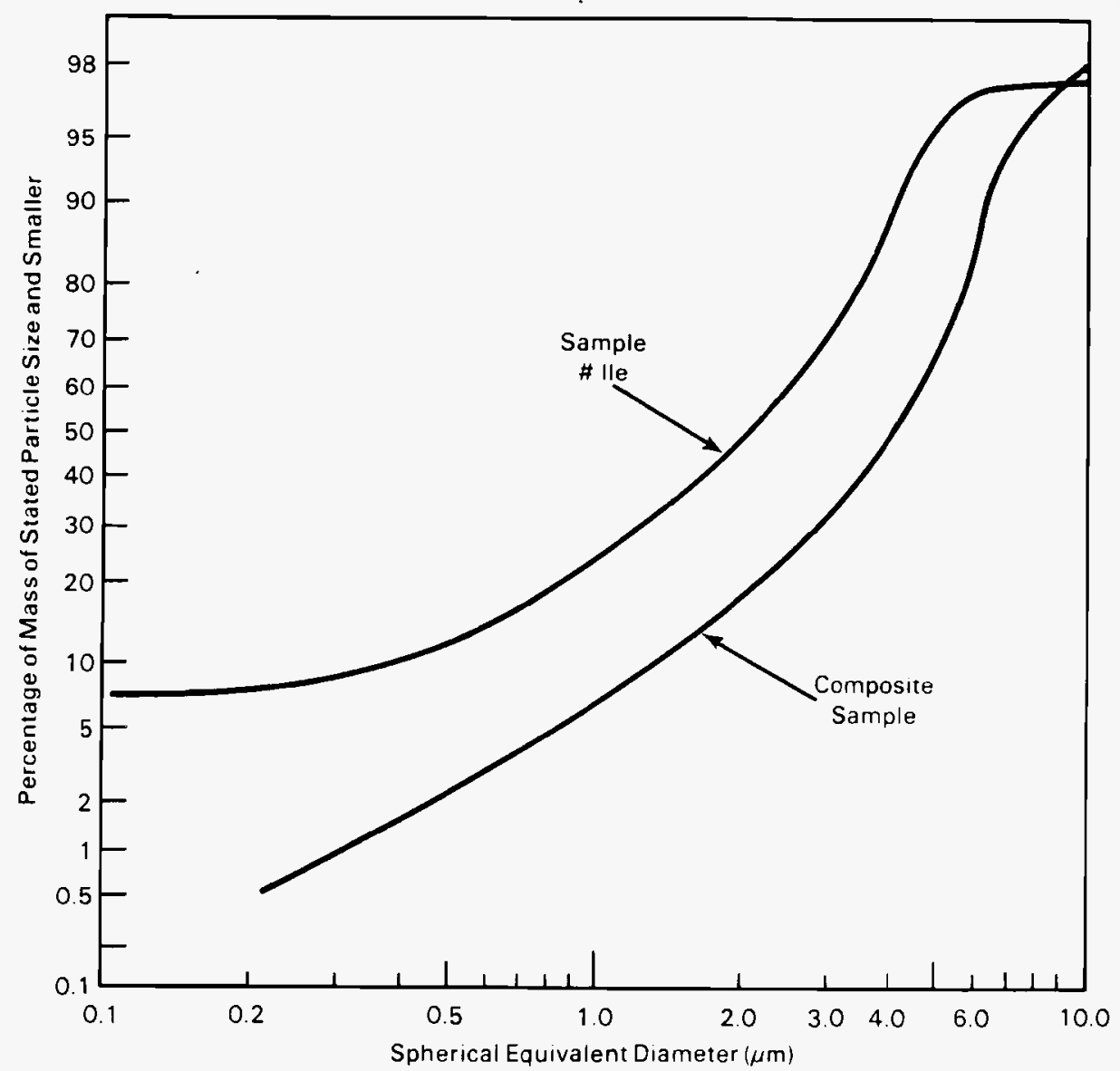

FIGURE 2.19. Size Distribution by Liquid Sedimentation - Fraction $<10$ um LLD, Sample \#11e and Composite

the upper end of the curves appear similar, perhaps indicating the strong influence of the DU oxide, while other materials (ash, soil, debris, etc.) have an effect upon the size distribution of the finer fraction. Thus, it appears that the maximum amount of DU oxide that could become airborne in the size fraction of concern would be $<0.6 \mathrm{wt} \%$.

\subsection{SOLUBILITY IN INTERSTITIAL LUNG FLUID}

The maximum solubility of uranium compounds in a simulated interstitial lung fluid is measured by placing the material in a suspension, stirring vigorously, and periodically sampling for dissolved uranium (Kalkwarf 1983). Predictions of the solubility of uranium compounds are made difficult by the presence of many stoichiometric and crystalline forms of uranium, some with 


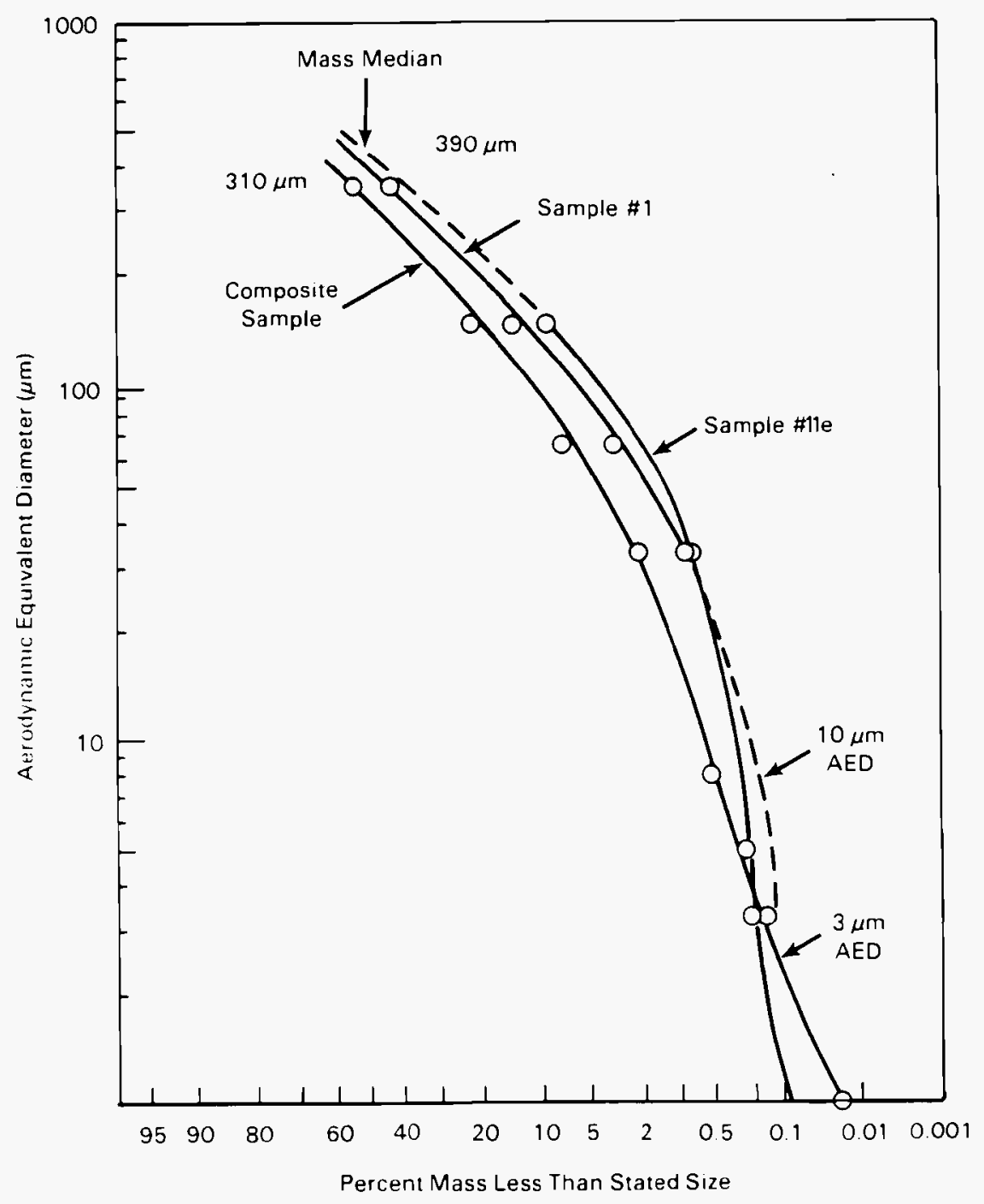

FIGURE 2.20. Size Distribution of DU Oxide From Apri1 1983 Burn Test

one or more hydrated forms (Kalkwarf 1983). The <10- $\mu m-A E D$ fraction from sample \#l was placed in a 5-ml vial of simulated lung fluid. The vial was sealed with a screw cap, held at $37^{\circ} \mathrm{C}$, and stirred vigorously. A17 the suspension was filtered, the solids were resuspended in a simulated lung fluid, and the quantity of uranium was measured by an extraction/fluorometric procedure (ASTM 1984) after 1d, 3d, 7d, 10d, 20d, 39d, and 60d to determine the fraction present in the three solubility classes - D (day), W (week), and $Y$ (year). The results are shown in Table 2.7 . 
TABLE 2.7. Comparison of Experimental Values of $F^{(a)}$

With Those Expected for $T=100$ Days

\begin{tabular}{|c|c|c|}
\hline$t$ (days) & $F($ Expt 1$)$ & $F(T=100 \mathrm{~d})$ \\
\hline 0.00 & 1.000 & 1.000 \\
\hline 0.96 & 0.993 & 0.993 \\
\hline 2.97 & 0.992 & 0.980 \\
\hline 6.75 & 0.991 & 0.954 \\
\hline 9.72 & 0.990 & 0.935 \\
\hline 20.79 & 0.984 & 0.866 \\
\hline 38.83 & 0.975 & 0.764 \\
\hline 59.87 & 0.965 & 0.660 \\
\hline
\end{tabular}

(a) $F$ is the fraction of the total uranium remaining undissolved after time $t$.

Generally, the dissolution half-times of uranium in a sample are evaluated by expressing the data in the form:

$$
F=\sum_{i} f_{i} \exp \left(-0.693 t / T_{i}\right)
$$

where $F$ = fraction of the total uranium remaining undissolved after time $t$

$f_{i}=$ initial weight fractions of uranium-containing species in the dust with dissolution half-times $T_{i}$

Since the experimental values of $F$ are all equal to or greater than the $F$ values for $T=100$ days, the dissolution half-time of the dust must be greater than 100 days. A value of $T=1170$ days was obtained by graphic analysis of the data. Thus, it is concluded that the uranium in the sample should be classified $100 \%$ Y class for calculations with the ICRP lung model. There is no evidence of any D- or W-class uranium in the sample, and it is concluded that any such components would comprise less than $1 \%$ by weight ( $1 \mathrm{wt} \%$ ) of the total uranium. Comparison of the measured weight of the dust with its total uranium content showed that it contained $63.7 \%$ uranium by weight; the remaining contents of the dust were oxygen, wood ash, soil, etc. 


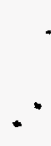

-

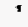

?

-

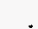

- 


\subsection{ACCIDENT SCENARIOS}

Two types of accidents are postulated for this study of M829 munitions: a shipping accident involving a truck collision and fire and a bulk storage accident involving a fire in an igloo or Stradley magazine.

\subsection{SHIPPING ACCIDENT - TRUCK ACCIDENT WITH FIRE}

Within the U.S., munitions such as the M829 are shipped primarily by single load truck (only one type of munitions is included in each truck load). The quantity of M829s that can be shipped in any single U.S. commercial semi-trailer is 512 rounds. The probability of a truck accident is small (2.4-2.7 $\times 10^{-6}$ per mile, Clarke 1975) and the probability of a fire in the event of an accident is only 1.1\% (Clarke 1975).

Nevertheless, since fire is the accident condition of concern, it is postulated that a truck collides with an accumulation of combustible materials similar in composition to that which is used in the external heat test (railroad ties) and the vehicle fuel (up to $130 \mathrm{gal}$ ) mixes with the combustible materials. The combustibles ignite under the bed of the truck resulting in a configuration similar to that used in the external heat test. Under these conditions, the temperatures generated and the timing of the various phases of the fire are assumed to be similar to those observed in the external heat test.

\subsection{BULK STORAGE ACCIDENT - FIRE IN AN IGLOO OR STRADLEY MAGAZINE}

In this scenario, the M829 munitions are assumed to be stored by themselves in either an igloo or Stradley magazine. The configuration for these storage facilities is shown schematically in Figures 3.1 and 3.2. The total number of rounds stored in each type of facility is 3408 for an igloo and 6176 for a Stradley magazine. Both types of facilities are covered on five of the six sides by earth with only one wall (the entrance) exposed to the atmosphere. Under ordinary conditions, the only other combustible materials present besides those in the munitions would be the wooden pallets and munition's packages. The quantity of combustible material per round is 


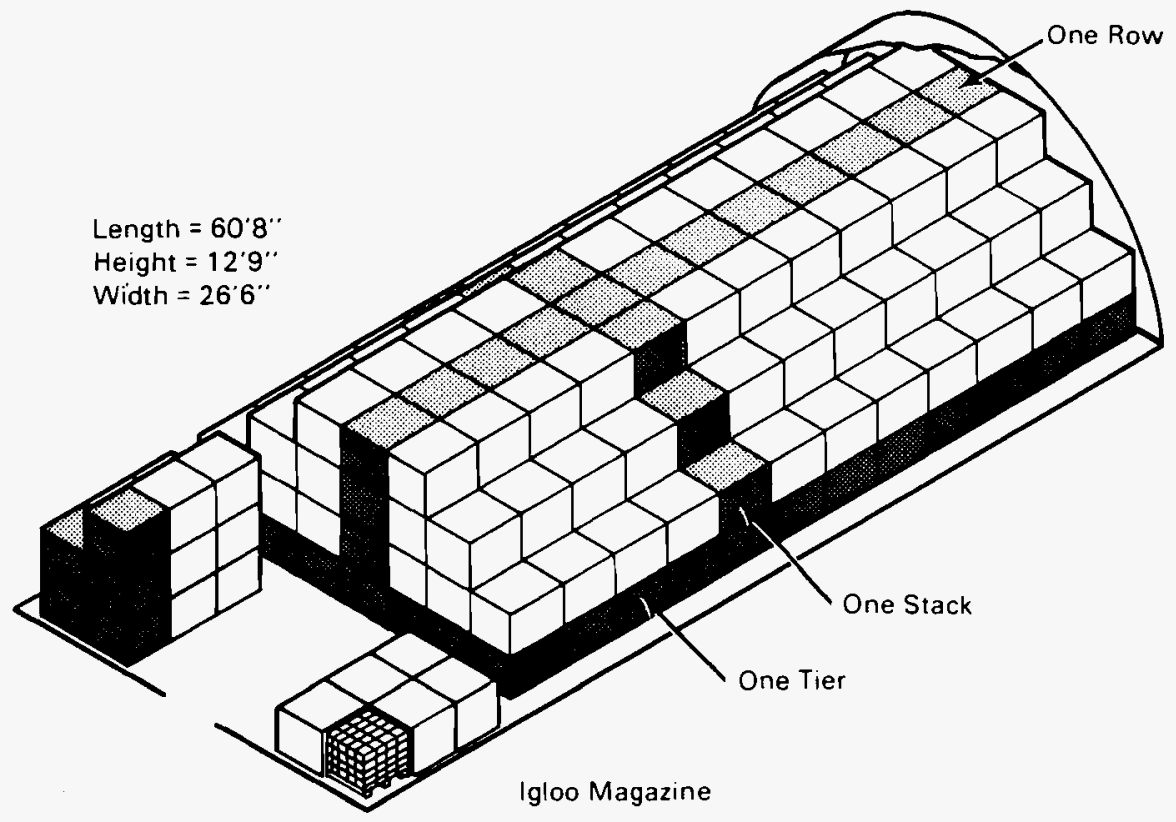

FIGURE 3.1. Typical Storage in Igloo Magazine

significantly less than that postulated for the transportation accidents and the availability of air would be more limited. The situation would be more like an enclosure fire, which is oxygen limited.

It is postulated that a vehicle collides with the entryway, creating an opening approximately the size of the vehicle $(8 \mathrm{ft} \times 8 \mathrm{ft})$. The fuel in the vehicle is spilled and is ignited by sparks generated by the contact of the vehicle's metal parts with structural materials (metal or concrete). The fuel ignites the exposed outer layers of ammunition containers. Rapid combustion of the liquid fuel would produce a situation similar to a "flashover" condition generating high temperatures, smoke, and two-phase flow at the opening (combustion products/flames out the upper portion and cold air in the lower portion of the opening). The fire would spread to other, uninvolved wood munition packages as the heat generated by the fire is absorbed. Wood burning involves both the pyrolysis of volatile vapors and the oxidation of char. As the internal temperatures within the package reach ignition temperature for the other packaging materials (cardboard) and munitions, they too will burn. If the stored munition has a noncombustible, rigid case (M774), the penetrators are displaced as the cases rupture and the impact of the displaced 


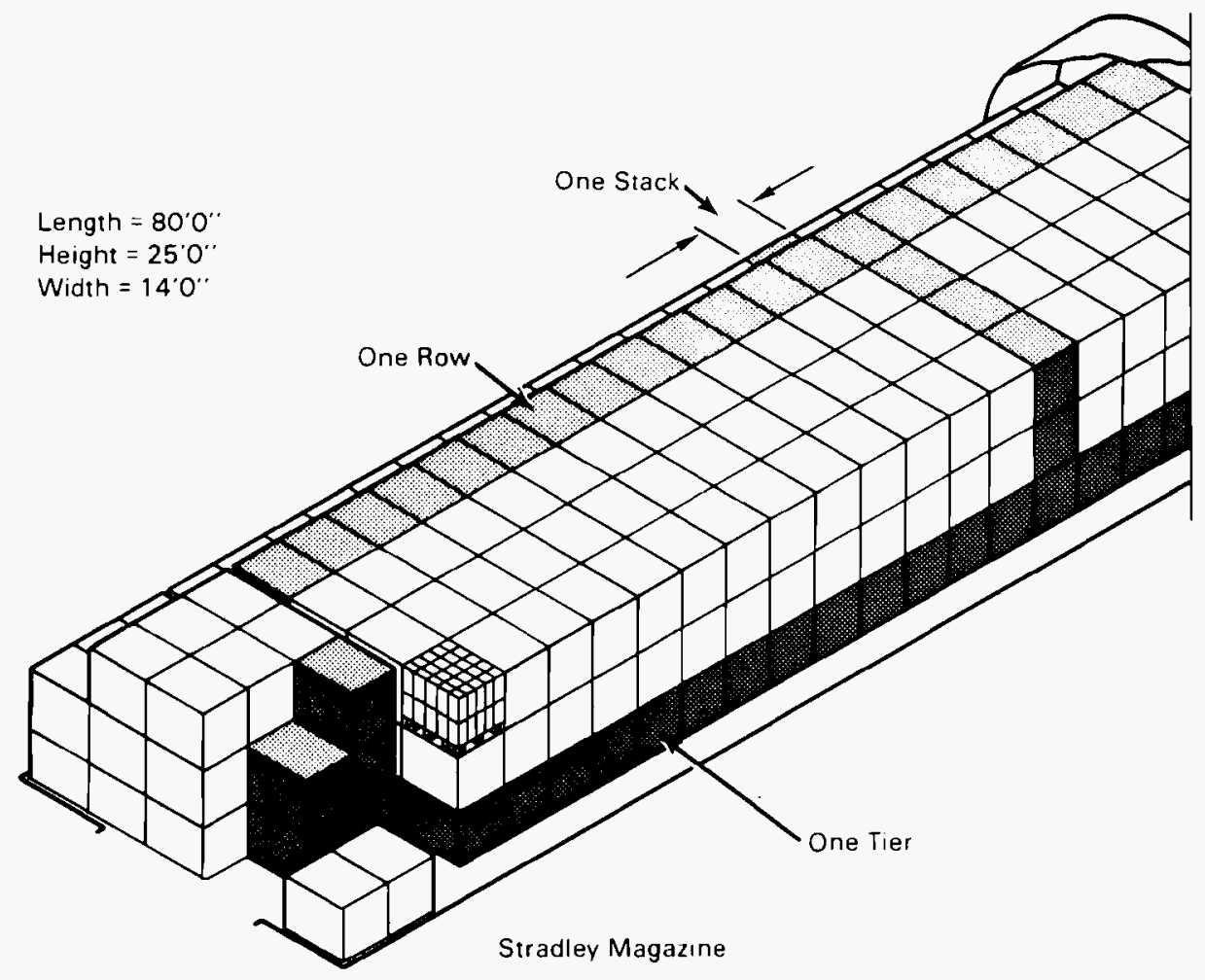

FIGURE 3.2. Typical Storage in Stradley Magazine

materials may cause damage/breakup of adjacent packages. If the munition cases are combustible (M829), the case and propellant "flare". The propellant contains its own oxidizers and does not require air to support combustion.

The M829 staballoy penetrators are not displaced but fall to the next rigid horizontal surface (the bottom of the wood package or the top of the wooden package below). The staballoy begins to absorb heat from the fire and, if sufficient oxygen is available, begins to oxidize. Burning of the wood packages may not be as vigorous in the tightly packed wooden cases as in a pile/crib fire. As each subsequent layer of munitions becomes involved, the staballoy penetrators continue to fall and oxidize. The impact of the fall could dislodge the oxide on the outer surface of the penetrator and, thus, the dispersion/injection of the DU oxide from staballoy may be a free-fall spill of a powder. 
The flaring of the propellant could also generate airborne DU oxide particles. The burning of the fuel creates a hot layer of gases near the ceiling of the enclosure and expels combustion gases and unburned pyrolyzates out into the atmosphere creating a buoyant plume. These hot gases rising from the wood packages could entrain and carry out airborne DU particles into the atmosphere.

Estimating the duration of the fire may be problematic since it is uncertain whether the conditions described would allow complete combustion of al1 the wood considering the depth of the enclosure/compartment. 


\subsection{LITERATURE SEARCH}

A literature search was conducted to find information about accidents involving fires, the behavior of DU in fires, the downwind transport of airborne DU particles, and the potential inhalation hazard from airborne DU.

\subsection{POSTULATED ACCIDENT CONDITIONS}

Our concern in this area is to determine the accident conditions that can lead to the airborne release of the staballoy penetrators. For the DU to be made airborne, be carried downwind, and be an inhalation hazard, it must be subdivided into particles $<10 \mu \mathrm{m}$ AED. Oxidation of the DU metal can convert it into an oxide, some of which can be in the "respirable" size fraction. Oxidation of DU metal is accelerated by heat, and, therefore, fire is the accident category of interest.

The literature on fires in textbooks, documents, and articles on the chemistry and physics of combustion is extensive, and the information covers controlled burning devices (e.g., boilers, incinerators, internal combustion engines, jet engines, etc.) as well as uncontrolled burning (e.g., pool fire, enclosure/compartment fires, unconfined burning, etc.). Since only a portion of the latter, uncontrolled burning, is pertinent to our study, only those references are provided.

\subsubsection{Analysis of Fires Involving DU Munitions}

Various analyses and field studies have evaluated fire conditions for potential fire scenarios involving DU munitions. The U.S. Army (ARMY 1979) evaluated the potential release of uranium during a fire and their report is mostly devoted to the characteristics of uranium and the assumptions used for calculation of control limits. A fire is postulated in an igloo magazine and it is assumed that all the released uranium is in the respirable size range.

Field tests were conducted in October 1977 to evaluate the hazards classification of the M774 round (Gilchrist, Parker and Mishima 1978). An external heat test was conducted involving 12 packaged rounds engulfed in a fire (wood crib under and around the rounds wetted with 50 gallons of fuel). 
The fire self-extinguished within 2 hours and all 12 penetrators were ejected from the fire. All penetrators were recovered intact and had undergone little observable damage.

The U.S. Army conducted a separate field test to determine the potential downwind hazard from the DU munitions during an "up-loaded" tank fire (Bloore and Wilsey 1979). A tank loaded with 37 rounds of M774, 20 M456 HEAT rounds, and six M393A2 HEP rounds and containing 300 gallons of fuel was ignited and burned. The actual burn time of the fire was not given but a 24-hour period was required for the tank to cool down sufficiently for examination. The temperature within the tank was monitored by 20 chrome 1 alumel thermocouples and remained generally under $1000^{\circ} \mathrm{C}$ with brief excursions to $1250^{\circ} \mathrm{C}$. Downwind air samplers and fallout trays with environmental air samplers at the periphery of the test site indicated no significant DU concentrations. Two separate plumes were observed; the initial plume reached $382 \mathrm{~m}$ some 2 min after ignition and the second reached $1620 \mathrm{~m}$ some 10 min after ignition. All 63 rounds "cooked off" and the tank was completely "gutted." Thirty-one of the DU penetrators survived intact and pieces equivalent to an additional 4.5 penetrators were recovered. For the 31 penetrators recovered intact, oxidation ranged from 0 (the total amount of uranium recovered exceeded the nominal weight of DU in a penetrator) to $40.5 \%$.

Walters, Elliot and Bloore (1979) addressed the Safety and Health Considerations for Handling Staballoy Munitions. Three classes of accident scenarios were addressed - transportation, storage, and use. Transportation of DU munitions alone or mixed loads with high-explosive (HE) rounds were considered. Storage scenarios included outside storage of mixed loads, igloo storage of DU alone, and igloo storage of DU and HE. Use covered "up-loaded" tanks. Several organizations involved in research of wood fires (National Bureau of Standards, John Hopkins Applied Physics Laboratory, Factory Mutual Research Corporation, and U.S. Naval Surface Weapons Station) were consulted as to the temperatures anticipated for unconfined and confined wood crib fires. They suggested that the temperature, duration of the fire, and time maximum temperature is sustained are functions of the configuration of the crib, surface-to-volume ratio, type of wood, and ventilation. Maximum temperatures of such a fire could reach $1300^{\circ} \mathrm{C}$ with gas temperatures at $750^{\circ} \mathrm{C}$ 
to $800^{\circ} \mathrm{C}$ within an enclosure or compartment. These fires could burn for several days if maximum conditions would not be maintained during the entire period. The data appears to apply to cribs that are controlled configurations allowing good ventilation. Based upon the data from the M774 rounds involved in the external heat test and tank burn or on the presence of $H E$, the DU penetrators are assumed to be ejected and not subjected to extreme oxidizing conditions for long periods of time.

The U.S. Army addressed Setting Control Boundaries from Igloo Storing Pyrophoric Depleted Uranium (Funkhouser 1981). No fire conditions are addressed. It is assumed that $30 \%$ of the rounds are "effected," $50 \%$ of the rounds are aerosolized, $50 \%$ of the aerosolized compounds are in the respirable size, and $50 \%$ of the respirable size are transportable (soluble in lung fluid).

Field tests on another type of DU munitions (M829) were conducted to evaluate their hazard classification (Hooker et al. 1983). The M829 is a $120-\mathrm{mm}$ round with a combustible cartridge case. Two tests were conducted, each with twelve packaged rounds engulfed in a fire (wood crib under and around the rounds and wetted with 55 gallons of fuel). For the first one (March 1982), the external heat test was performed in the same manner as for the M774. The cartridge cases burned prior to the ignition of the propellant and the penetrators fell into the fire rather than being ejected. The penetrators were oxidized extensively, and, owing to climatological conditions and the rudimentary collection methods that had to be applied, only $80 \%$ of the uranium could be accounted for after cleanup. The second external heat test was performed in April 1983. Additional equipment was utilized to monitor the airborne release, to collect samples for mass balance evaluation, and to measure the time/temperature curve in the burning material.

The details and results of the second test are covered in section 2.0, and the time/temperature curve is shown in Figure 2.8. The temperature rose rapidly to approximately $1000^{\circ} \mathrm{C}$ and remained at this level for the first three hours. The maximum recorded temperature was approximately $1200^{\circ} \mathrm{C}$. The temperature decayed slowly over the next 16 hours to the $600^{\circ}$ to $700^{\circ} \mathrm{C}$ range and remained at about that temperature for the next 16 hours. Due to a 
variety of reasons, including high temperatures, sample collection was delayed until 48+ hours after ignition when the temperature within the pile still exceeded $300^{\circ} \mathrm{C}$. During this period, the DU penetrators were $87 \%$ oxidized.

\subsubsection{Fires Where Wood is the Principal Fuel}

Harmathy (1972a) provided a comprehensive look at wood fires (confined and unconfined) and provided a semi-empirical model to estimate some of the important parameters influencing fire damage. He found that the use of the "fire loading" concept does not provide satisfactory estimates of fire endurance. Generally, poor reproducibility was found for enclosure/compartment fire (a confined space communicating with an unconfined atmosphere through one or more vertical openings) estimates. His conclusions do not normally apply to fires in very large or very deep compartments.

Wood decomposes into volatile vapors and char endothermically below $320^{\circ} \mathrm{C}$ and exothermically above that temperature. Heating at higher temperature enhances the exothermic products generating less char and more volatiles richer in carbon (and therefore with high calorific content). The decomposition is not noticeably affected by the presence or absence of air. Approximately $13 \%$ of the dry weight of wood results in char. The rate of volatilization is a function of the species of wood, moisture content, geometry, net heat flux, etc. The critical isotherm for decomposition appears to be the rate of heat penetration.

For complete combustion of wood, $5.11 \mathrm{~kg}$ of air $/ \mathrm{kg}$ of wood are required. Combustion is seldom complete and $\mathrm{CO}_{2} /\left(\mathrm{CO}_{2}+\mathrm{CO}\right)$ ratios of 0.6 are normally found in enclosure fires. On this basis assuming a "typical" composition for wood, $3.39 \mathrm{~kg}$ air $/ \mathrm{kg}$ of volatiles and $9.21 \mathrm{~kg}$ air $/ \mathrm{kg}$ of char are required. Heats of combustion for the "typical" composition of wood are $16.7 \times 10^{6} \mathrm{~J} / \mathrm{kg}$ volatiles and $33.4 \times 10^{6} \mathrm{~J} / \mathrm{kg}$ char.

For confined burning of wood, the mass-loss rate is not necessarily synonymous with burning, since material can be volatilized in an atmosphere that does not support combustion. The burning of a pile/crib of wood occurs in three stages - growth, primary burning (burning of volatiles and oxidation of char), and secondary burning (oxidation of char). The fire-growth duration is uncertain and is ignored in Harmathy's model. Generally, the mass-loss 
rate accelerates (growth stage) until approximately $20 \%$ of the initial mass is consumed. The mass-loss rate remains relatively constant (primary burning stage) until the mass is reduced to approximately $30 \%$ of its initial size and then the mass-loss rate declines (secondary burning stage).

Harmathy's model assumes that the primary burning stage covers the entire period of volatile generation and that half of the char is also oxidized during this period. It is further assumed that the volatiles are ignited by the glowing char surface and burn in the vicinity of the pile. (Special cases where the last statement is not valid are mentioned later.) The model indicates that the oxidation of char is independent of the availability of oxygen but really defines the relationship between air flow and mass-loss rate. It is assumed that the presence of oxygen in the pile affects volatilization by some indirect means such as controlling the combustion of some of the volatiles within the pile and, therefore, the net heat flux.

The process of burning wood is not analogous to a pool fire where the mass-loss rate is controlled by the "feedback" from the flames above and air can only be entrained from the sides of the vapor plume. In wood fires, volatiles can burn above and within the pile and air is entrained at the base and sides of the pile. Temperatures are normaliy much higher in the pile than the average flame temperature. The most plausible sequence appears to be: a wood fire is fed by air entering through the sides and base, a glowing layer of char (approximately $1000^{\circ} \mathrm{C}$ ) develops on the surface of the wood, heat generated from the oxidation of the char (and to a lesser extent from the burning of some volatiles within the pile) generates volatiles and char, and increases in air flow increase the amount of glowing char (and therefore the rate of volatilization) until heat loss from the pile balances the heat generated. Heat transfer within the pile is by conduction and, to a lesser extent, by convection and radiation (short-range, high-intensity fluxes). The average temperature flux within the pile depends upon the total area of glowing char and the geometry (internal - dimensions of the wood pieces/free surface area, porosity of the pile or fractional voidage, permeability in the horizontal and vertical direction, etc., - and external) of the pile. 
Bulk volatiles leaving the pile burn with the formation of a buoyant diffusion flame whose height is a function of the type of fuel used, the velocity of the gas at the base of the flame, and the diameter of the base. Harmathy provides equations to estimate the entrainment of air in the flame.

Although estimation of the ventilation of an unconfined wood pile is difficult, the ventilation of an enclosure/compartment is controlled by the size of the opening. In a fully developed fire, air enters through roughly the lower third of the vent due to the differential pressure generated by the fire. The velocity of the gases is virtually independent of the temperature of the gases, provided the temperature exceeds $300^{\circ} \mathrm{C}$. The mass-loss rate per time is quite different in a compartment, and pyrolysis may not occur over the entire pile. If the fire is zonal, a constant mass-loss rate may never be obtained.

There are two types of compartment fires - fuel controlled and ventilation controlled. A critical transition regime between the two types probably exists $(0.235$ <ventilation parameter/initial free surface of the wood $<0.290)$. The burning rate for a fuel-controlled fire is $0.0062 \mathrm{~kg} / \mathrm{m}^{2}$. seconds of initial free surface of wood and is independent of the geometry. Heat losses are less significant in compartments due to the presence of boundaries. Heat fluxes within the burning material tend to be more uniform and more independent of geometry. Size and shape of the compartment may have an effect.

The relationship between flame and compartment size is important (Harmathy 1972b) since it has a direct bearing upon the amount of heat released to the compartment. If the length of the flame is less than the height of the compartment, all the burning occurs in the compartment and the heat is all released in the compartment. If the length of the $f 1$ ame is greater than the height of the compartment, part of the burning and heat release may occur outside the compartment. Tall flames within a compartment have three sections: 1) a primary vertical section where air availability is limited but combustion rate is good due to the entrainment of air by the high turbulence of burning, 2) a horizontal section floating under the ceiling towards the vent (combustion in this section is poor due to a low air 
entrainment), and 3) a primary vertical section outside the compartment that burns under highly turbulent conditions but has restricted (one-sided) air entrainment due to the presence of the wall of the building above the vent and therefore combustion is, at best, only fair. Harmathy's model assumes negligible air entrainment in the horizontal section and that the flame outside the compartment is an extension of the vertical flame inside the compartment. Heat release from the burning of volatiles inside and outside the compartment can be calculated. Heat releases from the oxidation of char are always inside the compartment.

Fires within enclosures generally progress in three stages - initial growth of the fire, fully developed fire, and final decay of the fire. The first and last stages are not amenable to theoretic treatment, and the heat generated during these stages is only a fraction of the total. Actually, the rate of combustion is seldom a constant value even in outdoor burning of wood cribs, and the rate shows a considerable decrease as the predominant characteristics of the fire change from the combustion of the volatiles to the oxidation of the char. There does not appear to be a clear-cut point at which the fully developed fire stage ends and the final decay begins. Harmathy arbitrarily chose the point when the average gas temperature within the compartment is $80 \%$ of its maximum value. He also presents a formula to determine if the fire is fuel or ventilation controlled. The duration of an enclosure fire depends only on the free surface of the wood and is independent of the load. Large fires within the compartments are calculated to last 6 to 25 minutes, which Harmathy shows does not agree with experimental data.

Physio-chemical and thermodynamic data on wood can be found in many references (Harmathy and Mahaffey 1982; Tewarson 1972, 1979, 1980; Steciak, Tewarson and Newman 1983; Lynch undated). Probably the most sophisticated model of fire growth and behavior for compartment fires is the Harvard Computer Fire Code (Emmons 1978; Mitler and Emmons 1981; Mitler 1978). The model calculates the evolution of a fire in an enclosure with a number of vents and objects that can be flammable or not. The model calculates a number of important fire characteristics - hot layer temperature, mass flow rates, 
wall/ceiling/target temperatures, oxygen concentrations, etc. The model's concepts and mathematics are too complex to be covered adequately in this review (see the above references for more details).

So the type of fuel, the presence or absence of an enclosure/compartment, and the fuel configuration can have a significant effect upon fire conditions. The apparent differences in behavior of the fires during the tank burn (a liquid pool fire), the M774 external heat test (scrap wood with large surface to volume ratios), and the M829 external heat tests are now understandable. Some fires may generate conditions that are highly destructive but are not necessarily those that would be most conducive to complete oxidation of the staballoy penetrators.

\subsection{BEHAVIOR OF DEPLETED URANIUM (DU) UNDER ACCIDENT CONDITIONS}

Based upon the data discussed in the previous two sections (3.0 Accident Scenarios, and 4.1, Postulated Accident Conditions), the fire conditions anticipated for the three classes of fires are:

Transportation - The credible maximum conditions anticipated are similar to those during the external heat tests. The fire would be intense $\left(800^{\circ}\right.$ to $1000^{\circ} \mathrm{C}$ ) for six to 10 hours. Unless remedial actions were taken, the residual material would smolder for another day or two, gradually decreasing in temperature to a few hundred degrees.

Bulk Storage - The maximum credible conditions would be similar to those of a ventilation-limited enclosure fire. It is anticipated that the staballoy penetrators would be subjected to temperatures ranging from $1000^{\circ} \mathrm{C}$ (the temperature of glowing char) to $300^{\circ} \mathrm{C}$ for many days unless remedial measures were taken. It is uncertain whether the fire would continue or would self-extinguish or if the building would withstand the heat load. If the building collapsed, the fire would probably be extinguished, but some of the small-sized, lighter particles could be ejected from the enclosure by the air motion generated by the falling debris. The remainder of the debris would be buried. The atmosphere during the heating of the penetrators would be predominantly air, with increasing amounts of combustion products as the fire moved further into 
the enclosure. The penetrators would be subjected to the impact of falling debris (primarily remnants of the wooden packages and penetrators) and to the impact of falling and landing on solid surfaces as the fire progressed. The impacts would occur before and after significant oxidation of the penetrators.

Use - The assessment provided in Walters, Elliot and Bloore (1979) appears to adequately define the conditions anticipated for fires in an up-loaded tank.

The next data required for the assessment of the airborne radiological/ toxicological consequences are the behavior of the staballoy under fire conditions and of the airborne DU particles. The types of compounds can give some indication of the type of threat (radiological or toxicological) based upon their solubility in interstitial lung fluid. The particle size distribution is important in assessing the potential amount of material that can be transported and inhaled because it provides a "realistic estimate of the upper bound" for the inhalation hazard envelope. Knowing the fractional airborne release under fire conditions can provide some "realistic" estimates of the potential downwind hazard as a function of time.

\subsubsection{Uranium Compounds and Reaction Rates}

Uranium metal reacts with many materials. The rate and compounds formed are dependent upon the conditions imposed (temperature, pressure, time, concentration, etc.). For fires, the principal reactions appear to be with materials in the gaseous state (air, combustion products, etc.) but some solid materials could react (char, ash, etc.). The actual materials formed are a matter of equilibriums, kinetics, etc.

Penetrators are not entirely uranium but contain $0.75 \mathrm{wt} \%$ titanium, which can alter/modify the oxidation characteristics of uranium. Titanium forms solid solutions with uranium (ARMY 1962). As-cast, beta-quenched uranium exhibits significantly higher oxidation rates and lower ignition temperatures than other forms (ARMY 1962). Uranium oxidation generally proceeds in two stages with a break weight or time. The rate of oxidation increases with time under isothermal conditions and the reactions generally produce heat (Hilliard 1958; Schnizlein et al. 1959; Megaw et al. 1961; Gittus 1963; Ritchie 1981). 
An additive can affect the oxidation characteristics of the uranium in three ways: 1) change the first-stage rate, 2) change the break weight, and 3 ) change the second-stage rate. The effect is shown in a table (Table 16 in Schnizlein et a1. 1959), but the table does not contain information on titanium. Titanium is the lower atomic number of the same group in the periodic table as zirconium, which is listed and shows a slightly accelerated firstand second-stage rate constant at a concentration of $0.5 \mathrm{wt} \%$ (Schnizlein et a1. 1959). Titanium additives at concentrations of $0.5,0.99$, and 1.43 wt\% are reported to have an "aluminum-type" effect (inhibits transition to a protective oxide at $450^{\circ} \mathrm{C}$ ) (Schnizlein, Baker and Bingle 1966). Thus, staballoy may have a single rate constant or an oxidation rate higher than pure, unalloyed uranium.

The oxidation of pure, unalloyed uranium is a function of the amount of surface area exposed to the oxidizing atmosphere and the amount of oxidant reaching the metal. A thin, adherent layer of oxide forms at the interface and controls the rate at which oxidant reacts with the surface. The outer surface of the oxide reacts with the oxidant diffusing through it to form hyperstoichiometric uranium dioxide and, subsequently, the higher oxides of uranium. The physicochemical characteristics of the higher oxides formed are dependent upon the temperature and oxidant availability. The factors that could influence the oxidation of uranium are shown in Table 4.1 taken from Schnizlein et a1. (1959). The possibility that uranium oxidation could accelerate to ignition in various oxidants has been recognized and is a surface-to-volume function (see Figure 4.1). Based upon experiments conducted with staballoy penetrators at high temperatures and full accessibility to air (Elder and Tinkle 1980; Hooker et a1. 1983), it is not anticipated that penetrators will accelerate to ignition under fire scenario conditions (see Figure 4.1).

0xidation of uranium has been determined in various wet and dry atmospheres at temperatures up to $1400^{\circ} \mathrm{C}$. At low temperatures (less than approximately $300^{\circ} \mathrm{C}$ ), the rate in most atmospheres is low (Schnizlein et al. 1959; Leibowitz et a1. 1961; Gittus 1963; Bennett and Price 1981; Ritchie 1981), and the oxidation is then termed corrosion. Water vapor accelerates 
TABLE 4.1. Table from Schnizlein et al. 1959

Step

Metal surface of unit area oxidizing in air
Possible Factors Influencing Rate

(1) Metal purity

(2) Metaliurgical condition (grain size, strains, etc.)

(3) Temperature

(4) Time

(5) Gas composition

(6) Type of oxide film formed (protective or not)

(1) Thermat conductivity of metal

(2) Thermal conductivity of oxide coating

(3) Cross-sectional area at right angles to direction of heat flow

(4) Temperature gradient

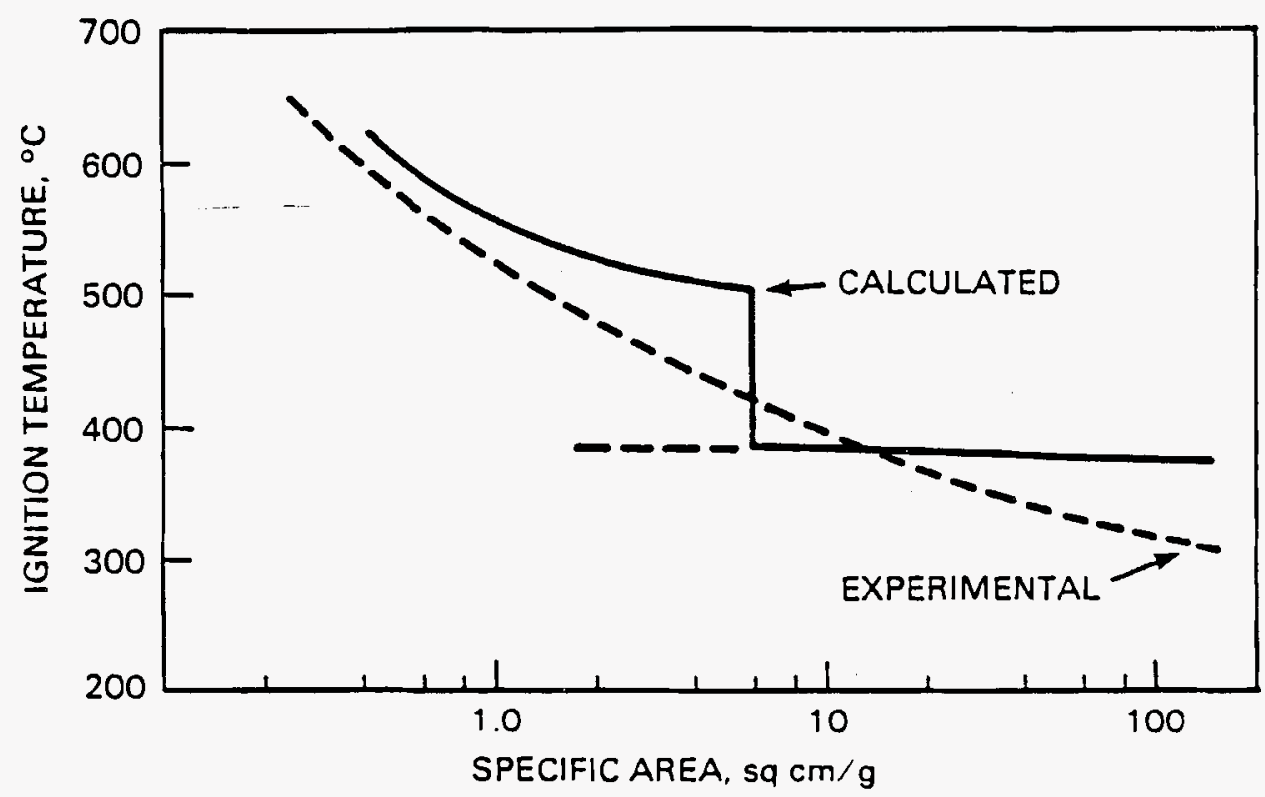

FIGURE 4.1. Dependence of Uranium Ignition on Specific Area (Baker, Schnizlein and Bingle 1966) 
the oxidation rates at these lower temperatures (Jackson, Condon, and Steckle 1977) but loses its effect at higher temperatures (Schnizlein et al. 1959; Gittus 1963; Tyzack and Cowen 1976; Bennett and Price 1981; Ritchie 1981; Condon, Cristy and Kirkpatrick 1983). The water vapor effect persists to higher temperatures $\left(350^{\circ}\right.$ to $500^{\circ} \mathrm{C}$ ) in carbon dioxide (Tyzack and Cowen 1976). Colmenares, Howell and McCreary (1981) reported that the effect of water vapor on the acceleration of the oxidation of uranium was sensitive to the oxygen content in the water vapor.

The oxidation of uranium is generally described as two linear rates separated by a break weight (Schnizlein et al. 1959; Leibowitz et al. 1961; Gittus 1963). At lower temperatures, the break weight appears to occur after the reaction with $50 \mu \mathrm{g}$ of oxygen per square centimeter of uranium surface (Leibowitz et a1. 1961).

At higher temperatures, uranium oxidation rates increase with temperature [see Figure 4.2, Overall 0xidation Rate Versus $1 / T$ for Various Specimen Sizes (after Hilliard 1958); Figure 4.3, Oxidation of Uranium in Air (after Megaw et al. 1961); Gittus 1963; Baker, Schnizlein and Bingle 1966]. Megaw et al. (1961) reported rates as high as 3000 to $8000 \mathrm{mg} \mathrm{U} / \mathrm{cm}^{2} \cdot \mathrm{hr}$ at $800^{\circ}$ to $1000^{\circ} \mathrm{C}$. Using a penetration rate of $55 \mu \mathrm{m}=100 \mathrm{mg} \mathrm{U} / \mathrm{cm}^{2} \cdot \mathrm{hr}$ oxidation rate and, assuming the surface area decrease in a cylindrical penetrator does not alter the penetration rate, a staballoy penetrator with a radius of $12.7 \mathrm{~cm}$ would be completely oxidized in 2.9 to 7.7 hours. Hilliard (1958) reports a rate of 950 to $1000 \mathrm{mg} \mathrm{U} / \mathrm{cm}^{2} \cdot \mathrm{hr}$ at $600^{\circ}$ to $800^{\circ} \mathrm{C}$ and others have reported values in the range of 700 to $1820 \mathrm{mg} \mathrm{U} / \mathrm{cm}^{2} \cdot \mathrm{hr}$. At a rate of $700 \mathrm{mg} \mathrm{U} / \mathrm{cm}^{2} \cdot \mathrm{hr}$ and using the assumptions above, a staballoy penetrator would oxidize completely in 33 hours. This range of times for complete oxidation is consistent with observed behavior in fires. Increase in the oxygen content above those normally found do not appear to have a significant effect but lowering the oxygen content decreases the oxidation rates [see Figure 4.4 Variation in Oxidation Rate at $600^{\circ} \mathrm{C}$ with Oxygen Content of Gas Stream (based on Megaw et al. 1961)]. Oxidation rates in carbon dioxide are similar to those for air at high temperature [see Figure 4.5 Oxidation of Uranium in Carbon Dioxide (based 


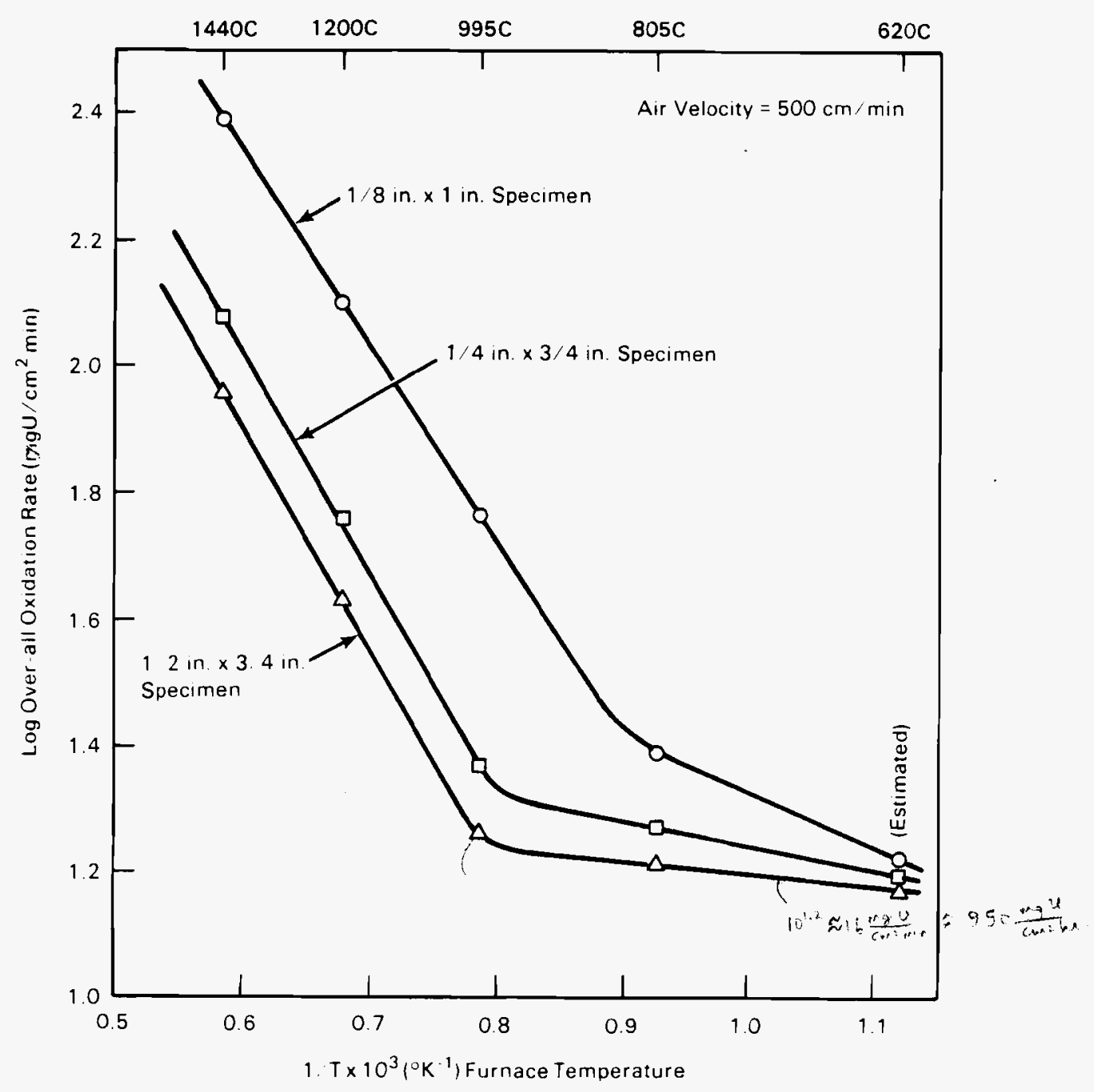

FIGURE 4.2. Overall Oxidation Rate Versus $1 / T$ for Various Specimen Sizes (Hilliard 1958)

on Megaw et al. 1961)] and may compensate to some extent for the reduction of oxidation due to oxygen content by carbon dioxide oxidation. A significant increase in oxidation rate at the beta-gamma phase transition has been observed by several authors.

Swelling (Bennett and Price 1981) and thermal stresses due to differential heating of materials (Stobbs and Whittle 1966) resulting in the cracking of the oxide coat, loss of outer oxide coat (Megaw et al. 1961) and 


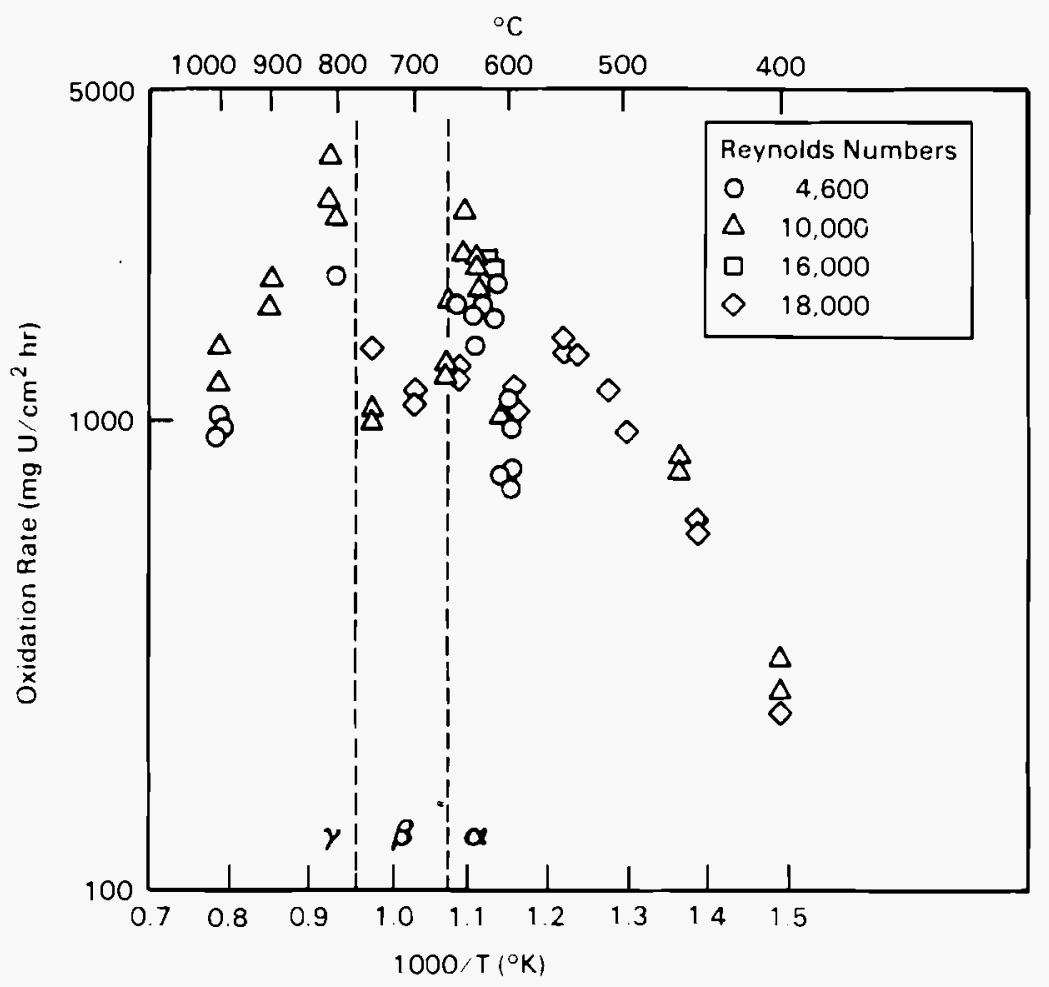

FIGURE 4.3. Oxidation of Uranium in Air (Megaw et a1. 1961)

surface inclusions such as carbides (Bloch and Mintz 1982; Tyzack and Cowen 1976; Stobbs and Whittle 1966) and hydrides (Bennett and Price 1981) al1 accelerate oxidation. Nitrogen can react with uranium at high temperature, but the reaction is very slow compared with air and carbon dioxide and will not react in the presence of any oxygen (Gittus 1963; Strafford 1979). Uranium will also react with hydrogen (Stakebake 1979; Stakebake and Bixby 1979), but free hydrogen is not anticipated in fire atmospheres. Carbon will react to form carbides (Stinton et al. 1979; Suzuki et a1. 1982) but the carbide converts to oxides when contacted with air.

Field and laboratory studies have been conducted on the oxidation of staballoy penetrators under simulated and actual fire conditions (Elder and Tinkle 1980; Hooker et al. 1983). Elder and Tinkle (1980) investigated the behavior of staballoy penetrators at various temperatures and atmospheres (air and $50 \%$ air $/ 50 \%$ carbon dioxide) under simulated fire conditions. The results of those laboratory oxidation studies are shown in Table 4.2. Oxidation 


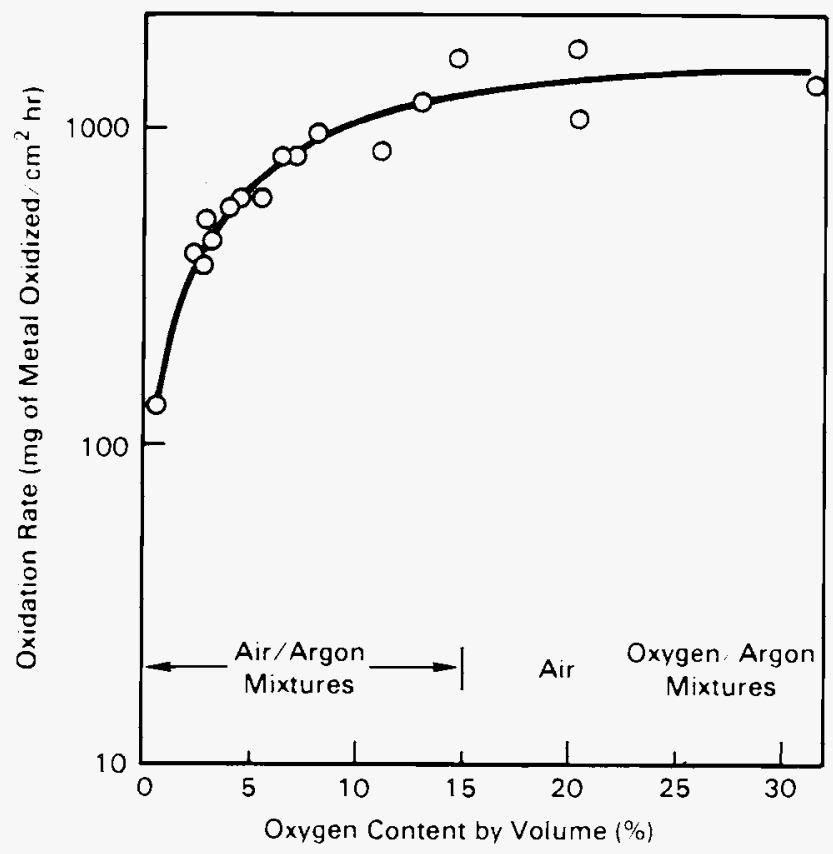

FIGURE 4.4. Variation of Oxidation Rate at $600^{\circ} \mathrm{C}$ with 0xygen Content of Gas Stream (Megaw et al. 1961)

values range from $6.0 \%$ in 2 hours at a temperature of $500^{\circ} \mathrm{C}$ in an air/carbon dioxide mixture to $30.2 \%$ in 4 hours at a temperature of $800^{\circ} \mathrm{C}$ in an air/carbon dioxide mixture. Significant oxidation was detected in one of the field tests in an apparatus like a forge-type furnace. Temperatures ranging from $700^{\circ}$ to $900^{\circ} \mathrm{C}$ were measured during most of the 3-hour run with air at a velocity of $223 \mathrm{~cm} / \mathrm{sec}(5 \mathrm{mph})$. The results of the test on the three penetrators are shown in Table 4.3 and represent an average oxidation of $44 \%$ during this period. At the rate indicated, all penetrators would have been oxidized in $62 / 3$ hours. For the maximum rates indicated in the laboratory study in air and air/carbon dioxide mixture, complete oxidation of the penetrators would occur in 9 to 13.5 hours. The oxidation of staballoy penetrators as a function of temperature in these experiments is shown in Figure 4.6. 


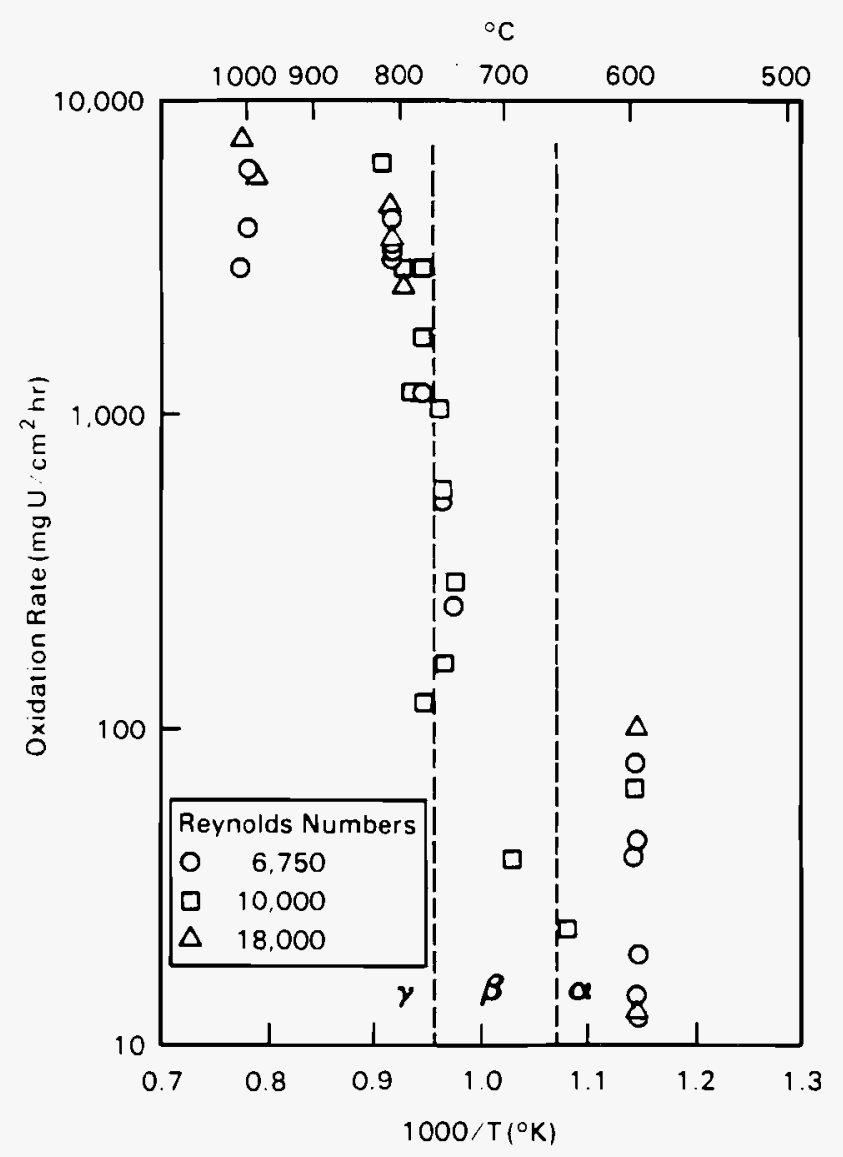

FIGURE 4.5. Oxidation of Uranium in Carbon Dioxide (Megaw et al. 1961)

Hooker et al. (1983) conducted field studies in which 12 M829 packaged rounds were engulfed in a fuel-wood fire until self-extinguishment of the fire. Temperatures during the steady-state burning of the wood in the second test were $1200^{\circ}$ to $700^{\circ} \mathrm{C}$. Temperatures remained at the $300^{\circ} \mathrm{C}$ level after 48 hours, when sample collection began. The penetrators were approximately $83 \%$ to $84 \%$ oxidized at that time, which probably reflects the reduced oxygen availability and the variable temperatures in a real fire. 


\section{TABLE 4.2. Penetrator 0xidation}

\begin{tabular}{|c|c|c|c|c|c|c|c|}
\hline $\begin{array}{c}\text { Penetrator } \\
\text { No. }\end{array}$ & $\begin{array}{l}\text { Nomina } 1 \\
\text { Temp } \\
\left({ }^{\circ} \mathrm{C}\right)\end{array}$ & $\begin{array}{r}\text { Time } \\
(\mathrm{h}) \\
\end{array}$ & $\begin{array}{c}\text { Original } \\
\begin{array}{c}(\mathrm{g}) \\
\end{array}\end{array}$ & $\begin{array}{l}\text { netrator Weig } \\
\text { After Light } \\
\text { Mechanical } \\
\text { Removal (g) } \\
\end{array}$ & $\begin{array}{l}\text { s } \\
\text { After wire } \\
\text { Brush } \\
\text { (g) }\end{array}$ & $\begin{array}{c}\text { Metal } \\
\text { 0xidation } \\
(\mathrm{g})\end{array}$ & $\begin{array}{c}\text { Metal } \\
\text { 0xidation } \\
(8)\end{array}$ \\
\hline \multicolumn{8}{|c|}{ Air at $223 \mathrm{~cm} / \mathrm{s}$} \\
\hline $\begin{array}{l}61512 \\
59603 \\
61310 \\
61501 \\
61510\end{array}$ & $\begin{array}{l}500 \\
600 \\
700 \\
800 \\
900\end{array}$ & $\begin{array}{l}2 \\
2 \\
2 \\
2 \\
2\end{array}$ & $\begin{array}{l}3354.0 \\
3358.8 \\
3354.9 \\
3354.5 \\
3354.0\end{array}$ & $\begin{array}{l}3130.8 \\
3162.0 \\
2640.0 \\
2794.5 \\
2869.4\end{array}$ & $\begin{array}{l}3123.8 \\
3149.2 \\
2613.1 \\
2761.5 \\
2827.1\end{array}$ & $\begin{array}{l}230.2 \\
209.6 \\
741.8 \\
593.0 \\
526.9\end{array}$ & $\begin{array}{r}6.8 \\
6.2 \\
22.1 \\
17.6 \\
15.7\end{array}$ \\
\hline \multicolumn{8}{|c|}{$\mathrm{CO}_{2} / \mathrm{Air}$ Mixture at $223 \mathrm{~cm} / \mathrm{s}$} \\
\hline $\begin{array}{l}61402 \\
61406 \\
45401 \\
45510 \\
45104 \\
59613 \\
45204\end{array}$ & $\begin{array}{r}500 \\
600 \\
700 \\
800 \\
800 \\
900 \\
1000\end{array}$ & $\begin{array}{l}2 \\
2 \\
4 \\
4 \\
4 \\
4 \\
4\end{array}$ & $\begin{array}{l}3355.0 \\
3353.0 \\
3357.0 \\
3354.2 \\
3355.4 \\
3352.8 \\
3355.0\end{array}$ & $\begin{array}{l}3156.8 \\
3149.0 \\
2652.9 \\
2405.9 \\
2378.1 \\
2544.2 \\
2586.2\end{array}$ & $\begin{array}{l}3153.2 \\
3140.9 \\
2642.2 \\
2351.1 \\
2343.7 \\
2518.8 \\
2564.7\end{array}$ & $\begin{array}{r}201.8 \\
212.1 \\
714.8 \\
1003.1 \\
1011.7 \\
834.0 \\
790.3\end{array}$ & $\begin{array}{r}6.0 \\
6.3 \\
21.3 \\
29.9 \\
30.2 \\
24.9 \\
23.6\end{array}$ \\
\hline \multicolumn{8}{|c|}{ Air at Zero Velocity } \\
\hline 45407 & 700 & 2 & 3355.9 & 2929.0 & 2908.9 & 447.0 & 13.3 \\
\hline
\end{tabular}

TABLE 4.3. Burn \#4, Final Penetrator Weights

\begin{tabular}{|c|c|c|c|c|}
\hline Location & Number & $\begin{array}{l}\text { Serial } \\
\text { Number } \\
\end{array}$ & $\begin{array}{c}\begin{array}{c}\text { Final } \\
\text { Weight }(\mathrm{g})\end{array} \\
\end{array}$ & $\begin{array}{c}\% \text { Oxide } \\
\text { (\% of Original } \\
3355 \mathrm{~g} \text { Weight) } \\
\end{array}$ \\
\hline Top & 3 & 045313 & 1874 & 44 \\
\hline Middle & 2 & 045109 & 1772 & 47 \\
\hline Bottom & 1 & 045108 & 1947 & 42 \\
\hline
\end{tabular}




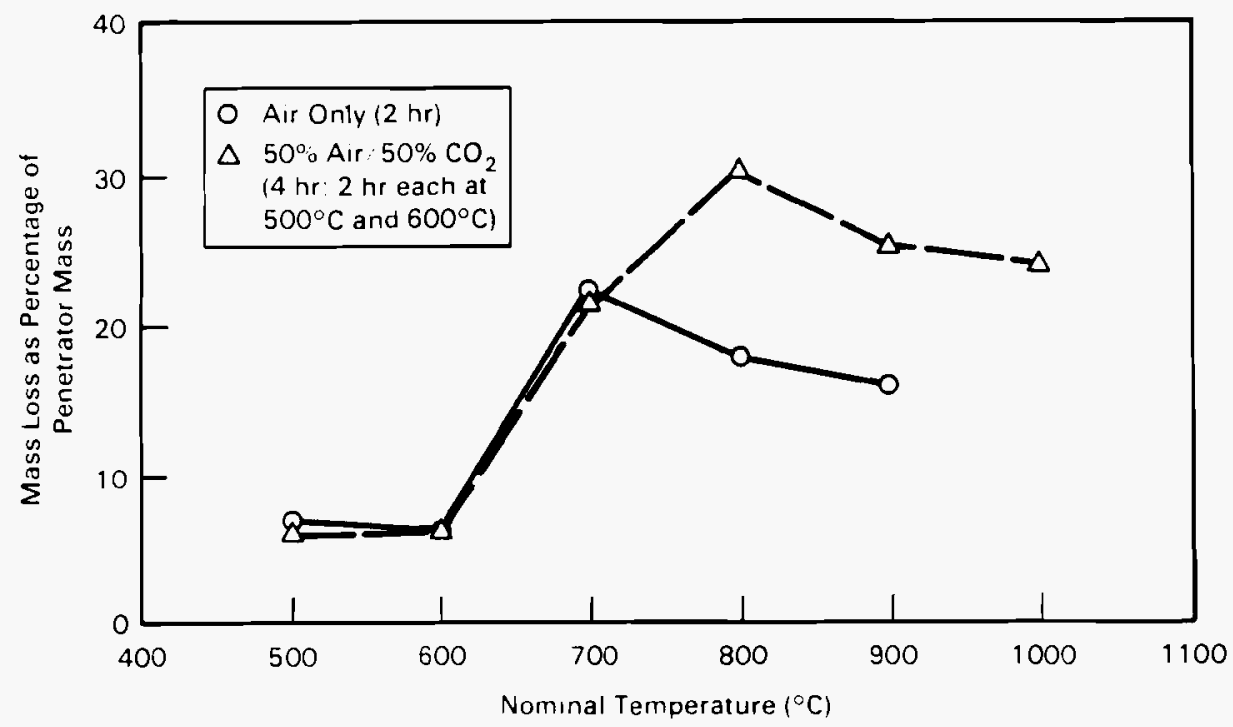

FIGURE 4.6. Oxidation as a Function of Temperature (Elder and Tinkle 1980)

\subsubsection{The Characteristics of DU Oxides Generated by Fires}

At low temperatures (less than $200^{\circ} \mathrm{C}$ ), hyperstoichiometric $\mathrm{UO}_{2+\mathrm{x}}$ (where $x$ may be as high as 0.45 ) are found (Schnizlein et al. 1959; Ritchie 1981; Colmenares, Howell and McCreary 1981; Iwasaki et al. 1969; Iwasaki and Ishikawa 1970; Bennett and Myatt 1977; Bennett and Price 1981). The presence of other compounds such as $\mathrm{U}_{3} \mathrm{O}_{7}$ and $\mathrm{U}_{3} \mathrm{O}_{8}$ (Schnizlein et al. 1959), and $\mathrm{U}_{4} \mathrm{O}_{7-y}$ (Colmenares, Howell and McCreary 1981) have also been reported at these and slightly higher temperatures. A combination of $\mathrm{UO}_{2+x}$ and $\mathrm{U}_{3} \mathrm{O}_{8}$ was found at temperatures greater than $275^{\circ} \mathrm{C}$ (Ritchie 1981). Ritchie (1981) reported the presence of yellow $\mathrm{UO}_{3} \cdot 0.8 \mathrm{H}_{2} \mathrm{O}$ for low temperature oxidation $\left(115^{\circ} \mathrm{C}\right)$ of uranium at relative humidities greater than $90 \%$. At a relative humidity of less than $90 \%, \mathrm{UO}_{2}$ was generated.

At higher temperatures (exceeding $300^{\circ} \mathrm{C}$ ), $\mathrm{U}_{3} \mathrm{O}_{8}$ mixed with hyperstoichiometric $\mathrm{UO}_{2}$ are found (Hilliard 1958; Megaw et al. 1961; Gittus 1963; Aronson, Roof and Belle 1957; Iwasaki et al. 1969; Iwasaki and Ishikawa 1970; Elder and Tinkle 1980). A thin layer of adherent $\mathrm{UO}_{2}$ forms at the metal surface (Tyzack and Cowen 1976) and the rate of conversion to higher oxides is controlled by the diffusion of oxidant through the oxide layer (Aronson, Roof and Belle 1957; Iwasaki and Ishikawa 1970). Figure 4.7 illustrates the phenomena. 


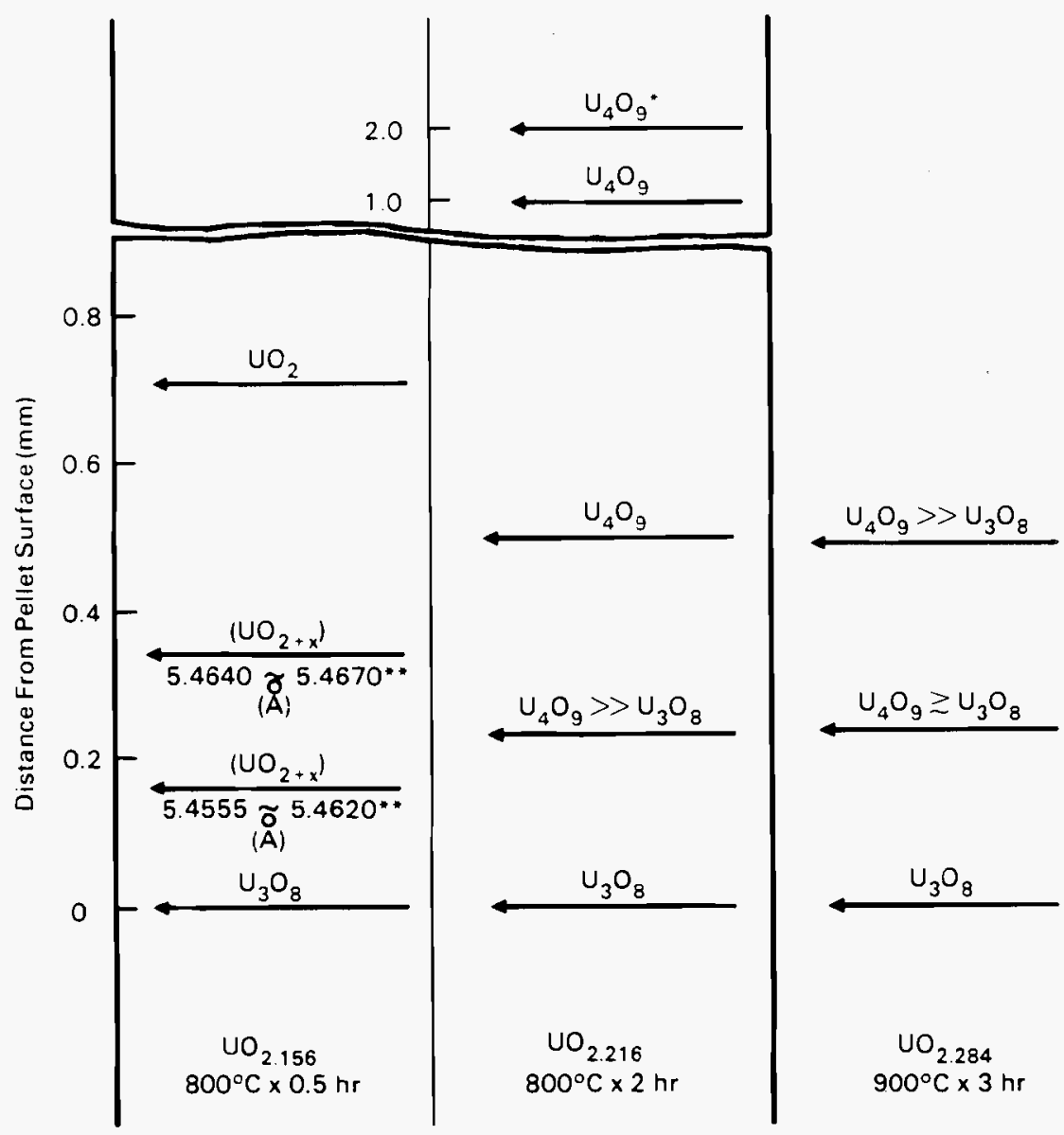

FIGURE 4.7. The Phases in Pellets Oxidized in Air at Various Temperatures.

* The peaks of the $x$-ray diffraction pattern are broad.

$\star \star$ Range of the value of a $(\AA)$.

(Iwasaki and Ishikawa 1970 )

Peakill and Antill (1960) found three regimes in the air oxidation of $\mathrm{UO}_{2}$ at temperatures ranging from $350^{\circ} \mathrm{C}$ to $1000^{\circ} \mathrm{C}$. In the $350^{\circ}$ to $600^{\circ} \mathrm{C}$ range, $\mathrm{UO}_{2}$ oxidized rapidly to $U_{3} 0_{8}$, which fell away as a fine powder. The oxide formed in the $650^{\circ}$ to $850^{\circ} \mathrm{C}$ range was protective but broke away at some point. At temperatures greater than $900^{\circ} \mathrm{C}$, the oxide was adherent and protective.

Iwasaki et a1. (1969) found the size of the powder produced from the air oxidation of sintered $\mathrm{UO}_{2}$ pellets depended upon the temperature; generally, powders were produced with a significant fraction less than $10 \mu \mathrm{m}$ (probably 
geometric diameter) at temperatures from $400^{\circ}$ to $500^{\circ} \mathrm{C}$ and greater than $10 \mu \mathrm{m}$ at temperatures exceeding $600^{\circ} \mathrm{C}$. At temperatures less than $600^{\circ} \mathrm{C}$, a fine, voluminous powder was found, but many flat lumps 1 and $2 \mathrm{~mm}$ in diameter were found at temperatures greater than $700^{\circ} \mathrm{C}$. Iwasaki and Ishikawa (1970) also found three temperature regimes during the air oxidation of $\mathrm{UO}_{2}$ pellets, but the temperature ranges observed were: $400^{\circ}$ to $700^{\circ} \mathrm{C} ; 800^{\circ}$ to $900^{\circ} \mathrm{C}$; and $1000^{\circ}$ to $1100^{\circ} \mathrm{C}$ (the maximum temperature used). The breakaway of the oxide at the $800^{\circ}$ to $900^{\circ} \mathrm{C}$ range led to an acceleration of the oxidation rate. The pellets did not breakup when the U:0 ratio was 2.25 , but broke into small pieces when the $U: 0$ ratio reached $2.7\left(U_{3} 0_{8}\right)$.

Schnizlein et al. (1959) observed that newly formed $\mathrm{UO}_{2}$ was more reactive than sintered $\mathrm{UO}_{2}$, and, thus, the phenomena cited above may occur at lower temperatures and higher rates for fire-generated materials. Hilliard found a fine, black, nonadherent powder from the air oxidation of metal at temperatures less than $450^{\circ} \mathrm{C}$, a fine powder sintered into lumps at a temperature of $535^{\circ} \mathrm{C}$, and a hard, black, scale from air oxidations at temperatures greater than $700^{\circ} \mathrm{C}$.

The high temperature oxidation of uranium metal in carbon dioxide produces a mixture of hyperstoichiometric $\mathrm{UO}_{2}$ and uranium carbide (Gittus 1963; Tyzack and Cowen 1976). Carbides rapidly oxidized to uranium oxides in air at elevated temperatures. Table 4.4 from Stobbs and Whittle (1966) describes some of the uranium materials formed during the oxidation of various grades of uranium metal in carbon dioxide. Elder and Tinkle (1980) reported the $\mathrm{UO}_{2}$ content of the powder formed from the oxidation of staballoy in air and air/carbon dioxide mixtures increased with temperature (see Table 4.5). This observation may be an artifact of the experiment since metal was not completely oxidized and the oxides produced did not have sufficient time to equilibrate with the atmosphere prior to quenching of the reaction.

\subsubsection{Particle Size of the Oxides Formed From a Fire}

Megaw et al. (1961) reported the size distribution of the oxides produced from the oxidation of the metal in air and carbon dioxide at temperatures from $600^{\circ}$ to $1000^{\circ} \mathrm{C}$ and various degrees of turbulence. The experimental apparatus allowed the oxide formed to drop away from the specimen as it broke away. 


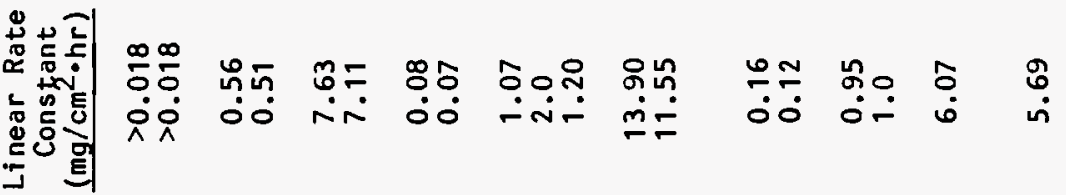

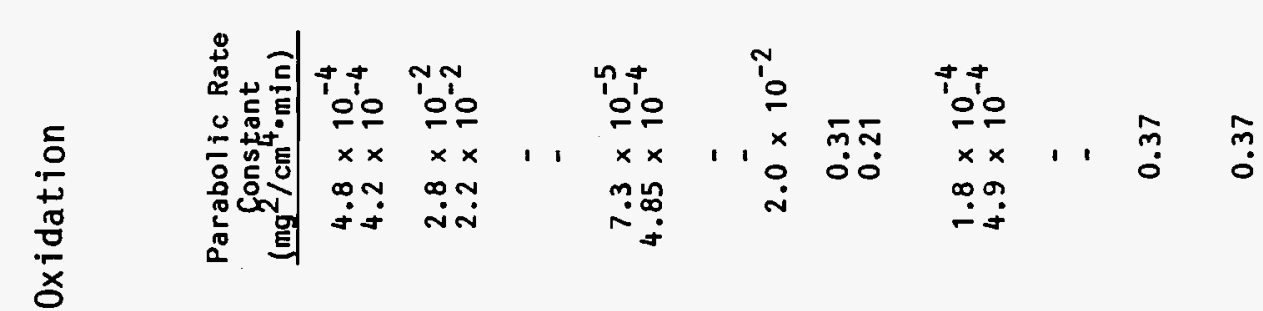
ำ

吾

므

ธับ

낭.

幽 它

웜

वर्ज

$\pm 4$

$\frac{\pi}{4}$ u

$\approx-\frac{1}{4}$

『ृ

它章

$\dot{8}$
$\dot{8}$
$\dot{\vec{p}}$
$\dot{0}$
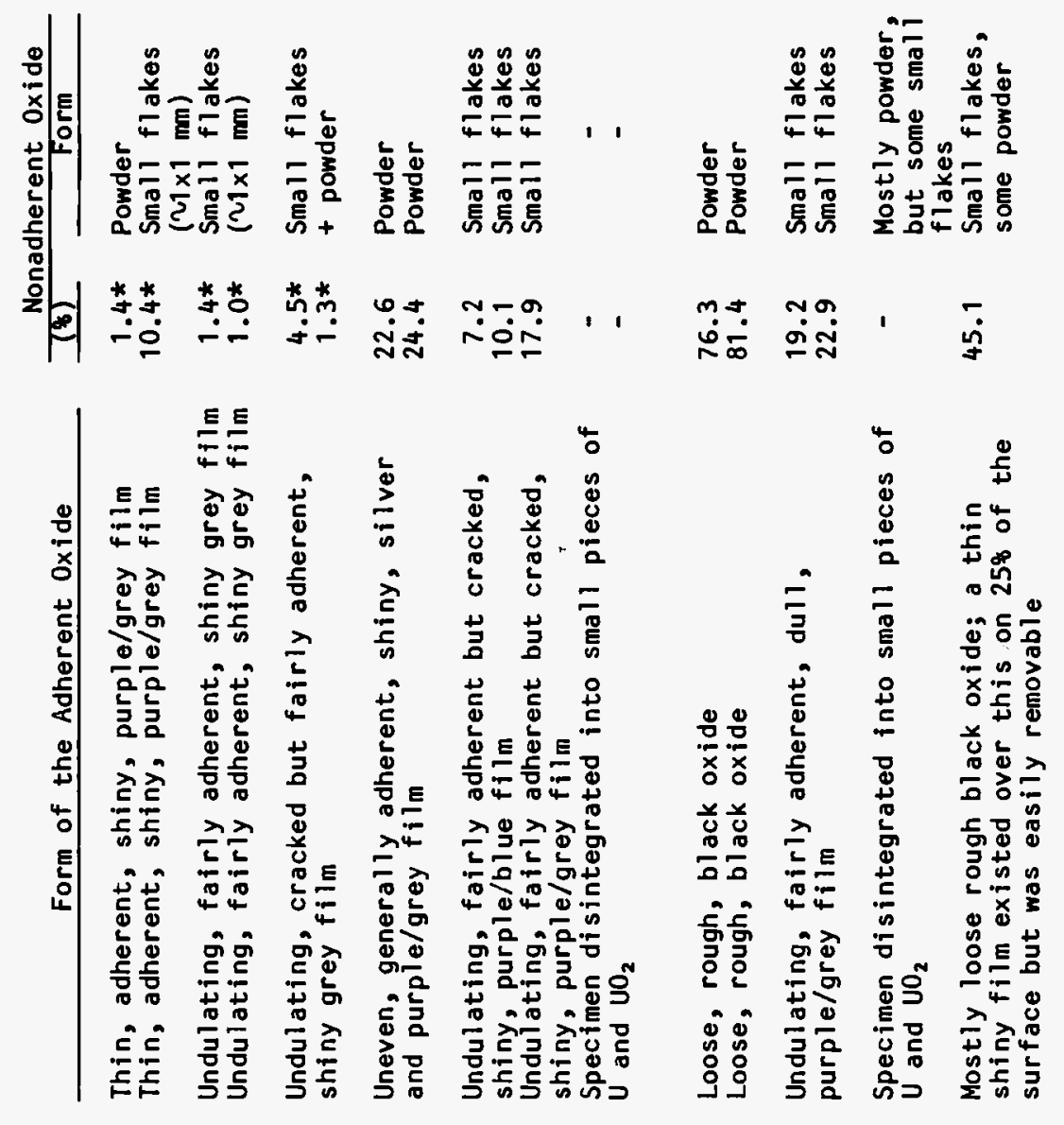

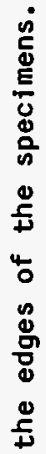

누음

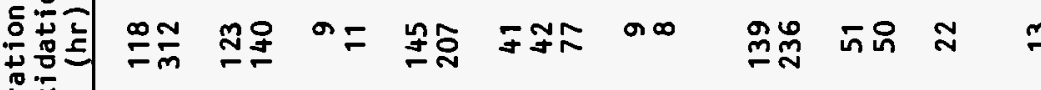
容

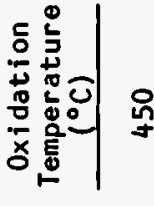

\section{ํㅐㅇํํ 앵ํํ}

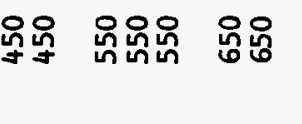

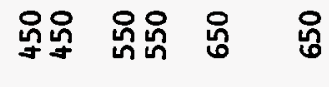

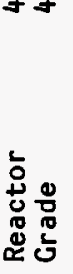


TABLE 4.5. Results of X-Ray Diffraction of DU Oxide Powders (Elder and Tinkle 1980)

\begin{tabular}{|c|c|c|c|c|c|}
\hline $\begin{array}{c}\text { Sample } \\
\text { No. }\end{array}$ & $\operatorname{Temp}\left({ }^{\circ} \mathrm{C}\right)$ & $\frac{\text { Test Cond }}{\text { Time (hr) }}$ & $\frac{\text { tions }}{\text { Atmosphere }}$ & $\begin{array}{c}\text { Effective } \\
\text { Crystaldite } \\
\text { Size (A) }\end{array}$ & $\begin{array}{c}\text { Relative } \\
\mathrm{UO}_{2} \\
\text { Amount }\end{array}$ \\
\hline A-774-7 & 500 & 2 & Air & 730 & 0.35 \\
\hline A-774-2 & 600 & 2 & Air & 1100 & 0.73 \\
\hline A-774-4 & 700 & 2 & Air & 1700 & 0.82 \\
\hline A-774-6 & 800 & 2 & Air & 2300 & 0.99 \\
\hline$A-774-5$ & 900 & 2 & Air & 3800 & 4.24 \\
\hline$M-774-1$ & 500 & 2 & $50 \% \mathrm{Air} / 50 \% \mathrm{CO}_{2}$ & 770 & 0.30 \\
\hline$M-774-2$ & 600 & 2 & $50 \% \mathrm{Air} / 50 \% \mathrm{CO}_{2}$ & 1350 & 0.22 \\
\hline$M-774-5$ & 800 & 4 & $50 \% \mathrm{Air} / 50 \% \mathrm{CO}_{2}$ & 1900 & 2.54 \\
\hline$N-774-1$ & 700 & 2 & Air - No Flow & 1650 & 2.19 \\
\hline
\end{tabular}

(a) The mass of $\mathrm{UO}_{2}$ divided by the mass of the other powder compounds.

Thus, the size distributions shown in Figures 4.8 and 4.9 may represent oxides that have greater access to oxidant from fire-generated material but may not have been exposed to high temperatures for as long. The size distribution for uranium metal oxidized in air and air/carbon dioxide mixtures at temperatures from $500^{\circ}$ to $1000^{\circ} \mathrm{C}$ reported by Elder and Tinkle (1980) are shown in Figure 4.10. The size distributions all indicate a minimum at a temperature around $600^{\circ} \mathrm{C}$ but the mass median diameters (MMD) reported by the two sets of authors appear to be a factor of 3 to 10 apart.

The size distribution (aerodynamic) for the material collected from the April 1983 burn of M829 rounds was shown in Figure 2.20 and indicates a MMD (in LLD) of 100 to $150 \mu \mathrm{m}$. This would indicate a nominal oxidation temperature of around $800^{\circ} \mathrm{C}$ using Megaw et a1. (1961) data and a temperature of $600^{\circ} \mathrm{C}$ using Elder and Tinkle's (1980) plot. 


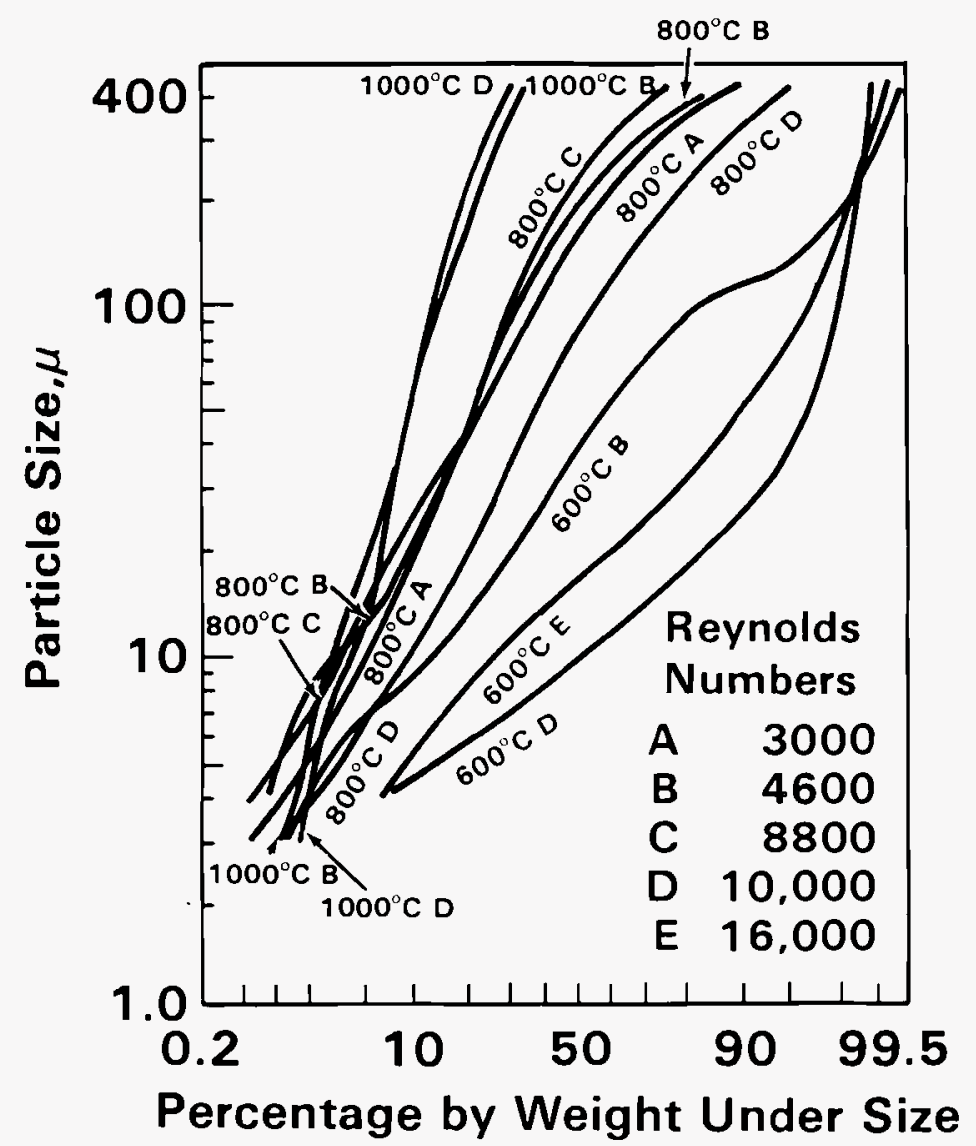

FIGURE 4.8. Size Distribution of Oxides from Uranium Oxidizing in Air (Megaw et a1. 1961) 


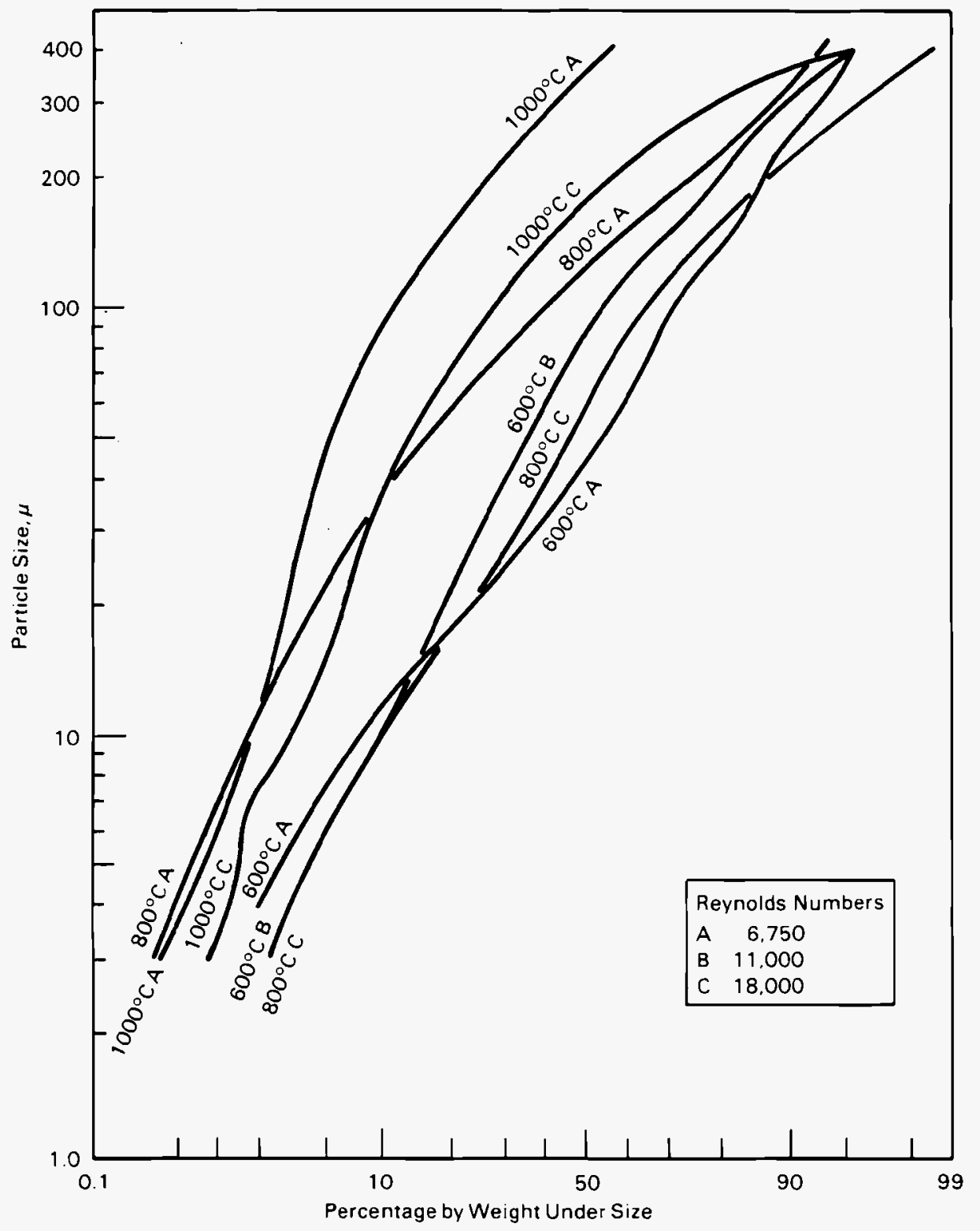

FIGURE 4.9. Size Distribution of Oxides from Uranium Oxidizing in Carbon Dioxide (Megaw et a1. 1961) 


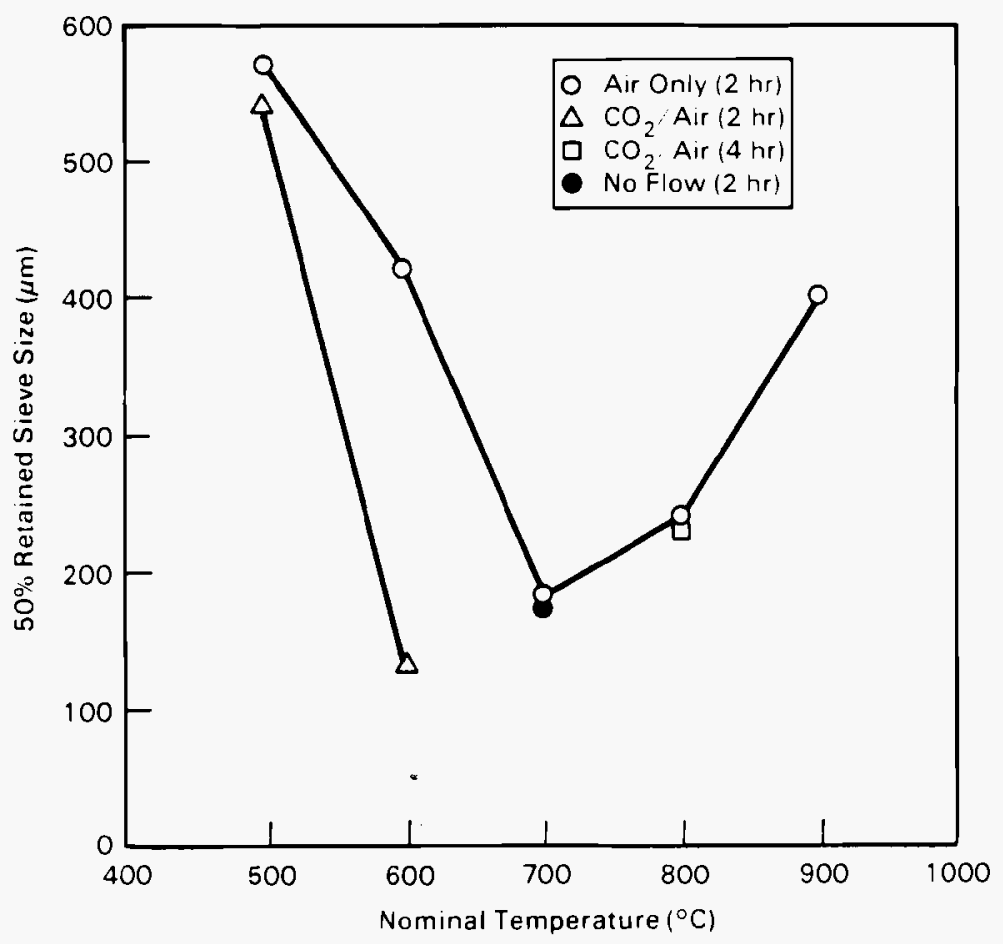

FIGURE 4.10. Sieve Particle Size of Uranium 0xides as a Function of Temperature (Elder and Tinkle 1980)

Finally, the size distribution for airborne material from a fire involving DU munitions used in a draft British document ${ }^{(a)}$ for predicting the dispersion is shown in Table 4.6 and a portion of the data is plotted in

Figure 4.11. The plot indicates that around $0.15 \mathrm{wt} \%$ is assumed to be $<10 \mu \mathrm{m}$ AED. This is somewhat less than the 0.2 to $0.65 \mathrm{wt} \%<10-\mu \mathrm{m}-\mathrm{AED}$ particles found in the April 1983 burn test.

(a) This document was obtained from D. G. Vallis, Ministry of Defense, United Kingdom. 
TABLE 4.6. Particle Size Distribution of DU Oxide Aerosol Used in Dispersion Prediction Calculations for a Fire Involving DU Munitions

Particle Size

Band, Nomina 1

dia (AMAD) ( $\mu \mathrm{m})$

$<0.7$

1.5

2.5

4.0

7.5

12.5

17.5

25

35

45

55

70

90

110

130

150

170

190

210

230

250

270

290

310

330

350
0.05

0.01

0.01

0.01

0.02

0.06

0.06

0.34

0.49

0.65

0.80

2.0

2.5

2.8

3.2

3.5

3.5

4.0

4.0

3.5

3.5

3.0

3.0

3.0

4.0

2.5
Particle Size

Band, Nominal Mass \% in dia (AMAD) $(\mu \mathrm{m})$ Size Band
3.0

2.5

2.5

2.5

2.5

2.5

2.0

1.5

2.5

1.0

2.0

2.0

2.0

1.5

1.5

2.0

1.5

1.5

1.5

1.5

1.0

1.5

2.5

2.5

1.5

0.5

(a) From draft document, "Guidance Notes for the Storage and Transport of Depleted Uranium Munitions (4th Draft)," obtained from D. G. Vallis, Ministry of Defense, United Kingdom. 


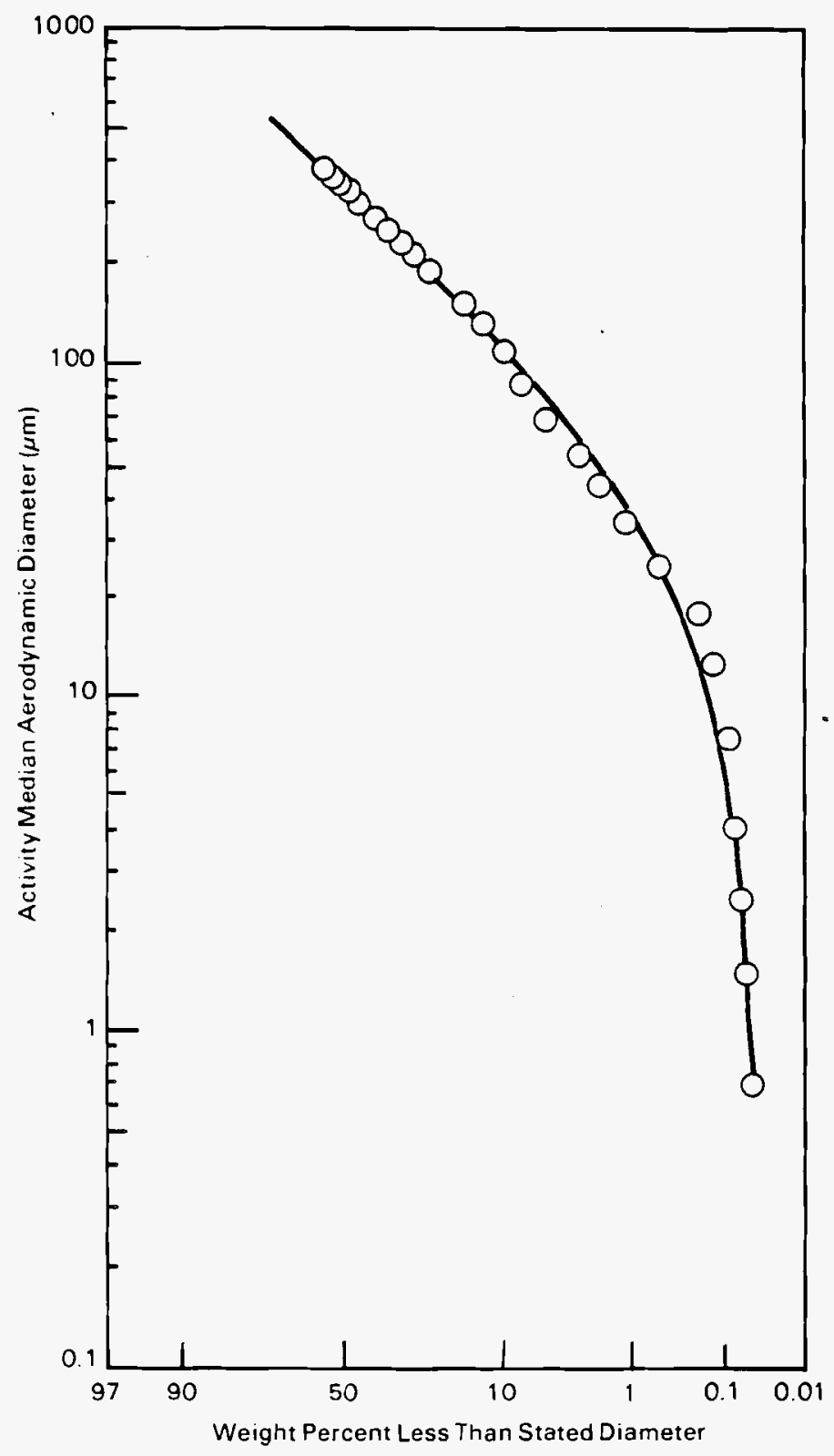

\section{FIGURE 4.11. Size Distribution for Dispersion Calculations}




\subsubsection{Airborne Release of Uranium Under Postulated Accident Conditions}

The potentially harmful material in the three types of fire scenarios appears to be the oxide formed by the fire. To pose a radiological/ toxiological hazard to the downwind population, DU oxide particles must be under 20 micrometers AED to be carried significant distances downwind, and must be less than 10 micrometers AED (a conservative estimate of the respirable size fraction) to be an inhalation hazard (See Figure 4.12 based on Mercer 1977).

DU oxide could be released during its formation (break-away and entrainment of the powder) and after formation. The types of events that

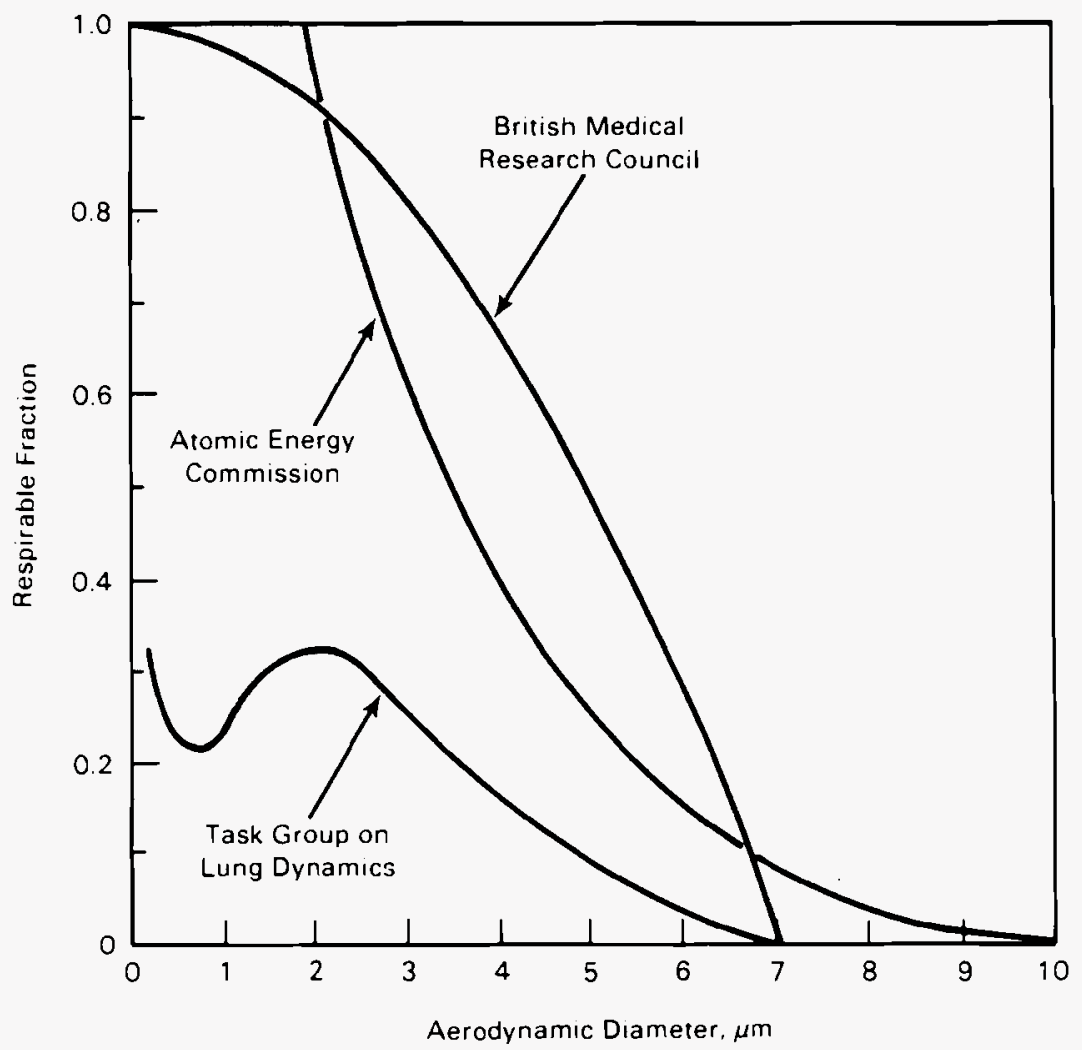

FIGURE 4.12. Respirable Size Fraction of Airborne Particles (Based on Figure 5 in Mercer 1977) 
could disperse and entrain the oxides after formation are: free-fall spills; combustion of the substrate upon which the powder lands; pressurized "flaring" (of propellant) or explosion (detonation of explosives or propellant); and aerodynamic entrainment (resuspension) of the powder after it has been on the ground.

Some of the fractional airborne release values reported in the published literature are shown in Table 4.7.

\section{TABLE 4.7. Uranium Airborne Releases}

\section{Material}

Oxidizing Metal, Penetrators (Elder \& Tinkle 1980)

$$
\begin{aligned}
& \text { Air, up to } 3.2 \mathrm{~m} / \mathrm{sec} \text {, Fire } \\
& \text { Air/Air }-\mathrm{CO}_{2}, 2.3 \mathrm{~m} / \mathrm{sec},
\end{aligned}
$$

Oxidizing Metal (Carter \& Stewart 1970)

Air, Static

Falling Molten Drops

Uranium 0xides on Combustibles From Burning (Mishima 1974)

$$
\begin{aligned}
& \text { Natural Convention } \\
& \text { Forced Ventilation } \\
& \text { Cellulosic } \\
& \text { Polymethylmethacrylate } \\
& \text { Polychloropene }
\end{aligned}
$$

Uranium Dioxide Powder (Sutter 1981, 1983)

$$
\text { Free-Fal1 Spi11, 1-3 m Fal1 }
$$$$
\text { Pressurized Release, } 50 \text { to } 500 \text { psig }
$$

$$
0.00003 \text { to } 0.0012
$$

0.02 to 0.21

(a) Particle $10 \mu \mathrm{m}$ aerodynamic equivalent diameter and less. 
Carter and Stewart (1970) estimate an airborne release of less than 0.04 wt\% for molten uranium under static conditions and a release of 0.6 wt\% from falling molten drops. Elder and Tinkle (1980) performed a series of experiments, which have been described in previous sections, on the oxidation of staballoy penetrators. The mass concentration airborne as a function of temperature is shown in Figure 4.13, and the mass concentration of respirable particles is shown in Figure 4.14. It appears that the respirable material represents from $5 \%$ to $10 \%$ of the airborne material.

Using the maximum mass concentration listed for the field experiments (burn \#4) and the respirable fraction (61\%) indicates that as much as $21.9 \mathrm{mg}$ $\mathrm{U} / \mathrm{min}$ could be released, of which $13.4 \mathrm{mg} / \mathrm{min}$ could be respirable. If this maximum rate could be maintained until all the material was oxidized ( 6.82 hours), $8.9 \mathrm{~g}$ of uranium ( $5.47 \mathrm{~g}$ respirable) would be released. This represents $0.089 \mathrm{wt} \%$ of the three penetrators used. The MMAD decreased with temperature in the laboratory experiments (see Figure 4.15).

Hooker et al. (1983) detected no significant airborne release during their field experiment. If the maximum value inferred from Elder and Tinkle's (1980) study is applied (0.09 wt\%), an airborne release of $45 \mathrm{mg} \mathrm{U} / \mathrm{min}$ would be anticipated. Since Elder and Tinkle's study was on uncovered penetrators exposed to an airflow of $525 \mathrm{~cm} / \mathrm{sec}$, the lack of release may imply that the fire residue provided an additional barrier to airborne release. Schmitt (1975) reported the airborne release of ignited uranium was reduced a factor of 30 when covered with carbon microspheres $(0.5 \mu \mathrm{m})$. Experience in nuclear facilities handling plutonium indicates a reduction of airborne release when ignited metal is covered with magnesium dioxide.

Data on the airborne release from events that could disperse and entrain particles generated by the fire are also covered. Mishima (1976) reported on airborne release values in a variety of accident situations. He reported releases of 0.5 wt\% of a fine uranium dioxide powder for static conditions and self-extinguishment of the burning cellulosic material (paper, rags, etc.) and up to $38 \mathrm{wt} \%$ for forced convection $(150 \mathrm{~cm} / \mathrm{sec})$. More recently, Halverson and Ballinger (1984) conducted experiments on the airborne release of contaminants 


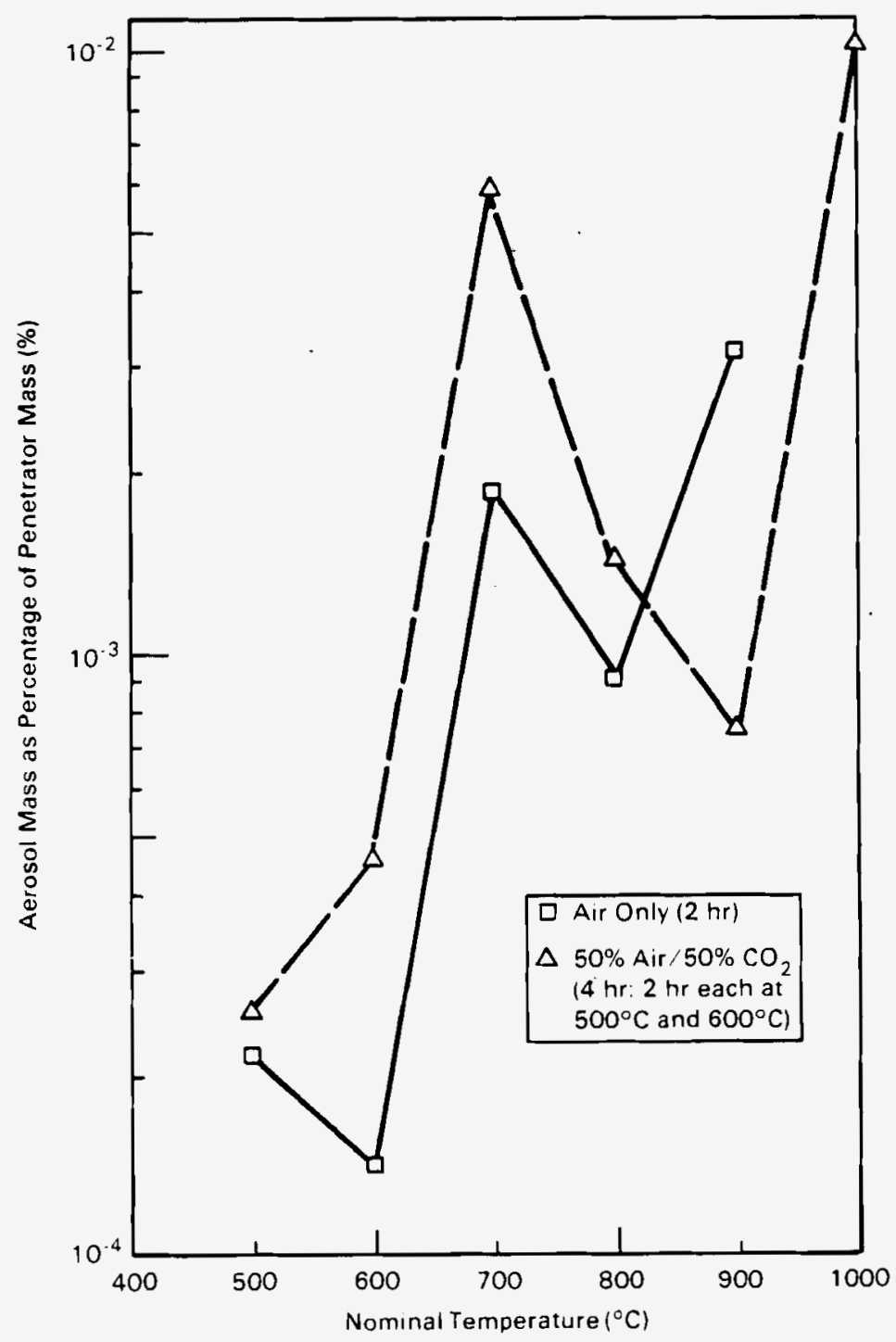

FIGURE 4.13. Aerosol Mass as a Function of Temperature (Elder and Tinkle 1980) 


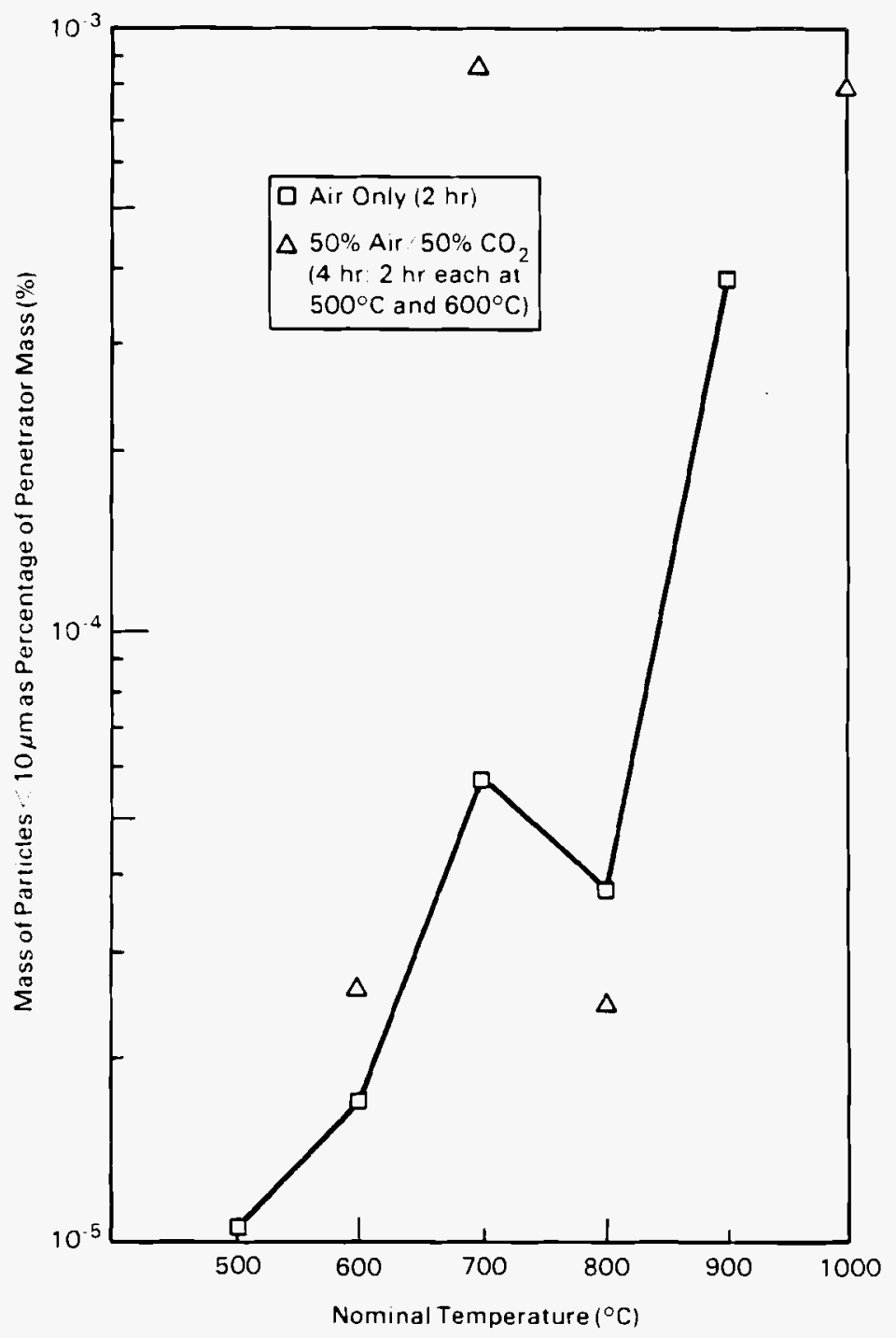

FIGURE 4.14. Respirable Mass as a Function of Temperature (Elder and Tinkle 1980) 


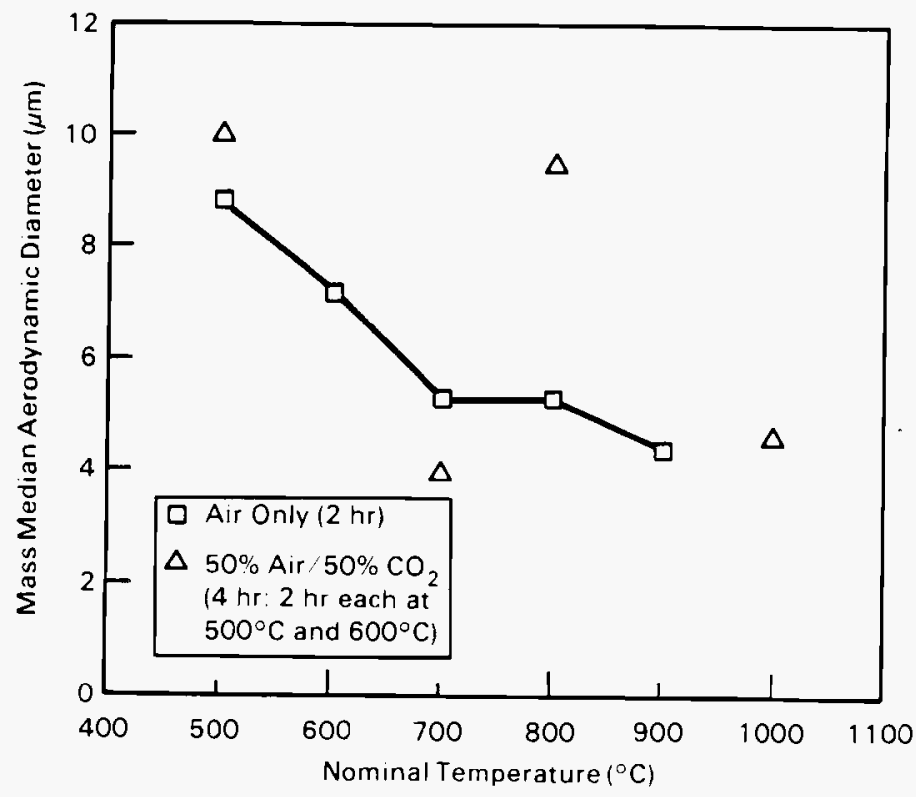

FIGURE 4.15. Size of Aerosol $<10 \mu \mathrm{m}$ as a Function of Temperature (Elder and Tinkle 1980)

(a fine uranium dioxide powder) from the burning of various polymeric materials found in fuel-cycle facilities. Their results are listed in Table 4.7 and indicate a maximum of $0.09 \mathrm{wt} \%$ from the burning of cellulosics (paper).

Sutter, Johnston and Mishima (1981) conducted a series of experiments to evaluate the airborne release from a fine uranium dioxide powder while it fell through air. A maximum of $0.12 \mathrm{wt} \%$ was reported. Sutter (1983) found as much as $21 \mathrm{wt} \%$ was made airborne by the release of pressurized uranium dioxide powder. Since the air in the interstice of the powder was pressurized to the level indicated, it is felt that this type of release would exceed most situations for the dispersal of uranium products from fires.

Sehmel (1980) reviewed the information on resuspension (aerodynamic entrainment) and concluded that the physics of the situation are so poorly defined that much more research is needed. In an earlier work, Sehmel and Lloyd (1976) indicated a value of $10 \times 10^{-8} / \mathrm{sec}$ was a general powder resuspension flux applicable for normalized annual conditions at the Hanford site. Mishima (1976) reported the resuspension of a fine uranium dioxide powder from wind tunnel experiments using various surfaces before and after a 
gasoline fire. The values ranged from $9.8 \mathrm{wt} \%$ in a 24 -hour period from smooth, sandy soil at a windspeed of $8.9 \mathrm{~m} / \mathrm{sec}$ to $9 \times 10^{-3}$ wt\% from a stainless steel surface following a gasoline fire. Resuspension factors have been found to vary over 11 to 13 orders of magnitude.

Finally, various computer code models have been generated that can calculate the potential airborne release under some accident conditions. FIRIN is a fire compartment code that can calculate some of the fire parameters and source terms (Ballinger and Owczarski 1985). Empirical correlations to previously generated experimental data have been included to cover fractional airborne releases from the burning of contaminated combustible solids and liquids, the heating of contaminated noncombustible surfaces, the heating of unpressurized contaminated liquids, the pressurized release of radioactive powders and liquids, the spills of radioactive powders and liquids, and the burning of pyrophoric metals. A draft user manual for the initial FIRIN code was prepared but the code and user manual for the latest version is not publically available at this time.

Steindler and Seefeldt (1980) provided an empirical fit to all airborne release values they could find for detonations. The model predicts the mass and median diameter of the material airborne as a function of TNT equivalency and the total amount of inert material involved. The model has not been verified with any experimental effort, and the authors caution against applying the model before this is done. One problem with application of this method for fire-generated material is the lack of knowledge as to the total amount of inert material (soil, ash, charcoal, noncombustibles, etc.) involved. A code, DETIN, has been generated for this model but is not currently available.

Bander (1982) reviewed the soil loss models to predict the long-term entrainment of material from the ground. Most of the applicable models were agricultural models to predict the erosion of soil. If the quantity of material involved were known, this type of model could be applied to predict the aerodynamic entrainment of the fire-generated debris. Martin et al. (1983) reviewed Travis' frictional velocity (shear stress) model for the entrainment of particles from surfaces as a function of the horizontal air 
velocity above the surface. The model applies to thick beds (nominally greater than 3- to 4-particle-diameters thick). The horizontal velocity is used to calculate a surface friction velocity. A characteristic threshold frictional velocity for the material of interest (Figure 4.16) is determined. If the surface friction velocity does not exceed the threshold friction velocity for the material, no entrainment occurs. If the threshold friction velocity is exceeded, semi-empirical equations can be used to calculate the vertical flux of suspendable material and, knowing the area covered by the suspendable material, the total amount of material suspended. This model is most applicable for the entrainment of a powder from an powder-like surface.

\subsubsection{Conclusions}

Although the conditions postulated for fires in transport and use are based upon maximum physical damage, they are a reasonable maximum for the expected conditions for these classes of accidents. The conditions postulated for fires in bulk storage of munitions do not appear to be as easily categorized, and additional data/information is required to make a reasonable assessment of the potential DU behavior for this class of accidents. None of the accidents postulated appear to address the "worst case" for airborne release, but the conditions to generate the amount of DU oxide representing the worst case may not be credible.

For fires during the shipping of different munitions, the information in the section indicate that:

- One anticipates, as a maximum, a severe fire as in the external heat test "C" for truck transport accidents. Truck accidents involving fires are rare - approximately $1 \times 10^{-8}$ per mile. Less severe accidents than simulated in the external heat test would not be self-sustaining.

- The high explosives in mixed loads would detonate and relocate almost al1 the munitions and penetrators away from the fire before significant oxidation could occur. The penetrators not relocated would oxidize about $85 \%$ in 16 to 20 hours if they were buried in wood residues and maintain a temperature of greater than $600^{\circ} \mathrm{C}$. An airborne release of less than 


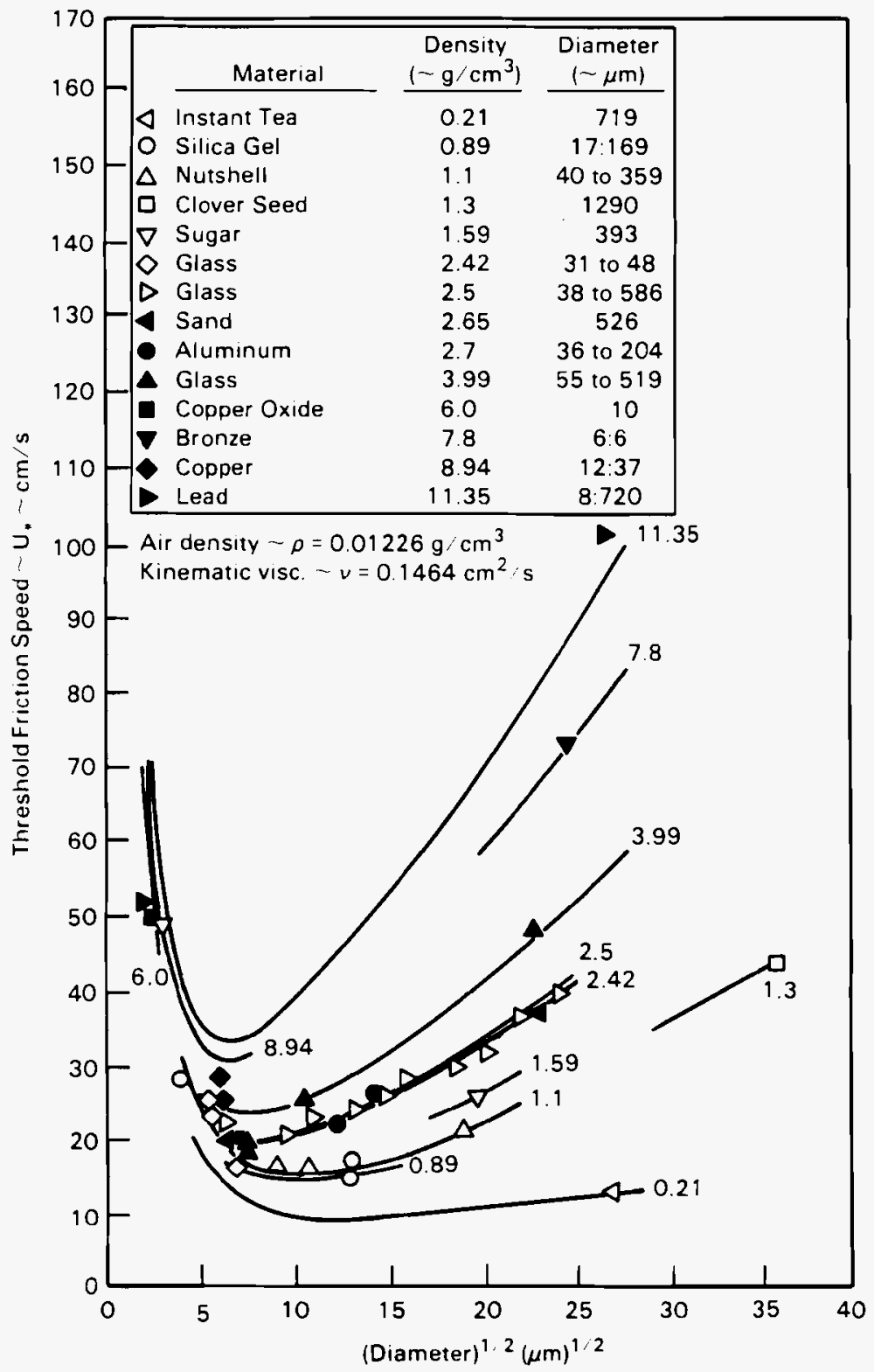

FIGURE 4.16. Particulate Threshold Friction Speed (Martin et al. 1983) 
0.1 wt\% of the total amount of uranium oxidized, as respirable particles, is anticipated for oxide buried in wood fire residues.

- The response and airborne release anticipated for single-load shipments of solid-cased munitions such as the M774 would be the same as for mixed loads.

- The response of combustible-cased munitions such as the M829 would be similar to that observed in the external heat test of that round. The anticipated airborne release of respirable particles would be less than $0.1 \%$ of the uranium oxidized.

- The conditions postulated in Walters, Elliot and BToore (1979) appear to be credible for fires in up-loaded tanks. It is anticipated that $5 \%$ to $10 \%$ of the total uranium would be oxidized during the fire. Since the material would be buried in organic and metal fire residue, less than $0.1 \mathrm{wt} \%$ of the uranium oxidized would be released as respirable particles (the airborne release might be even less since the tank is an enclosure with a large surface area presenting opportunity for deposition as well as thermophoresis). Bloore and Wilsey (1979) indicated that the uranium penetrators remaining in the tank did not oxidize, and, if the uranium did not oxidize when heated, this potential DU behavior should be investigated to determine if the uranium did not react because of the atmosphere or if some other mechanism prevented oxidation.

- The conditions and behavior of the DU munitions in field storage are adequately defined by the analysis of a fire involving mixed-load shipments.

- The conditions and material responses for fires involving bulk storage of munitions (mixed, single storage of solid- and combustible-cased munitions) cannot be adequately defined with the information available at this time. Some of the questions that must be investigated to evaluate the potential airborne release from such an incident are:

- Can a fire in closely-packed, packaged munitions continue to propagate under the conditions postulated (a ventilation-limited, enclosure fire)? 
- Can the magazine (igloo or Stradley) withstand the heat load?

- If high explosives are present or if the propellant becomes sensitized, can the compromised magazines (a large hole in the entry wall) withstand the blast?

- What is the temperature and atmosphere in the residue from the fire (the region where the penetrators will be)?

- What is the effect of these temperatures and atmospheres on the behavior of staballoy (size distribution of the oxides and solubility)?

- What is the fractional airborne release under these conditions?

Using the current information, the airborne release can be conservatively estimated by choosing the maximum release mechanism that could be operating and the finest size distribution found. The release mechanism with the highest potential for the airborne release of fire-generated particles that could be reasonably postulated would be an explosion. Since the potential energy available is not known, the Steindler and Seefeldt (1980) model cannot be applied (the total quantity of inert material is also not known), and the force of the blast is assumed to be sufficient to eject the fire residue from the enclosure. It is further assumed that all the uranium present is oxidized prior to the blast at a temperature that results in a size distribution shown in Figure 4.8 for $600^{\circ} \mathrm{C}$ at a Reynolds number exceeding 8800 . Thus, as much as $4 \%$ of the particles could be in the respirable size range $(<3.3 \mu \mathrm{m}$ LLD shown in the graph) and transported downwind.

\subsection{DOWNWIND TRANSPORT OF AIRBORNE DU PARTICLES}

In the accident scenarios discussed in Section 3.0, the hazardous material is moved from the site of the accident (the release point) to the site of a person potentially at risk (the dose point) by atmospheric transport. Atmospheric transport takes into account the direction and speed of movement and the relative concentrations of the hazardous material in air as the movement progresses. The released material is assumed to move in either a plume (for a continuous release of long duration) or a puff (for a short-term or instantaneous release). 
The starting point for an atmospheric transport calculation requires finding the "source term": a complete description of the hazardous material released to the atmosphere. This source term is usually described as the total amount of hazardous material released during the course of the accident or as the release rate, which may be either constant or variable during the course of the accident. For radioactive material, the total quantity released is usually specified as a list of radionuclides, with an appropriate number of curies for each. The release rate would then be in curies released per unit time, with a value (or set of values, if the release rate is variable) for each radionuclide. If the hazardous material were toxic rather than radioactive, the release would be specified in mass units rather than curies.

In addition to quantity released, the source term should also include a description of other characteristics of material that affect biological hazard at the dose point. Thus, chemical composition (for uranium, amount oxidized) and particle size description are also important characteristics of the source term.

The source term for any accident analysis must be determined from the accident conditions. For a fire involving depleted uranium, to determine the quantity of DU that could be released into the atmosphere, the characteristics of the fire and quantity of DU involved must be compared to the results of previous experiments or to a mathematical model.

\subsubsection{Models For Initial Plume Characterization}

The initial mixture of released material into the plume depends on the nature of the release. For a fire in an enclosure, a detailed analysis may be performed to evaluate the amount that actually leaves the building, but such an analysis requires a complex model (Martin et al. 1983). When material is forcibly ejected into the atmosphere, as in an open fire or an explosion, a conservative approach assumes that all of the released material becomes part of the plume. The atmospheric dispersion model must then account for the initial size of the plume (that is, the volume of air that the material is originally released into) and the subsequent entrainment into the plume of additional air and any resuspended material that had previously been deposited on the ground. 
Entrainment of particles into the plume. In the Gaussian plume model and others that calculate downwind transport of a release, the material is assumed to be released from a point source. Thus, the initial dilution is a function of the wind speed, and downwind dilution depends on the crosswind dispersion parameters. For a release caused by an explosion, the point source assumption will result in a high value for the downwind air concentration. A more realistic value can be obtained by modifying the equation by a term for the initial volume of the explosion, based on the energy released. Slade (1968) discussed an initial-volume modification to the Gaussian equation for instantaneous releases.

Particles that are deposited on the ground may be resuspended by subsequent wind or mechanical disturbances, such as animals or people walking through the contaminated area. The resuspension can be calculated using a resuspension factor, $k$ :

$$
K=\frac{\text { ajrborne contamination }}{\text { surface contamination }}
$$

where $K$ has units of $1 / \mathrm{m}$. $K$ depends on the roughness of the ground, vegetation, disturbing action, and particle characteristics. Sutter (1982) presents an extensive compilation of resuspension factors and demonstrates that there is a large variability and uncertainty in estimated values.

Building wake effects. The initial circumstances and characteristics of the release can have an important effect on the ground-level concentrations downwind of the release point. When air is flowing around a building or other large obstacle, turbulence is introduced, and the flow pattern is broken up in a way that tends to decrease the concentration of material in a plume. Usually the decrease in concentration only occurs in the range of a few kilometers downwind of the obstacle, and the concentrations farther downwind are nearly unaffected by the obstacle. For a plume emitted in the immediate vicinity of a building, the building wake effect should be taken into account when calculating the downwind concentrations.

A commonly used model discussed by Gifford (1976) modifies the crosswind standard deviations in the Gaussian plume formula using the cross-sectional 
area of the building. In the equation for finding relative concentrations, the term is replaced by:

$$
\left(\pi \sigma_{y} \sigma_{z}+C A\right)
$$

where $\sigma_{y}=$ horizontal crosswind standard deviation (m)

$\sigma_{z}=$ vertical crosswind standard deviation $(\mathrm{m})$

$A=$ building cross-sectional area normal to wind direction $\left(\mathrm{m}^{2}\right)$

$C=$ the fraction of $A$ over which the plume is initially dispersed

$=0.5$ (appropriate value for most situations).

One of the defects of this model is its failure to account for meandering of the plume under stable atmospheric conditions with low wind speeds. The NRC, in Regulatory Guide 1.145 (NRC 1979), recommends accounting for the effects of plume meander and building wake effect, to a degree determined by the atmospheric conditions, by selectively using three equations. One of these equations uses the term suggested by Gifford; the others use different adjustments to the $\sigma$ values.

Plume rise effects. Other release characteristics affecting downwind air concentrations are the elevation of the release point and factors that would cause the plume to rise even further above the point of release. Plume rise can typically increase the effective plume release height by a factor of 2 to 10, thus decreasing maximum downwind concentrations by a factor as large as 100. In a very hot release, such as might occur in a fire involving metallic depleted uranium, the effective plume height could very well be high enough to guarantee no exposure within the first one or two kilometers from the release point. Models that accurately predict potential plume rise are therefore important parts of any scheme of accident analysis.

There are two types of plume rise mechanisms that should be considered in an accident analysis: momentum effects (due to the initial upward velocity of the released particles) and buoyancy effects (due to the heat released into the plume).

Momentum effects for plume rise are usually smaller than buoyancy effects, especially for a plume rising from a hot fire, but momentum effects could be important for particles ejected by an explosion. An early empirical 
formula for momentum-dominated plume rise for effluent leaving a stack was (Rupp 1948):

$$
\Delta h=\frac{1.5 v_{g} d}{u}
$$

where $\Delta h=$ release height correction due to plume rise $(\mathrm{m})$

$$
\begin{aligned}
v_{g} & =\text { velocity of effluent leaving the release opening }(\mathrm{m} / \mathrm{s}) \\
d & =\text { inside diameter of top of stack }(\mathrm{m}) \\
u & =\text { average wind speed at release height }(\mathrm{m} / \mathrm{s}) .
\end{aligned}
$$

This formula was based on a number of observations of the point at which the plume flattened out to a rise of less than eight degrees. The formula was fairly useful, but improvements were made by making the plume rise a function of downwind distance (Briggs 1969). Briggs also used a dimensional-analysis approach to derive another model.

Buoyancy effects dominate the plume rise correction in cases where significant heat is generated by the accident. In a severe fire the plume can rise to 800 or more meters above the release point, greatly decreasing the downwind ground-level air concentrations. Plume rise due to buoyancy effects is usually calculated based on the temperature profile and stability of the ambient air, and the temperature (or heat content) of the effluent. A number of models are used for calculating buoyant plume rise. Briggs (1969 and 1975) has several good discussions of existing models.

An early model for buoyant plume rise was presented by Morton, Taylor and Turner (1956). This model calculates the plume rise by the following formula:

$$
\Delta h=2.66\left(\frac{F}{S}\right)^{\frac{3}{2}}
$$

where

$$
\begin{aligned}
F & =\frac{g E}{C p \rho T} \\
g & =\text { acceleration due to gravity }\left(9.8 \mathrm{~m} / \mathrm{s}^{2}\right) \\
E & =\text { energy released in plume }(\text { calories) } \\
C_{p} & =\text { specific heat of air }\left(10^{7} \mathrm{erg} / \mathrm{g} \cdot{ }^{\circ} \mathrm{K}\right) \\
\rho & =\text { density of air }\left(.00125 \mathrm{~g} / \mathrm{cm}^{3}\right)
\end{aligned}
$$




$$
\begin{aligned}
T & =\text { temperature of ambient } \operatorname{air}\left({ }^{\circ} \mathrm{K}\right) \\
S & =\text { stability parameter; } S=\frac{\mathrm{g}}{\mathrm{T}}\left[\frac{\partial \mathrm{T}}{\partial \mathrm{z}}+9.8\right] \\
\frac{\partial T}{\partial \mathrm{z}} & =\text { temperature gradient }\left({ }^{\circ} \mathrm{K} / \mathrm{km}\right) .
\end{aligned}
$$

The Morton, Taylor and Turner model was described in Slade (1968) as being suitable for use with an instantaneous release, such as an explosion. The formula was compared to observations from a series of small nuclear explosions and only slightly underestimated the observed plume rises.

In Briggs' critical review of plume rise models (1969), he recommended the use of a model that also took into account the atmospheric stability class and the downwind distance traveled by the plume. Such a model would be more appropriate for a plume released during a fire or a release that lasted more than approximately half an hour.

\subsubsection{Nearfield Atmospheric Transport}

Many difficulties arise when evaluating atmospheric diffusion in an area that is very close to the release point. Many models assume that the source is emitted from a dimensionless point rather than a region of finite volume. For a source such as a burning vehicle, this point source assumption is adequate for a dose point several kilometers away, but the assumption may be questionable for a dose point only 100 meters from the release point.

Several atmospheric transport models, including the Gaussian model, use empirically determined standard deviations to calculate the downwind concentrations. These data were often derived from measurements made at distances greater than 100 meters, and using $\sigma$ values for closer distances must rely on

extrapolating from observed values. Since the $\sigma$ values are small at distances less than 100 meters, minor uncertainties in $\sigma$ can cause large uncertainties in the resulting concentrations.

Another problem with close-in estimates of concentrations is the need for the plume to be well developed to be adequately modeled by most techniques. close to the release point, the plume may be influenced unpredictably by building wake effects or by the structure of the generating point. 


\subsubsection{Effects of Complex Terrain and Rough Surfaces}

In many calculations of atmospheric dispersion, the accident scenario does not involve a specific site, but rather deals with a release in a hypothetical location. For such a calculation, the configuration of the terrain in the vicinity of the release would probably not be considered in evaluating atmospheric transport. In a specific location, however, or for a hypothetical evaluation specifically incorporating certain terrain features, the changes in elevation in the vicinity of the release can play an important role in the atmospheric transport.

The configuration of the terrain between the release point and the dose point can have several different effects on the movement of the plume. The roughness of the terrain can introduce turbulence into the flow of air, and the dispersion parameters $\left(\sigma_{y}\right.$ and $\left.\sigma_{z}\right)$ should be chosen for the type of terrain being evaluated. Different sets of dispersion parameters have been compiled for forests, deserts, farmlands, and other types of terrain. Atmospheric transport modeling for movement of a plume over a body of water presents an especially difficult problem because of local circulations such as sea breezes. Dispersion parameters used for flow over land of ten cannot be applied to flow over large bodies of water, and experimental studies of dispersion over water have been limited.

The terrain can affect the direction of the plume when there are features such as a winding river valley. If a straight-line model is used, the applicability of the model should be carefully evaluated for the specific site being modeled. If the atmospheric dispersion model uses a realistic windfield, the windfield can be adjusted to account for these features.

Many models account for differences in elevation over the path of plume travel. NRC Regulatory Guide 1.111 (NRC 1977) recommends subtracting $h_{t}$ from the effective release height (actual release height plus plume rise correction factor). $h_{t}$ is the highest terrain height above the base of the stack between the release point and the dose point. This adjustment to the release height can be overly conservative for many situations, and Briggs (1973) and Egan (1975; Egan, D'Errico and Vaudo 1979) recommend release-height adjustments 
based on a more careful analys is of the height of a terrain rise or drop, evaluated in the light of the atmospheric stability conditions. This technique is summarized by Hanna, Briggs and Hosker (1982).

\subsubsection{Calculation of Downwind Atmospheric Transport}

The actual calculation of the atmospheric transport of a plume or puff results in values for concentrations of the hazardous material in air or on the ground at each of the dose points downwind of the release point. The mathematical model most commonly used for calculating atmospheric transport is the Gaussian model. This model is based on the assumption that at any distance downwind of the release point, the material concentration in the plume (or puff) is normally distributed in the horizontal and vertical directions perpendicular to the wind direction, with a maximum value on the plume centerline. The model was originaliy developed by Sutton (1932), Pasquill (1961, 1974) and Gifford (1968). Descriptions of the Gaussian model as currently used can be found in Slade (1968) and Hanna, Briggs and Hosker (1982).

The basic equation using the Gaussian model for calculating the relative air concentration due to a continuous plume release at a point off the plume centerline is (Hanna, Briggs and Hosker 1982):

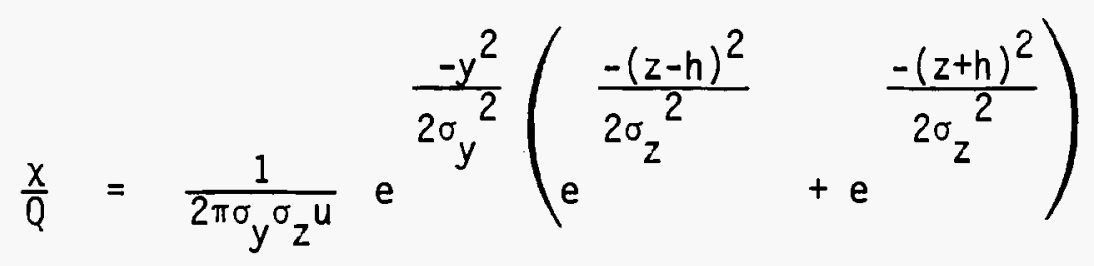

where

$$
\begin{aligned}
X / Q & =\text { relative air concentration } \\
\sigma_{y} & =\text { horizontal crosswind standard deviation of concentrations } \\
\sigma_{z} & =\text { vertical standard deviation of concentrations } \\
u & =\text { average wind speed } \\
y & =\text { crosswind distance from the plume centerline } \\
z & =\text { elevation of the dose point } \\
h & =\text { effective release height, including plume rise correction factor } \\
& \cdot \text { and terrain effects. }
\end{aligned}
$$


An important feature of the Gaussian model is the use of standard deviations, mathematically corresponding to the standard deviations used in Gaussian distributions in statistics. Several different sets of standard deviations are in use; the Pasquill values (Gifford 1968) are commonly used for many situations. Values of $\sigma_{y}$ and $\sigma_{z}$ are tabulated for different downwind distances and for different atmospheric stability conditions. The Pasquillo values are tabulated for six stability conditions, identified by the letters $A-F$. Classes $A, B$, and $C$ are for unstable atmospheres, $D$ is neutral, and $E$ and $F$ are for stable conditions. The atmospheric stability class is usually selected by measuring the vertical temperature gradient of the air at the release point.

Equation (3) is strictly applicable to a continuous release, with a constant wind direction and speed, with the release lasting long enough for the plume to be well established. For a release lasting less than approximately one hour, depending on conditions, the release should be treated as instantaneous rather than continuous and should be considered a puff rather than a plume. The Gaussian equation is sometimes formulated differently for a puff release, and different standard deviations should be used for a puff release. The Gaussian model for an instantaneous puff release is discussed by Slade (1968) and Hanna, Briggs and Hosker (1982).

One major limitation of the straight-line Gaussian model is the invariability of the wind. A more realistic approach is to model the release as a series of puff releases, with each puff allowed to be influenced by changing wind direction and speed. In such a "variable trajectory" model, the release produces a chain of puffs that can move about a two-dimensional grid representing the area around a release point. Such a model is implemented in the computer code MESOI (Ramsde11, Athey, and Glantz 1983). While a computer code like MESOI allows for a realistic representation of puff movement, a realistic windfield must be constructed to cover the whole grid. Thus the code can only be used for a site that has enough historical data on wind velocities to make a good prediction for the simulation, or instrumentation must be in place to transfer real-time data into the computer used to perform the calculations. If good windfield data is available, a variable trajectory 
model can be a very powerful tool for evaluating atmospheric transport, but in its absence, a straight-line dispersion code will perform almost as well.

Models other than the Gaussian model have been developed for atmospheric transport. Whereas the Gaussian model is essentially empirical, other atmospheric transport models have been developed based on numerical or statistical analysis. A statistical model uses Monte Carlo calculations to follow individual particles as they diffuse during movement of the puff. The results of simulations of many thousands of particle movements are then combined to predict the behavior of a puff. Similarity models use dimensional analysis to combine the governing factors of diffusion into usable equations for specific conditions. Gradient transport (or $K$ theory) models use numerical integration to solve the basic diffusion equations. The advantage of $K$ theory models is that they are not limited by an assumption of constant eddy diffusivity as the Gaussian model is, and thus can be used in applications where the Gaussian model cannot. Good discussions of the non-Gaussian models and their applicability can be found in Slade (1968), Hanna, Briggs and Hosker (1982) and Alpert, Gudiksen and Woodard (1981).

Since the non-Gaussian models use powerful mathematical procedures, they are frequently able to handle certain atmospheric conditions that are outside the scope of the simple Gaussian model. In practice, however, when the non-Gaussian models are applied to most atmospheric transport situations, several empirical modifications must be made, thus diluting the "first principles" attraction of the technique. The Gaussian model, although firmly grounded in empiricism, has been widely used and has been the standard tool for many accident consequence modelers. The wealth of experience and study by modelers help make the Gaussian model a good choice for a "work horse" technique for atmospheric transport.

\subsubsection{Application of Atmospheric Transport Calculations to Hazard Analysis}

The object of an atmospheric transport calculation in an accident analysis is to arrive at the concentration of hazardous material at a location where a person could be exposed to the hazardous material. In a typical analysis, a number of these locations would be specified, and the concentrations would be calculated at each of these dose points. For toxic material, 
these calculated values would be in units of mass per unit volume at the dose points. The potential consequence of exposure to the release could then be evaluated by calculating the quantity of the toxic material that would be inhaled by a person at the dose point, and using this inhaled quantity to determine the toxic hazard to the person.

Air concentrations. For radioactive material, the air concentration at each dose point would be evaluated in units of activity per unit volume (e.g., curies per cubic meter) for each radionuclide in the plume or puff. This value could then be used to evaluate the hazard from each of the possible exposure pathways. One common exposure pathway is inhalation, and this evaluation would be similar to that for toxic material. Another exposure pathway is the external dose: radiation emitted by radionuclides in the plume directly irradiating a person at the dose point. In some cases this external dose can be evaluated knowing only the air concentration of radionuclides at the dose point. For a more careful evaluation, it may be necessary to use air concentrations for many positions within the range of the emitted radiation (as much as 100 meters) around the dose point.

Ground concentrations. For evaluating the short- and long-range effects of exposure to hazardous material in a puff or plume passing a dose point, it is also necessary to evaluate the concentrations of material deposited on the ground. The amount deposited depends on the air concentration in the plume as it passes the dose location, using a factor called the "deposition velocity." For radioactive material, the radionuclides deposited on the ground can emit radiation that directly gives an external dose to a person at that dose location. The material on the ground can also be resuspended, and a person at the dose point may then inhale the resuspended toxic or radioactive material or be exposed to radiation emitted by resuspended radionuclides.

Any long-term effects from released material are usually from material deposited on the ground. The radionuclides could be deposited on fruits and vegetables and then ingested by a person. The deposited radionuclides could also be inhaled or ingested by farm animals, and then be ingested by a person eating the contaminated meat or dairy products. The dose evaluations for all 
these pathways use the ground concentration, in units of activity per unit area, to evaluate the potential exposures.

\subsection{POTENTIAL INHALATION HAZARD FROM THE AIRBORNE RELEASES AND TRANSPORT OF AIRBORNE DU}

The health hazard of inhaled uranium is a function of four main factors: isotopic composition, chemical composition, particle size, and solubility. The isotopic concentration is dependent on quantities of the various uranium isotopes remaining in the ore during penetrator fabrication. As noted in the previous discussions, the chemical compounds likely to be present during and after the accident scenario fires are various uranium oxides. Fire tests with the M829 round in its shipping container indicated that the oxidized DU had a particle size distribution that included 0.9 to $2.3 \mathrm{wt} \%$ of fines below $10 \mu \mathrm{m}$ LLD and 0.2 to 0.65 wt\% less than $10 \mu \mathrm{m}$ AED. The solubility of particles of a size that may be respired $(<10 \mu \mathrm{m}$ AED) determines whether the inhalation exposure presents primarily a radiological or toxicological hazard.

With depleted uranium there are two concerns about toxicity. The first is the radiological hazard to the respiratory system and, to a lesser degree, to the rest of the body. The second is the chemical toxicity of uranium, particularly to the kidney. The type of toxicity that is most limiting depends on the uranium compound, its solubility, and its particle size. Generally, the particles that are nearly insoluble or very slightly soluble will pose more of a radiological concern, while the soluble compounds will be transported by the blood stream to other organs including the kidney, which is the most sensitive to damage from uranium.

This section focuses on the activity and concentration levels known to have deleterious health effects and on determining whether the radiological or toxicological hazard is the most limiting. A discussion on how to derive exclusion area boundaries, based on the radiological and chemical hazards of the rounds, will conclude the section.

Previous reports released by the U.S. Army have discussed in detail the health and environmental effects of airborne releases of DU as the result of 
testing the 105-mm M774 and M735AI projectiles and in the event of a transportation or storage fire (TASC 1979; TASC 1980; MCMillan 1979; Funkhouser 1981). These findings will be summarized here and the assumptions and criteria will be updated where possible with data from the M829 cartridge tests and recent radiological criteria. The relevance of this analysis to the 120-mm M829 cartridge will also be discussed.

Depleted uranium, a by-product of the uranium enrichment process, contains a smaller percentage of the ${ }^{234} U$ and ${ }^{235} U$ isotopes than are found in natural uranium and consequently has a lower activity than natural uranium. Its radiological hazard, therefore, is reduced over that of natural uranium. The chemical properties of the natural and depleted forms are nearly identical and the chemical toxicity of the two is not dependent on isotopic content. The type of hazard that presents the most serious consequences generally depends on the solubility of the material and to a lesser extent, its particle size distribution. The smaller and more soluble the particle is, the more likely that the chemical toxicity is more limiting than the radiation activity.

\subsubsection{Identification of the Limiting Hazard}

First, therefore, to identify the limiting hazard, the isotopic and chemical composition and the particle size distribution must be determined. Solubility can be estimated if the chemical composition is known. Once these parameters are established or approximated, an analysis of the type and extent of hazard can be initiated.

Isotopic composition. Uranium ore has a typical uranium fraction of 99.3\% ${ }^{238} U, 0.7 \%{ }^{235} U$, and minute quantities of ${ }^{234} U$ and ${ }^{236} U$. Enriched uranium has a concentration of $2+\%$ of ${ }^{235} U$ and a correspondingly reduced ${ }^{238} U$ concentration. Depleted uranium is the waste product left after extracting some portion of ${ }^{235} U$ from the starting material. Because ${ }^{235} U$ has the highest activity and therefore produces the highest contribution to dose, extracting this from the ore leaves a product of reduced activity. The fractions of the various isotopes remaining after the enriching process varies and, consequently, so does the total DU activity. Variance of the total specific activity of these isotopic mixtures ranges from $3.4 \times 10^{-4} \mathrm{Ci} / \mathrm{kg}$ to $3.8 \times$ $10^{-4} \mathrm{Ci} / \mathrm{kg}$, with $3.6 \times 10^{-4} \mathrm{Ci} / \mathrm{kg}$ recommended by $10 \mathrm{CFR} 20$ as the average 
value and considered representative for the rounds (TASC 1979). This represents weight fractions of $0.00037 \%{ }^{234} U, 0.25 \%{ }^{235} U$, and $99.75 \%{ }^{238} U$. These numbers translate to activities and weight fractions in the M735A1 and M774 penetrators as listed in Table 4.8. The M829, with an approximate average mass of $4 \mathrm{~kg}$ DU per round, has a similar weight fraction and activity preponderance from ${ }^{238} \mathrm{U}$. Uranium-238 contributes the majority of the weight fraction and $92.3 \%$ of the total activity per penetrator. Thus, ${ }^{238} U$ is the isotope of radiological concern. Because of the long half-lives of the uranium isotopes, the effect of decay on the concentration of uranium is not significant for short time periods.

Chemical composition. Depleted uranium is produced from the uranium fluoride tailings of the uranium enrichment process. The $U F_{6}$ gas is solidified by cold trapping and is stored either as $U F_{6}$ or as the reduced product $\mathrm{UF}_{4}$. The uranium flouride is reacted with magnesium granules to produce the uranium metal. Titanium is added to the uranium to produce a $\mathrm{U}-\mathrm{Ti}(0.75 \%)$ alloy, which is then cast into the penetrator shape (0lofson, Meyer and Hoffmanner 1976).

A severe fire may oxidize the DU penetrators to form $\mathrm{UO}_{2}, \mathrm{U}_{3} \mathrm{O}_{8}$, and small quantities of other $\mathrm{U}_{\mathrm{x}} \mathrm{O}_{\mathrm{y}}$ oxides and hydrates. Uranium carbide may also be formed in the fire but quickly reacts with air to form an oxide. The extent

TABLE 4.8. Isotopic Composition of Depleted Uranium in M735A1, M774, and M829 Penetrators

\begin{tabular}{|c|c|c|c|c|c|c|}
\hline Round & $\begin{array}{c}\text { Approximate } \\
\text { Average Mass } \\
\text { of DU Per } \\
\text { Penetrator } \\
\text { (kg/round) } \\
\end{array}$ & I sotope & $\begin{array}{c}\text { Weight } \\
\text { Fraction }\end{array}$ & $\begin{array}{c}\text { Specific } \\
\text { Activity Per } \\
\text { Unit Mass } \\
\text { Isotope } \\
\text { (Ci/kg) } \\
\end{array}$ & $\begin{array}{l}\text { Activity Per } \\
\text { Penetrator } \\
\text { (Ci/round) } \\
\end{array}$ & $\begin{array}{c}\text { Percent } \\
\text { Activity Per } \\
\text { Penetrator } \\
\end{array}$ \\
\hline M735A1 & 2.18 & $\begin{array}{l}234 \mathrm{U} \\
235 \mathrm{U} \\
238 \mathrm{U}\end{array}$ & $\begin{array}{r}3.7 \times 10^{-6} \\
2.5 \times 10^{-3} \\
9.975 \times 10^{-1}\end{array}$ & $\begin{array}{r}6.05-3 \\
2.14 \times 10^{-3} \\
3.33 \times 10^{-4}\end{array}$ & $\begin{array}{l}4.88 \times 10^{-5} \\
1.17 \times 10^{-5} \\
7.24 \times 10^{-4}\end{array}$ & $\begin{array}{r}6.2 \\
1.5 \\
92.3\end{array}$ \\
\hline M774 & 3.40 & $\begin{array}{l}234 \mathrm{U} \\
235 \mathrm{U} \\
238 \mathrm{U}\end{array}$ & $\begin{array}{r}3.7 \times 10^{-6} \\
2.5 \times 10^{-3} \\
9.975 \times 10^{-1}\end{array}$ & $\begin{array}{r}6.05-3 \\
2.14 \times 10^{-3} \\
3.33 \times 10^{-4}\end{array}$ & $\begin{array}{l}7.61 \times 10^{-5} \\
1.82 \times 10^{-5} \\
1.13 \times 10^{-3}\end{array}$ & $\begin{array}{r}6.2 \\
1.5 \\
92.3\end{array}$ \\
\hline M829 & 4.00 & $\begin{array}{l}234 \mathrm{U} \\
235 \mathrm{U} \\
238 \mathrm{U}\end{array}$ & $\begin{array}{r}3.7 \times 10^{-6} \\
2.5 \times 10^{-3} \\
9.975 \times 10^{-1}\end{array}$ & $\begin{array}{r}6.05-3 \\
2.14 \times 10^{-3} \\
3.33 \times 10^{-4}\end{array}$ & $\begin{array}{l}8.95 \times 10^{-5} \\
2.14 \times 10^{-5} \\
1.33 \times 10^{-3}\end{array}$ & $\begin{array}{r}6.2 \\
1.5 \\
92.3\end{array}$ \\
\hline
\end{tabular}


of oxidation is dependent on the fire's duration and its temperatures. In a field test of a wood fire, the penetrators from $M 829$ packaged rounds were about $85 \%$ oxidized.

Chemical solubility. Aerosols of depleted uranium may be either soluble or insoluble or combinations of the two. Solubility assessment of the uranium oxides is complicated by the many nonstoichiometric and crystalline uranium compounds, some of which have one or more hydrated forms (Kalkwarf 1983). In most cases they are insoluble or only slightly soluble in water. Various factors controlling solubility of the compounds include temperature, $\mathrm{pH}$, and the surface-to-volume ratio. Their solubility in the body is somewhat in question. Certain studies show that the compounds are dissolved in fresh water or salt water in a matter of one to several weeks. Other studies of depleted uranium and the oxides remaining after a severe fire show that the dissolution in synthetic lung fluid takes months to years (Kalkwarf 1982). Tests with simulated lung fluid indicate that up to $50 \%$ of aerosolized DU dissolves in simulated lung fluid in seven days (Glissmeyer and Mishima 1979). The study (in Section 2) of the $<10 \mu \mathrm{m}$ AED fraction of DU ash recovered from the April 1983 hazard classification test revealed that $96 \%$ remained undissolved after 60 days (Table 2.7).

Particle size. For a DU aerosol to be carried significant distances by prevailing winds, the particles must be $<20 \mu \mathrm{m} \mathrm{AED}$. For it to pose a respiratory hazard, the particles must be $<10 \mu \mathrm{m}$ AED and perhaps <3 $\mu \mathrm{m}$ AED.

The retention of DU and its transport from the respiratory system to other parts of the body is greatly influenced by the particle size distribution. The particle size influences not only where the particles are initially deposited but also what the clearance pathway will be. The dramatic contribution to dose based on particle size demonstrates how the dose to the lung, kidney, and bone marrow increases with smaller particle size (Figure 4.17).

For any inhaled aerosol, the size determines where in the respiratory system the particles will be deposited--in the nasal passage (N-P), in the trachea and bronchial tree $(T-B)$, or in the pulmonary parenchyma $(p)$. This distribution pattern is illustrated for an aerosol with an activity median aerodynamic diameter (AMAD) between 0.2 and $10 \mu \mathrm{m}$ (Figure 4.18). The dashed 


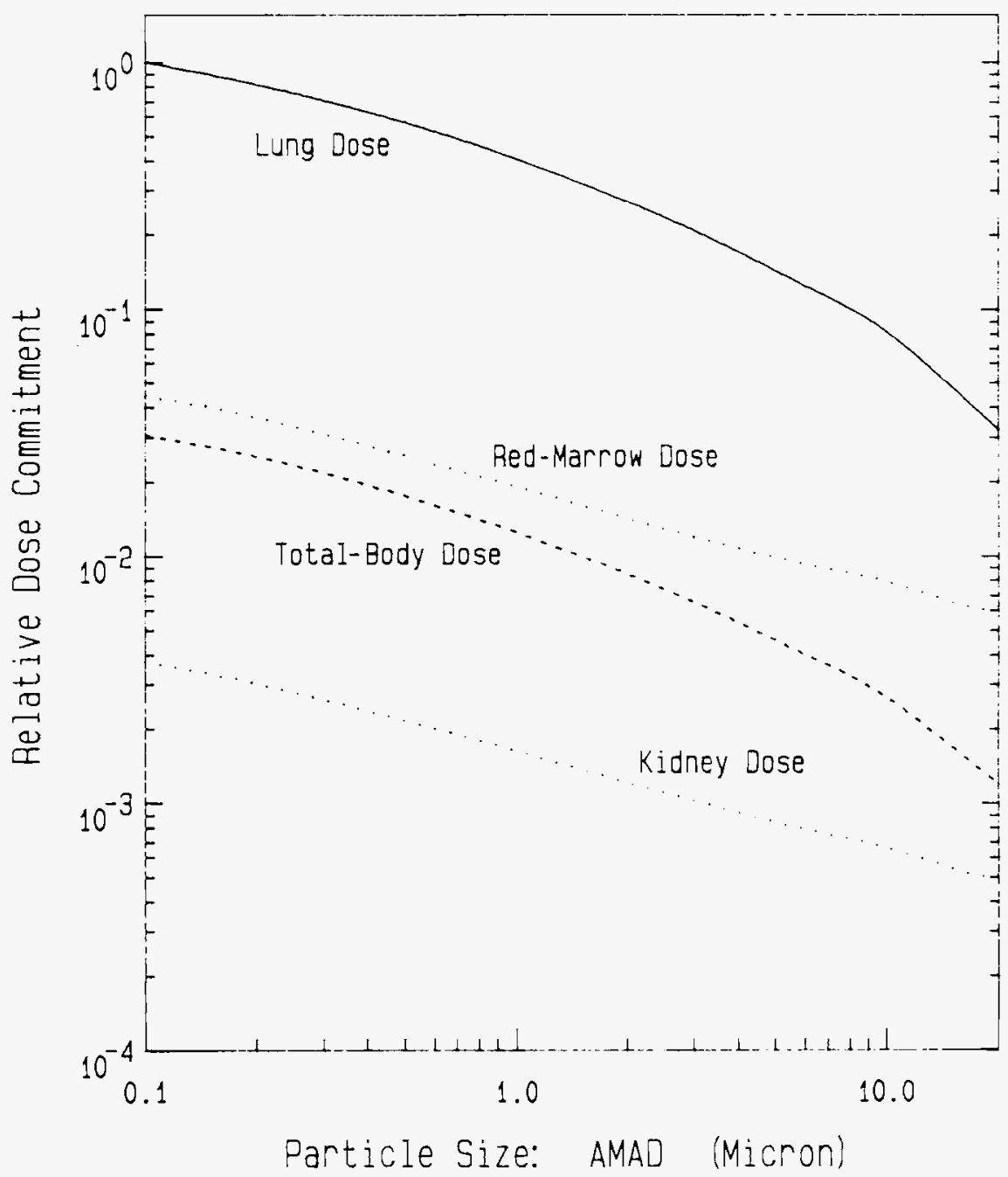

FIGURE 4.17. Variation of Inhalation Dose with Particle Size

lines are estimates of deposition beyond the $0.2-$ and $10-\mu \mathrm{m}$ size range. Particles larger than $3 \mu \mathrm{m}$ are typically deposited in the nasopharyngial and trachiobronchial region by impaction. Deposition by gravitational settiing can occur with all nonvertical airways. Deposition by Brownian diffusion is characteristic of particles smaller than $0.5 \mathrm{\mu m}$ and occurs most often in the lung bronchioles and parenchyma. Interception and electrostatic attraction are other less important deposition mechanisms of particles in the respiratory tract (Raabe 1980). 


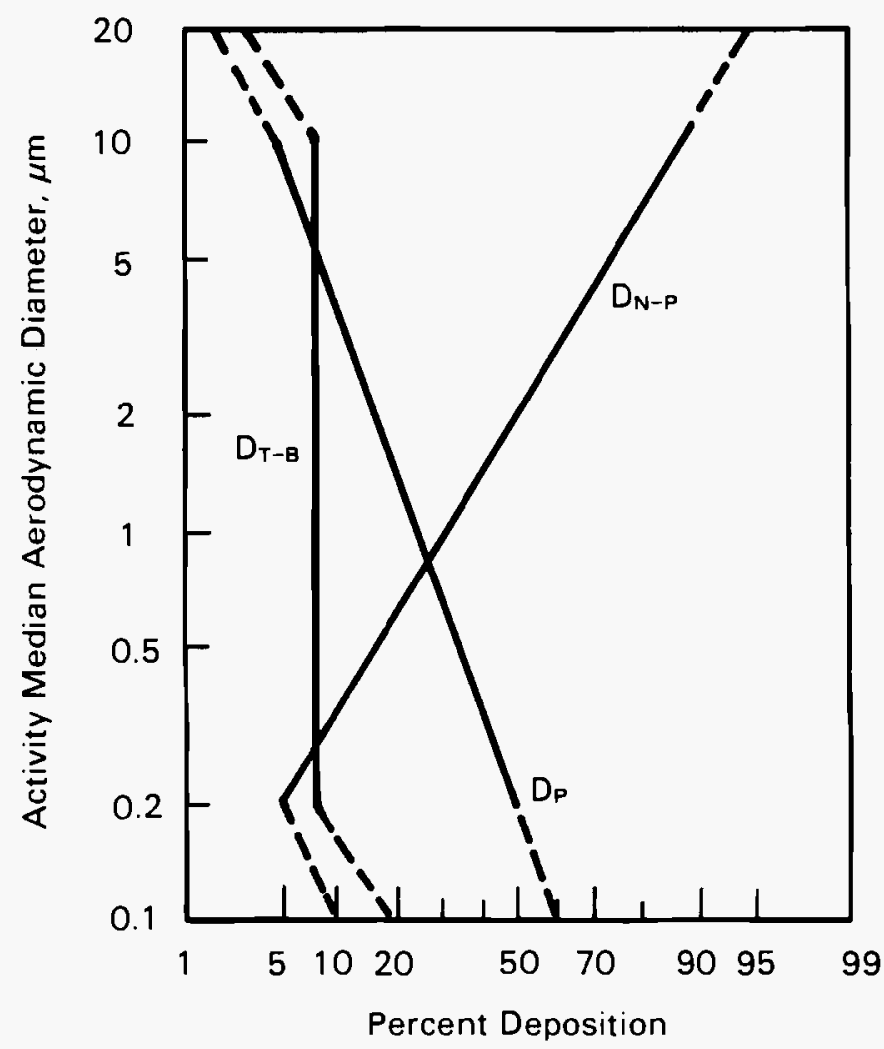

FIGURE 4.18. Particle Size Related to Dose

Clearance of particles deposited in the respiratory tract proceeds at different rates for the three categories. The clearance pathway also depends on the solubility as well as specific particle size. These paths are through the gastrointestinal tract and the lymphatic system, and by direct transfer to the blood. The ICRP Task Group on Lung Dynamics (1966) model and its updated version in ICRP 30 (1979) use mathematical models to represent the retention times and clearance pathways of inhaled radionuclides. A schematic of the different portions of the respiratory system and of removal pathways shows the various deposition and removal compartments labeled a through $j$ (Figure 4.19).

These dosimetric models break compounds into three solubility classes: $D$ (days) for relatively soluble compounds with half-times in the lungs of less than 10 days, $W$ (weeks) for compounds with half-times of 10 to 100 days, and $Y$ (years) for compounds with long retention times. Compartments a, c, and e are 


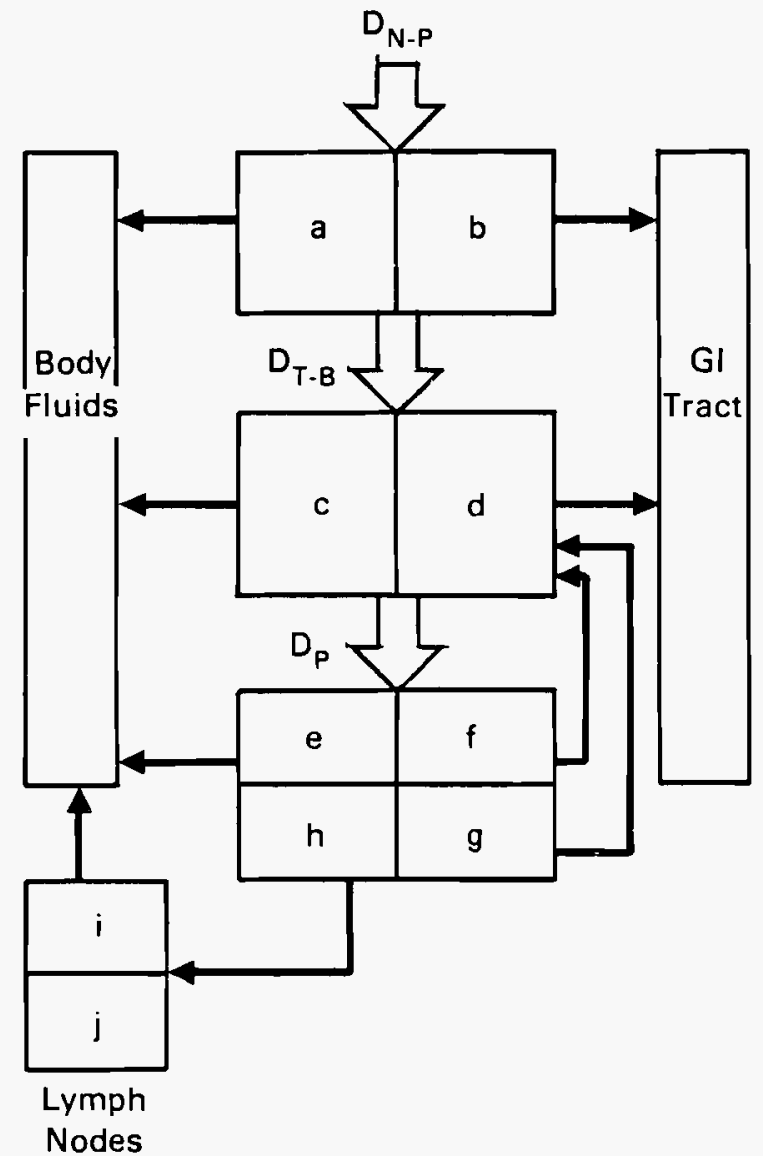

\begin{tabular}{|c|c|c|c|c|c|c|c|}
\hline \multirow[b]{3}{*}{ Region } & \multirow[b]{3}{*}{$\begin{array}{l}\text { Compart- } \\
\text { ment }\end{array}$} & \multicolumn{6}{|c|}{ Class } \\
\hline & & \multicolumn{2}{|c|}{$D$} & \multicolumn{2}{|c|}{$w$} & \multicolumn{2}{|l|}{$\mathbf{Y}$} \\
\hline & & $\begin{array}{c}T \\
\text { day }\end{array}$ & $F$ & $\begin{array}{c}T \\
\text { day }\end{array}$ & $F$ & $\begin{array}{c}\mathrm{T} \\
\text { dáy }\end{array}$ & $F$ \\
\hline $\begin{array}{l}N-P \\
\left(D_{N-P}=0.30\right)\end{array}$ & $\begin{array}{l}\mathrm{a} \\
\mathrm{b}\end{array}$ & $\begin{array}{l}0.01 \\
0.01\end{array}$ & $\begin{array}{l}0.5 \\
0.5\end{array}$ & $\begin{array}{l}0.01 \\
0.40\end{array}$ & $\begin{array}{l}0.1 \\
0.9\end{array}$ & $\begin{array}{l}0.01 \\
0.40\end{array}$ & $\begin{array}{l}0.01 \\
0.99\end{array}$ \\
\hline $\begin{array}{l}\mathrm{T}-\mathrm{B} \\
\left(D_{\mathrm{T}-\mathrm{B}}\right.\end{array}$ & $\begin{array}{l}c \\
d\end{array}$ & $\begin{array}{l}0.01 \\
0.2\end{array}$ & $\begin{array}{l}0.95 \\
0.05\end{array}$ & $\begin{array}{l}0.01 \\
0.2\end{array}$ & $\begin{array}{l}0.5 \\
0.5\end{array}$ & $\begin{array}{l}0.01 \\
0.2\end{array}$ & $\begin{array}{l}0.01 \\
0.99\end{array}$ \\
\hline $\begin{array}{l}\mathrm{P} \\
\left(D_{\mathrm{P}}=0.25\right)\end{array}$ & $\begin{array}{l}\text { e } \\
f \\
g \\
h\end{array}$ & $\begin{array}{l}0.5 \\
\text { n.a. } \\
\text { n.a. } \\
0.5\end{array}$ & $\begin{array}{l}0.8 \\
\text { n.a. } \\
\text { n.a. } \\
0.2\end{array}$ & $\begin{array}{l}50 \\
1.0 \\
50 \\
50\end{array}$ & $\begin{array}{l}0.15 \\
0.4 \\
0.4 \\
0.05\end{array}$ & $\begin{array}{c}500 \\
1.0 \\
500 \\
500\end{array}$ & $\begin{array}{l}0.05 \\
0.4 \\
0.4 \\
0.15\end{array}$ \\
\hline L & i & $\begin{array}{l}0.5 \\
\text { n.a. }\end{array}$ & $\begin{array}{l}1.0 \\
\text { n.a. }\end{array}$ & $\begin{array}{l}50 \\
\text { n.a. }\end{array}$ & $\begin{array}{l}1.0 \\
\text { n.a. }\end{array}$ & $\begin{array}{r}1000 \\
\infty\end{array}$ & $\begin{array}{l}0.9 \\
0.1\end{array}$ \\
\hline
\end{tabular}

FIGURE 4.19. Schematic of Removal Pathways 
absorption processes; b, $d, f$, and $g$ are particle transport processes. Material in compartment $i$ is translocated to body fluids while for Y-class aerosols, compartment $j$, the pulmonary lymph nodes, retain material translocated there indefinitely. The removal half-times, $T$, and compartmental fractions, $F$, are tabulated for the three classes and the ten compartments for aerosols with a 1-um AMAD. The $L$ stands for the pulmonary lymphatic system.

Inert and insoluble particles may be tenaciously retained in the lungs. However, very small particles, particularly <100 A in diameter, may be small enough to move readily into blood, resulting in clearance indistinguishable from the less likely chemical dissolution. In fact, material thought to be relatively insoluble may have high dissolution rates and short half-times in the lung if the particle size distribution is very small. $\mathrm{PuO}_{2}$ is an example of very small particles demonstrating a very high dissolution rate where previous theory did not predict such behavior. Uranium oxides may follow a similar pattern if the aerosols consist of very small particles.

The influence of particle size on the dose to the lungs, kidney, red bone marrow and to the total body illustrates the order of magnitude difference in

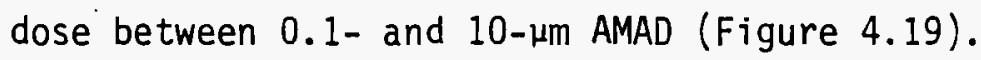

The size distribution of the particles formed in a fire depend on the fire temperature and the particles' access to oxidants. The 1983 burn test formed 0.2 to 0.65 wt\% particles <10 $\mu \mathrm{m}$ (AED). This created an airborne release of $<0.1 \mathrm{wt} \%$ of the uranium oxidized as respirable particles. However, as a maximum release using conservative assumptions (complete oxidation of all uranium in the worst-case temperature producing the finest particle distribution) and assuming that the uranium oxides are transported from the site, as much as $4 \%$ of the particles could be in the respirable size range of $<3.3 \mu \mathrm{m}$ LLD.

Chemical toxicity. The chemical toxicity of uranium and uranium compounds in humans is not very well known. Most of the data on the quantities necessary for adverse effects and the mechanisms of interaction are extrapolated from studies on laboratory animals; studies on uranium miners are available, but they have concentrated on the rapidity of clearance/excretion and its correlation with quantities of uranium in body tissues. 
Unoxidized depleted uranium penetrators present little chemical hazard in the metallic form. However, if the uranium is oxidized as the result of a severe fire, the uranium oxide formed may be hazardous if inhaled or ingested.

Soluble DU inhaled into the lungs or DU solubilized in the lungs poses a toxicological concern when it is transported to the kidneys. About $80 \%$ of the dissolved DU that is transported through the bloodstream to the kidneys is released in the urine within $24 \mathrm{hr}$ (Funkhouser 1981). The remaining 20\% has a biological half-life in the kidneys of about 5 days. According to ICRP 2 (1959), 2.8\% of the total inhaled uranium is deposited in the kidneys.

A sufficiently high dose of DU in the kidneys may lead to binding of uranium with "protein in the cells walls, poisoning of cells and interfering with the vital functions of waste elimination and electrolyte balance" (TASC 1979). This is a threshold effect, where a certain concentration of the substance must be present before any deleterious effects are noted.

The body is able to repair minor damage to the kidneys from periodic doses of uranium, but chronic exposure at elevated levels could lead to renal failure. Insoluble DU cleared through the GI tract apparently adds little to the kidney dose; most is quickly excreted.

Toxic dose levels. The toxicity of the different uranium compounds varies widely. Compounds $1 \mathrm{ike} \mathrm{UO}_{2}, \mathrm{U}_{3} \mathrm{O}_{8}$, and $\mathrm{UF}_{4}$ are relatively insoluble and are practically nontoxic even when fed to laboratory animals in large (mg) doses. $\mathrm{UO}_{2}\left(\mathrm{NO}_{3}\right) 2, \mathrm{UCl}_{4}$, and $\mathrm{Na}_{2} \mathrm{U}_{2} \mathrm{O}_{7}$ are toxic in moderate doses. $\mathrm{UO}_{2} \mathrm{~F}_{2}$, on the other hand, is toxic in relatively small doses partially due to the toxicity of the fluoride. These differences are based particularly on the extent of absorption of the different compounds (Tannenbaum 1951).

Chemical toxicity of the uranium oxides in inhalation studies has also been found to be relatively low. In 30-day inhalation studies, $\mathrm{UO}_{2}$ and similar insoluble dusts were rarely fatal in animal studies at $20 \mathrm{mg} / \mathrm{m}^{3}$ daily and produced little or no renal damage at the $2.5 \mathrm{mg} / \mathrm{m}^{3}$ level; further, workers exposed to 40 to 100 times the maximum permissible concentration (MPC) $1 \times 10^{-10} \mu \mathrm{Ci} / \mathrm{ml}$ did not show signs of overexposure (Hodge, Stannard and Hursh 1973). 
Several agencies' recommended limits for exposure to uranium and uranium oxides, based primarily on the chemical toxicity of the uranium compounds, are in Table 4.9.

Most of these recommended exposure limits are based on chronic exposure concentrations. Their use for short-term releases is very conservative. Table 4.10 is a summary of limits for chronic exposures.

Radiological hazard. Depleted uranium metal emits $4.15-$ and $4.20-\mathrm{MeV}$ alphas from ${ }^{238} \mathrm{U}$ and $4.37-, 4.40-$ and $4.58-\mathrm{MeV}$ alphas, as well as low-energy gamma-rays, from ${ }^{235} \mathrm{U}$. Uranium decay products as a group emit high-energy alphas and beta and gamma radiations. As assembled projectiles, the DU metal presents primarily an external hazard from photons because of the low activity of most of the alpha emitters. The maximum exposure rate at the surface is about $23 \mathrm{mrem} / \mathrm{hr}$ for the round or $272 \mathrm{mrem} / \mathrm{hr}$ for the bare penetrator (Hooker et a1. 1983). Gloves and safety glasses are usually the only protection required for short-term handling of the penetrators.

Oxidation of the DU alters the type of radiological hazard to primarily inhalation, with potential injury to the lungs from alpha radiation from confined DU particles. Depending on the exposure pathway, the oxidized DU may also contribute beta and gamma radiations, adding to the whole-body dose. Under conditions described in the shipping and storage scenarios, the beta and gamma dose contributions to the whole-body dose would be insignificant compared with the inhalation dose. (a)

Depending on their solubility, inhaled uranium particles concentrating in the lungs may be transported to the kidney and bone. The biological half-life in the kidney is several days. In the lungs and bone, however, it is more like 180 days, so these are the main radiological concerns.

Regulatory and recommended exposure limits, most based on chronic exposures, are listed in Table 4.11.

(a) Documented in a letter report, "Calculations of the Effects of Shipping and Bulk Storage Accidents Involving Depleted Uranium Penetrators," from R. I. Scherpelz, J. Mishima and M. A. Parkhurst (Pacific Northwest Laboratory) to the U.S. Army in 1984. 
TABLE 4.9. Recommended Limits for Uranium and Uranium Oxide Exposures (based primarily on chemical toxicity)

Patty's (Clayton and Clayton 1978) nonoccupational in air in water
${ }^{238} \mathrm{U}$
soluble
insoluble
$3 \times 10^{-12}$
$\mu \mathrm{Ci} / \mathrm{ml}$
$5 \times 10^{-12} \mu \mathrm{Ci} / \mathrm{ml}$
$\begin{array}{lll}4 \times 10^{-5} & \mu \mathrm{Ci} / \mathrm{ml} \\ 4 \times 10^{-5} & \mu \mathrm{Ci} / \mathrm{ml}\end{array}$

ICRP 2 (1959)

$$
{ }^{238 \mathrm{U}} \quad \begin{aligned}
& \text { insoluble } \\
& \text { soluble } \mathrm{UO}_{2} \\
& \text { soluble } \mathrm{U}_{3} \mathrm{O}_{8}
\end{aligned} \quad \begin{gathered}
180 \mathrm{\mu g} / \mathrm{m}^{3} \\
\text { (even lower) }
\end{gathered}
$$

ACGIH (1983)

uranium (natural) soluble and insoluble compounds as $U$

TLV-TWA $-0.2 \mathrm{mg}^{3}$

TLV-STEL - $0.6 \mathrm{mg} / \mathrm{m}^{3}$

where TLV-TWA is the time-weighted average for a normal 8-hr workday and $40-h r$ work week to which nearly all workers may be repeatedly exposed, day after day, without adverse effect where TLV-STEL is the short-term exposure limit defined as "the concentration to which workers can be exposed continuously for a short period of time without suffering from 1) irritation, 2) chronic or irreversible tissue change, or 3) narcosis of sufficient degree to increase the likelihood of accidental injury, impair self-rescue or materially reduce work efficiency, and provided that the daily TLV-TWA also is not exceeded. . . ."

A STEL is defined as a 15-minutes time-weighted average exposure not to be exceeded at any time, and "should not be repeated more than 4 times per day with at least 60 minutes between exposures."

NIOSH (Mackison, Stricoff and Partridge 1978)

Permissible Exposure Limit

IDLH

$U$ and insoluble compounds
soluble compounds

$0.25 \mathrm{mg} / \mathrm{m}^{3}$
$0.05 \mathrm{mg} / \mathrm{m}^{3}$

$30 \mathrm{mg} / \mathrm{m}_{3}^{3}$

where IDLH is the concentration designated as "immediately dangerous to life or health" and represents a maximum level from which one could escape within 30 minutes without any escape-impairing symptoms or irreversible health effects. 
TABLE 4.10. Summary of Chronic Exposure Limits

\begin{tabular}{|c|c|c|c|c|c|c|}
\hline \multirow[b]{2}{*}{ Exposure Index } & \multicolumn{3}{|c|}{ Occupational Limits } & \multicolumn{3}{|c|}{ General Populace Limits } \\
\hline & Units & $\begin{array}{c}\text { Tnsolubie } \\
\text { DU }\end{array}$ & $\begin{array}{c}\text { Solubie } \\
\text { DU }\end{array}$ & Units & $\begin{array}{c}\text { insoluble } \\
\text { DU } \\
\end{array}$ & $\begin{array}{c}\text { Soluble } \\
\text { DU }\end{array}$ \\
\hline Whole-Body Dose & rems/year & 5 & 5 & rems/year & 0.5 & 0.5 \\
\hline Critical-Organ Dose & rems/year & 15 & 15 & rems/year & 1.5 & 1.5 \\
\hline $\begin{array}{l}\text { Radiological } \\
\text { Concentration } \\
\text { of DU in Air }\end{array}$ & $\begin{array}{l}\mathrm{Ci} / \mathrm{ml} \\
\text { (averaged } \\
\text { quarterly) }\end{array}$ & $1 \times 10^{-10}$ & $7 \times 10^{-11}$ & $\begin{array}{l}\mathrm{Ci} / \mathrm{ml} \\
\text { (averaged } \\
\text { annual ly) }\end{array}$ & $5.0 \times 10^{-12}$ & $3.0 \times 10^{-12}$ \\
\hline $\begin{array}{l}\text { Toxicological } \\
\text { Concentration } \\
\text { of Soluble } \\
\text { DU in Air }\end{array}$ & $\begin{array}{l}\mathrm{mg} / \mathrm{m}^{3} \\
\text { (average } \\
\text { weekly) }\end{array}$ & - & 0.2 & $\begin{array}{l}\mathrm{mg} / \mathrm{m}^{3} \\
\text { (averaged } \\
\text { annually) }\end{array}$ & - & 0.007 \\
\hline
\end{tabular}

TABLE 4.11. Regulatory and Recommended Exposure Limits (based on radiological hazards)

NRC (10 CFR 20) (1983)

\begin{tabular}{l}
$\begin{array}{l}\text { Occupational Exposure } \\
\mu \mathrm{Ci} / \mathrm{ml}\end{array}$ \\
\hline $\mathrm{air}$
\end{tabular}

238 u soluble $7 \times 10^{-11}$
$238 U$ insoluble $1 \times 10^{-10}$
General Public $\mu \mathrm{Ci} / \mathrm{ml}$

\begin{tabular}{ll}
\hline air & water \\
$3 \times 10^{-12}$ & $4 \times 10^{-5}$ \\
$5 \times 10^{-12}$ & $1 \times 10^{-3}$
\end{tabular}

$0.2 \mathrm{mg} / \mathrm{m}^{3}-{ }^{238} \mathrm{U}$ aerosols (weekly occupational exposure)

$8 \mathrm{mg}-\mathrm{hr} / \mathrm{m}^{3}$ - time-integrated factor

ACGIH (1983)

$T L V-0.2 \mathrm{mg} / \mathrm{m}^{3}$ for $U$ and $i$ ts aerosols

Recommendations presented by I.S. Eve (1964)

$8 \mathrm{mg}-\mathrm{hr} / \mathrm{m}^{3}\left(480 \mathrm{mg}-\mathrm{min} / \mathrm{m}^{3}\right)$ - as maximum planned emergency concentration integration factor (noted by Funkhouser (1981) as consistent with lab studies addressing nephrotoxicity from acute inhalation and ingestion of $U$ compounds)

ICRP 30 (1979)

Inhalation Exposures - Solubility Classes $D=$ days, $W=$ weeks, $Y=$ years

$\operatorname{ALI}(\mathrm{Bq})$

(annual limits on intake)

$\frac{\text { Class D }}{5 \times 10^{4}}$

$\operatorname{DAC}\left(\mathrm{Bq} / \mathrm{m}^{3}\right)(40 \mathrm{hr} / \mathrm{wk})$

(derived air concentrations) $2 \times 10$

$\frac{\text { Class W }}{3 \times 10^{4}}$

Class $Y$

$2 \times 10^{3}$

$1 \times 10$

$7 \times 10^{-1}$ 
The EPA (1980) provides some guidance for acute exposure limits in its protective action guides (PAGs). These PAGs suggest general population and emergency worker limits in the event of nuclear incidents releasing radioactive materials to the atmosphere. They are intended for use by emergency personnel in determining whether actions such as sheltering or evacuating are warranted to "ameliorate the impact" to exposed or likely-to-be exposed populations. The assumed duration of the release is a few hours to a few days (EPA 1980).

The whole-body external gamma radiation limits conservatively assume that gamma exposure and whole-body gamma doses are equivalent and are as follows:

$$
\begin{array}{lr}
\text { general population } & 1-5 \mathrm{rem} \\
\text { emergency workers } & 25 \mathrm{rem} \\
\text { lifesaving activities } & 75 \mathrm{rem}
\end{array}
$$

The inhalation limits for radioactive material in an airborne plume as recommended in the PAGs are based on dose to the thyroid:

$$
\begin{array}{lr}
\text { general population } & 5-25 \text { rem } \\
\text { emergency workers } & 125 \text { rem } \\
\text { lifesaving activities } & \text { (no limit specified) }
\end{array}
$$

In both sets of limits, the lower numbers in the range should be used where there are no local constraints that prevent providing for such protection.

Since the thyroid dose implies protection from beta-emitting radioiodines, these values are not strictly relevant for lung dose from alpha emitters. While no PAG has been set for lung doses, 10 CFR 20 (sections 20.4 and 20.101) indicates that the dose to the lung should be treated as the dose to the total body. These PAG 1 imits provide somewhat arbitrary and conservative guidance on the dose equivalent levels "allowed" in an emergency situation.

Calculation of the chemical levels. Calculation of the concentration of soluble DU in air is expressed as:

$$
\begin{aligned}
C_{K 1}^{T}= & \left(\frac{f_{a} \cdot f_{b} \cdot N_{1} \cdot 10^{6}}{T_{K 1}}\right) \cdot F \quad \text { (inhalation) } \\
& +\left(f_{a} \cdot M_{1} \cdot v_{d} \cdot K_{r} \cdot 10^{6}\right) \cdot F \quad \text { (resuspension) }
\end{aligned}
$$


where

$C_{K 1}^{T}=$ average toxicological concentration of soluble DU in air to which a person in population class $K$ is exposed during averaging period $1\left(\mathrm{mg} / \mathrm{m}^{3}\right)$

$f_{a}=$ fraction of available DU that is dispersed to the air as aerosols (particles <20 $\mu \mathrm{m}$ AED)

$f_{b}=$ fraction of aerosolized DU that is respirable (particles $\leqq 3 \mu m$ AED)

$\mathrm{N}_{1}$ = amount of DU available for release to the air during averaging period $1(\mathrm{~kg})$

$F=$ normalized concentration of material in the passing cloud at a ground-level receptor $\left(\mathrm{sec} / \mathrm{m}^{3}\right)$

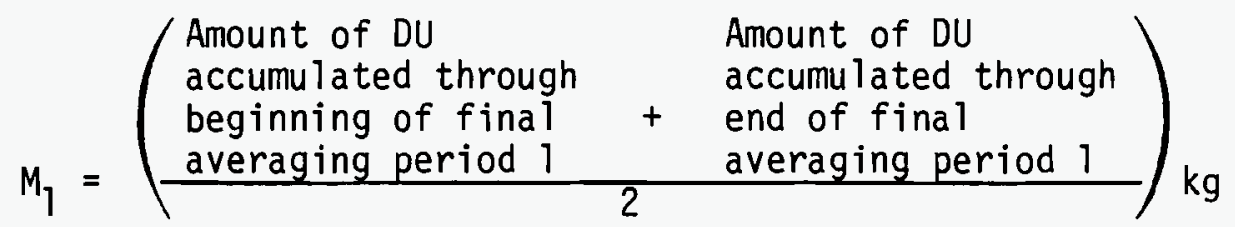

When the actual duration of release is $\leqq$ the averaging period, $M_{1}=N_{1}$

$v_{d}=$ deposition velocity $(\mathrm{m} / \mathrm{sec})$

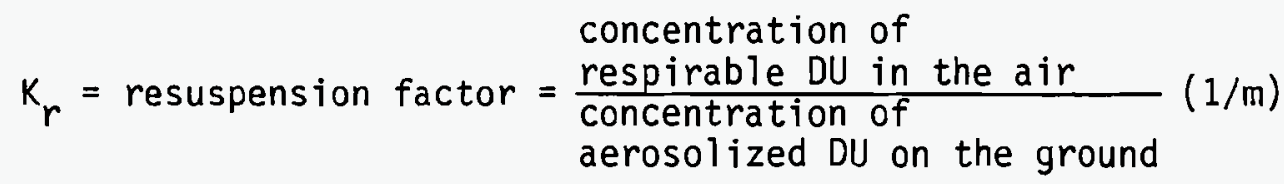

$10^{6}=$ conversion factor $(\mathrm{mg} / \mathrm{kg})$.

\subsubsection{Calculation of Exclusion Area}

If a scenario-type transportation or storage accident occurred, an exclusion area boundary could be established to limit access near the accident site or downwind of an airborne DU release. The exclusion boundary limits are based on the potential for radiological and toxicological hazards as well as the potential missile impact and explosive hazards of the M829. 
Exclusion criteria may be set up on the basis of radiological and toxicological limits to occupationally exposed persons or to members of the general public, depending on the people at risk. Exposure to either of these groups is usually based on the long-term exposure to the specified material-usually $40 \mathrm{hr} /$ week for occupational and $168 \mathrm{hr} /$ week for the public. For short-term releases, the inhalation limits may be overly conservative and the use of the short-term exposure limit (STEL) may be more directly applicable for these cases.

As discussed in Section 4.2.1, the compounds most likely to be formed from $\mathrm{DU}$ by fire are $\mathrm{UO}_{2}, \mathrm{UO}_{3}$, and $U \mathrm{C}$. The limit of insoluble compounds that can legally be inhaled is governed by the dose received to the lungs from inhalation. Exposure to soluble DU compounds through inhalation is limited by the concentration to the kidney.

Previous analyses determining exclusion boundaries have addressed the issues of radiation and chemical toxicity in establishing criteria (McMillan 1979; Funkhouser 1981). However, neither of these had much relevant field data to base their analyses on and both had to use assumptions they generally suspected were conservative. Their approaches deriving exposure limits are outlined here followed by a discussion of how the results differ using available field data in place of the assumptions. Certain assumptions will be retained where no actual information/data exists.

This analysis assumes a munitions accident as described in Section 4.2 where a fire is responsible for the oxidation of a portion of the depleted uranium penetrators and an explosion disperses the aerosolized uranium oxides downwind of the accident site. Concentration limits imposed on occupational workers will be contrasted with limits to the general public.

Population characteristics. ICRP reports have been used to derive population exposure limits and occupationally exposed worker limits to uranium. These limits are based on continuous exposure and are conservative enough to protect both workers and the public from long-term radiological and toxic effects of inhaled (and ingested) uranium. The population at large consists of individuals within a wide age distribution. There are also likely to be large variances in health and tolerances to chemical insult within this popu- 
lation. Protection of the population is generally based on protection to the individuals most at risk. For soluble compounds of uranium, the kidney is the critical organ and its mass is the basis for calculated uranium tolerances. For example, at exposure levels above a threshold concentration, children's much smaller kidneys puts them at greater risk of kidney poisoning than adults with normally functioning kidneys. Other factors influencing individual tolerance variations include the ventilation rate (respiratory rate), the duration of the exposure, and exposure through other pathways. Applying the conservative nephrotoxic limit based on weight of uranium per gram of kidney across the population appears to provide reasonable protection for all members of the public.

Deriving an exposure limit. Almost all of the radiological or toxic limits for exposure to uranium are based on continuous exposure. If the postulated accident occurred, the release would have a limited duration and the inhalation hazard to persons downwind would be acute in the sense that it would cease after the release was concluded or when the wind changed direction away from the reference dose point. Resuspension of deposited particles could certainly add to the total inhaled dose, but the initial release would be the major concern. Because a regulatory limit does not exist for acute exposure, particularly in emergency situations, completion of this analysis requires that a limit or group of limits be derived so that control boundaries can be established to protect against overexposure from such an accident.

The ACGIH (1983) recommended TLV 1 imits are $0.2 \mathrm{mg} / \mathrm{m}^{3}$ for a $40-\mathrm{hr}$ work week and $0.6 \mathrm{mg} / \mathrm{m}^{3}$ for occasional, short-term exposures. Neither of these limits is adequate for short-term releases. Two approaches suggested by McMillan (1979) are to derive an emergency exposure limit from the continuous exposure limit and to derive it based on a maximum concentration of uranium in the kidneys. Both approaches assume that the exposed individuals have no previous exposure and therefore no initial body burden.

Deviation from continuous exposure. Given that with continuous exposure, the amount of uranium in the kidneys is constant and the amount excreted daily equals the amount taken into the body, then: 


$$
L \cdot N=r \cdot V \cdot C
$$

where $L=\ln (2) / 15$, the decay constant based on a biological half-life of 15 days

$\mathrm{N}=$ amount of uranium in the kidneys

$r=$ fraction absorbed into the body

$V=$ ventilation rate $\left(1.25 \mathrm{~m}^{3} / \mathrm{hr}\right)$

$\mathrm{C}=$ occupational concentration $1 \mathrm{imit}\left(0.2 \mathrm{mg} / \mathrm{m}^{3}\right)$.

Limiting the total body absorption to that quantity permissible in the kidneys under continuous exposure conditions, the equation becomes:

$$
\begin{aligned}
& N=r \cdot V \cdot C / L \\
& N=r \cdot V \cdot(t / 8) \cdot D
\end{aligned}
$$

where $\quad t=$ number of hours over which exposure occurs

$D=$ derived concentration limit

and the 8 represents hours/day.

Solving for the derived concentration time limit, the result becomes:

$$
D \cdot t=8 \cdot C / L
$$

which gives a concentration time factor of $34.6 \mathrm{mg}-\mathrm{hr} / \mathrm{m}^{3}$.

His second approach derives the limit by back calculating from the maximum permissible concentration (MPC) of uranium in kidney tissue. This MPC is $3 \mu \mathrm{g}$ of $\mathrm{U} / \mathrm{g}$ of tissue (Alexander 1974). Using the ICRP 2 (1959) standard (which does not specify whether the uranium is soluble or insoluble) of 0.028 as the fraction of inhaled uranium deposited in the kidneys and a kidney mass of $300 \mathrm{~g}$ for the average adult, the limiting condition can be calculated:

$$
\begin{gathered}
0.028 \cdot V \cdot C \cdot T=0.003 \cdot M \\
\text { or } \\
C \cdot T=0.003 \cdot M /(0.028 \cdot V)
\end{gathered}
$$


where $\quad V=$ ventilation rate $\left(\mathrm{m}^{3} / \mathrm{hr}\right)$

$C=$ concentration $\left(\mathrm{mg} / \mathrm{m}^{3}\right)$

$M=\operatorname{mass}(\mathrm{g})$

$T=$ time (hours)

0.028 = fraction of inhaled uranium deposited in the kidneys

$0.003=.003 \mathrm{mg}$ of uranium per $\mathrm{g}$ of kidney tissue.

This equation can be used for other age groups if the kidney mass and the ventilation rates are known. McMillan calculated these exposure limits based on data in NUREG-0172 (Hoenes and Soldat 1977) and the Radiological Health Handbook (1970) (see Table 4.12). These emergency limits range from 25 to $40 \mathrm{mg}-\mathrm{hr} / \mathrm{m}^{3}$.

Results of these two strategies are very similar and yield values greater than $25 \mathrm{mg}-\mathrm{hr} / \mathrm{m}^{3}$. This is about 3 times the weekly 1 imit of $8 \mathrm{mg}-\mathrm{hr} / \mathrm{m}^{3}$ for an occupational worker. Given that the transfer of uranium from the blood to the kidneys is $11 \%$ (Hoenes and Soldat 1977), the derived $25 \mathrm{mg}-\mathrm{hr} / \mathrm{m}^{3}$ can be compared to the postulated dose of uranium in the blood stream that may cause death. This concentration has been estimated at $1 \mathrm{mg} / \mathrm{kg}$ of body weight. Assuming that $25 \%$ of the soluble uranium that is inhaled will be absorbed and using a concentration time factor of 25 to calculate the body intake, the $\mathrm{mg} / \mathrm{kg}$ ratios that can be obtained for each age group are in Table 4.13.

TABLE 4.12. Calculated Emergency Exposure Limits

\begin{tabular}{|c|c|c|c|}
\hline Group & $\begin{array}{c}\text { Kidney } \\
\text { Mass } \\
\mathrm{g} \\
\end{array}$ & $\begin{array}{c}\text { Ventilation } \\
\text { Rate } \\
\mathrm{m}^{3} / \mathrm{hr} \\
\end{array}$ & $\begin{array}{c}C \cdot T \\
m g-h r / m^{3} \\
\end{array}$ \\
\hline $\begin{array}{l}\text { NUREG } 0172 \\
\text { Infant } \\
\text { Child } \\
\text { Teen } \\
\text { Adult }\end{array}$ & $\begin{array}{r}55 \\
100 \\
210 \\
300\end{array}$ & $\begin{array}{l}0.233 \\
0.292 \\
0.562 \\
0.833\end{array}$ & $\begin{array}{l}25.24 \\
36.66 \\
39.97 \\
38.57\end{array}$ \\
\hline $\begin{array}{l}\text { Radiological } \\
\text { Infant }\left(\begin{array}{ll}1 & y\end{array}\right) \\
\text { Child (10 y) } \\
\text { Adult } \\
\text { Adult (work) }\end{array}$ & $\begin{array}{c}\text { th Handb } \\
55 \\
175 \\
300 \\
300\end{array}$ & $\begin{array}{l}0.195 \\
0.616 \\
0.95 \\
1.25\end{array}$ & $\begin{array}{l}30.09 \\
30.43 \\
33.83 \\
25.71\end{array}$ \\
\hline
\end{tabular}


TABLE 4.13. Calculated $\mathrm{mg} / \mathrm{kg}$ Limits

\begin{tabular}{|c|c|c|c|c|}
\hline Group & $\begin{array}{c}\text { Respiration } \\
\text { Rate } \\
\mathrm{m}^{3} / \mathrm{hr} \\
\end{array}$ & $\begin{array}{l}\text { Absorbed } \\
\text { Uranium } \\
\text { mg } \\
\end{array}$ & $\begin{array}{c}\text { Body } \\
\text { Mass } \\
\mathrm{kg} \\
\end{array}$ & $\begin{array}{l}\text { Ratio } \\
\mathrm{mg} / \mathrm{kg}\end{array}$ \\
\hline Infant & 0.233 & 1.456 & 10.7 & 0.136 \\
\hline Child & 0.292 & 1.825 & 21 & 0.086 \\
\hline Teen & 0.562 & 3.512 & 45 & 0.078 \\
\hline Adult & 0.833 & 5.206 & 70 & 0.074 \\
\hline Adult (work) & 1.25 & 7.812 & 70 & 0.111 \\
\hline
\end{tabular}

McMillan concludes that the body burden is less than $0.15 \mathrm{mg} / \mathrm{kg}$, which represents less than $15 \%$ of the 1 imit of $1 \mathrm{mg} / \mathrm{kg}$ set for an acute exposure, and it is therefore "not unreasonable" to use the concentration time factor of $25 \mathrm{mg}-\mathrm{hr} / \mathrm{m}^{3}$ as the maximum acute exposure. He also suggests the use of the $8 \mathrm{mg}-\mathrm{hr} / \mathrm{m}^{3}$ (the maximum weekly exposure for workers) and $2.5 \mathrm{mg}-\mathrm{hr} / \mathrm{m}^{3}$ (a value of 0.1 times the derived maximum acute exposure) as other logical levels of control limits. A diagram of the fraction of DU reaching each compartment gives an overall transfer of 2.8 (ICRP 1959) or 25\%, depending on the approach used, reaching the kidney (Figure 4.20).

Funkhouser (1981), addressing the same issue, supports the use of a maximum planned emergency time-integrated concentration factor of $8 \mathrm{mg}-\mathrm{hr} / \mathrm{m}^{3}$, which he reports is conservative with respect to the radiological models but is consistent with laboratory studies assessing nephrotoxicity following acute inhalation and ingestion of both soluble and insoluble uranium compounds in excess of this value. He notes that the somatic transportable nephrotoxic contribution to the kidneys from the aerosolized, respirable, soluble fraction is $3.75 \%$. The somatic nontransportable radiotoxic contribution to the lungs is also $3.75 \%$. He bases these fractions on the following assumptions:

" - $30 \%$ of the rounds are "effected"; $70 \%$ are "uneffected"

- $50 \%$ of the rounds are aerosolized; $50 \%$ are deposited onsite

- $50 \%$ of the aerosolized compounds are of respirable size; $50 \%$ are nonrespirable 


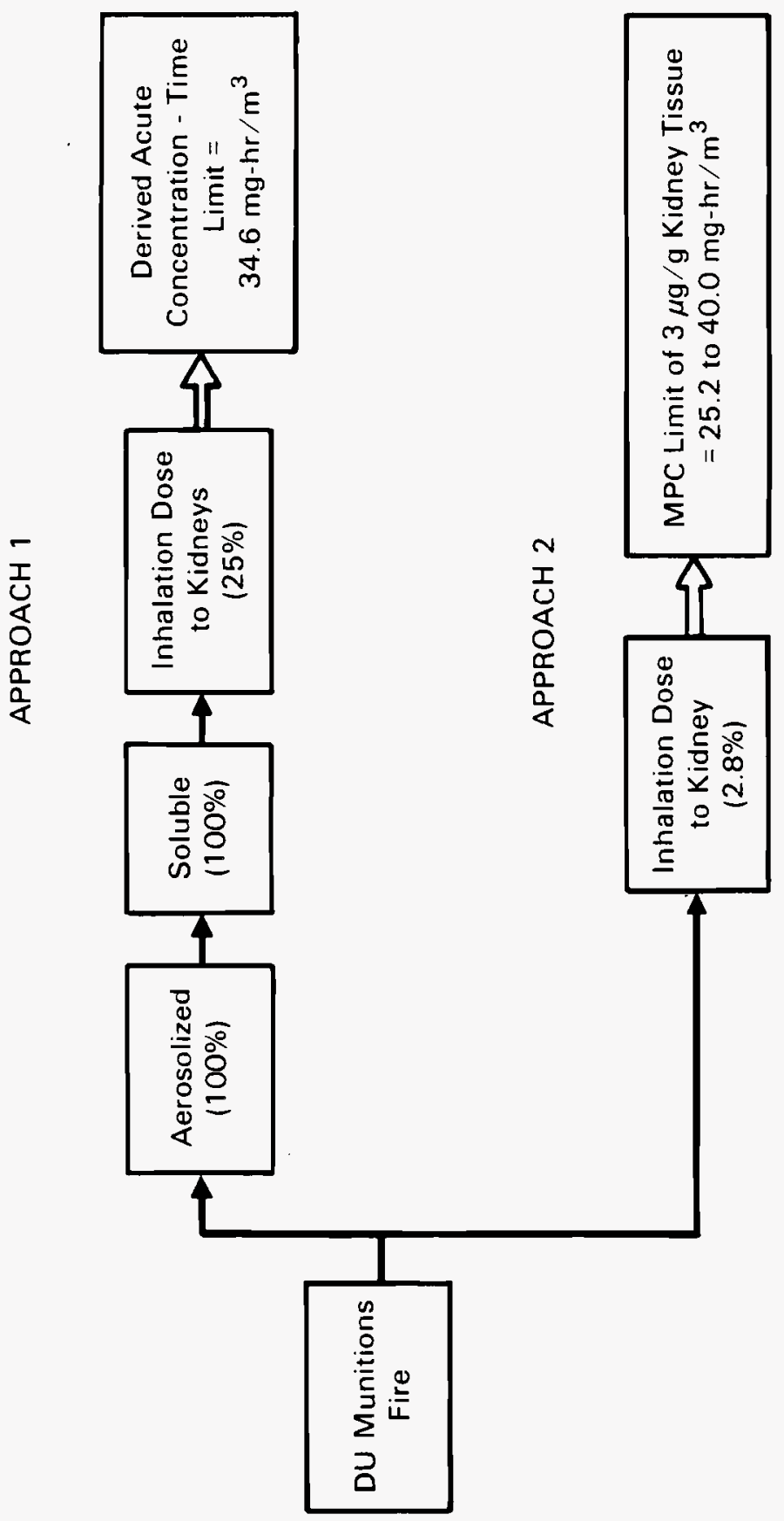

$\frac{1}{8}$

$\frac{9}{2}$

$+$

के

ह

兵

$=$

민

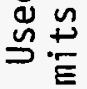

등

은 군

员客

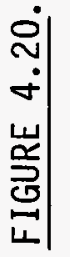


- $50 \%$ of the aerosolized compounds of respirable size are transportable (nephrotoxic limits); 50\% are nontransportable (radiotoxic limit)."

These assumptions are diagramatically illustrated and show $3.75 \%$ entering the kidney from inhalation exposure (Figure 4.21).

Funkhouser also analyzed the radiological dose commitment to the lungs following a single acute inhalation of respirable uranium that remains (is somatic nontransportable) in the lungs assuming no previous accumulation and no additional exposure to uranium. He calculates the inhaled activity deposited to the lungs from the uranium initially present by the equation:

$$
A_{0}(\mu C i)=C T\left(\frac{m g-h r}{m^{3}}\right) \times V\left(\frac{m^{3}}{h r}\right) \times \operatorname{SpA}\left(\frac{\mu C i}{m g}\right) \times f_{i}
$$

where $\mathrm{CT}$ is the integrated time-concentration factor

$V$ is the ventilation rate of $1.25 \mathrm{~m}^{3} / \mathrm{hr}$

$\mathrm{SPA}$ is the specific activity for uranium-238 of $0.333 \mu \mathrm{Ci} / 10^{3} \mathrm{mg}$ of DU and $f_{i}$ is the insoluble, nontransportable fraction deposited in the lungs. Upon substitution and evaluation of the numerical constants, the inhaled deposition is:

$$
\begin{aligned}
& A_{0}=8.0 \frac{\mathrm{mg}-\mathrm{hr}}{\mathrm{m}^{3}} \times \frac{1.25 \mathrm{~m}^{3}}{\mathrm{hr}} \times \frac{0.333 \mu \mathrm{Ci}}{10^{3} \mathrm{mg}} \times 0.0375 \\
& A_{0}=1.25 \times 10^{-4} \mu \mathrm{Ci}
\end{aligned}
$$

The dose equivalent rate to the lungs is calculated as mrem/day following this equation: 


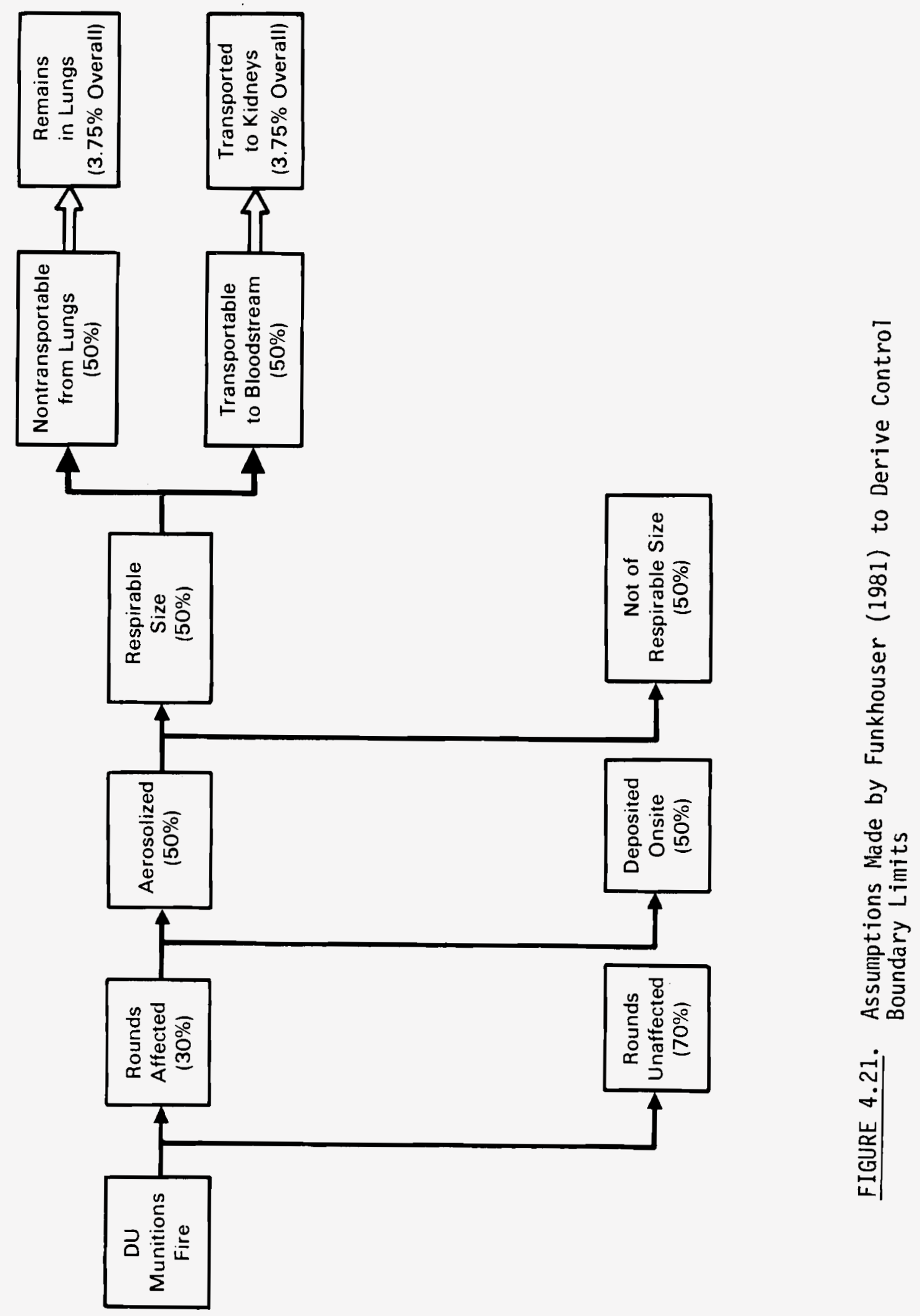




$$
\begin{aligned}
\frac{d}{d t} D E\left(\frac{m r e m}{d a y}\right)= & A_{o} e^{-\lambda E^{\top}}(\mu C i) \times \varepsilon\left(\frac{M e V \cdot r e m}{d i s \cdot r a d}\right) \times \frac{1}{m(g m)} \\
& \times\left[\frac{10^{3} \mathrm{mrem}}{r e m} \times 1.6 \times \frac{10^{-6} \mathrm{erg}}{\mathrm{MeV}} \times \frac{\mathrm{gm} \cdot \mathrm{rad}}{100 \mathrm{erg}}\right. \\
& \left.\times \frac{86400 \mathrm{sec}}{\text { day }} \times 3.7 \times 10^{4} \frac{\mathrm{dis}}{\mathrm{sec} \cdot \mu \mathrm{Ci}}\right]
\end{aligned}
$$

where $\varepsilon=$ the effective absorbed energy per disintegration of $43 \mathrm{MeV} \cdot \mathrm{rem} / \mathrm{dis} \cdot \mathrm{rad}$ for uranium-238 (DU) $m=1000 \mathrm{gm}$, the total mass of both lungs and $\lambda_{E}=$ the effective elimination rate of $1 \mathrm{n} 2 / 380$ days.

For a one-year dose commitment to the lungs, this becomes:

$$
\begin{aligned}
D E(\text { mrem })= & \frac{2.2 \times 10^{3}\left(1.25 \times 10^{-4} \mu C i\right)}{1.82 \times 10^{-3}} \cdot \text { day } \cdot(1-\exp (-1.82 \\
& \left.\left.\times 10^{-3} \times 365\right)\right) \frac{(\text { mrem })}{\mu C i \cdot \text { day }}=73.3 \mathrm{mrem}
\end{aligned}
$$

The resulting one-year dose commitment of about 73 mrem to the lungs is less than $15 \%$ of the exposure permitted the nonoccupationally exposed public.

The 50-year dose commitement to the lungs is:

$$
D E(\text { mrem })=2.2 \times 10^{3}\left(\frac{1.25 \times 10^{-4}}{1.83 \times 10^{-3}}\right)=151 \mathrm{mrem}
$$

While Funkhouser's calculation of $3.75 \%$ as the quantity to the lungs from the DU at the accident site is logical based on his assumptions, the choice of 0.0375 as the $f_{i}$ value may not be appropriate. The $8.0 \mathrm{mg}-\mathrm{hr} / \mathrm{m}^{3}$ integrated time-concentration factor is the quantity of uranium in the air over the period of acute intake. Using Funkhouser's assumptions, the starting point for calculating $f_{j}$ would be with the quantity of DU that is aerosolized. The assumptions are that $50 \%$ of the aerosolized compounds are of respirable size 
and that $50 \%$ of the respirable-sized particles are nontransportable from the lungs. The $f_{i}$ would then be 0.25 and the equation:

$$
A_{0}=\frac{8 \mathrm{mg}-\mathrm{hr}}{\mathrm{m}^{3}} \times \frac{1.25 \mathrm{~m}^{3}}{\mathrm{hr}} \times \frac{0.333 \mu \mathrm{Ci}}{10^{3} \mathrm{mg}} \times 0.25
$$

would yield an activity of $A_{0}=8.33 \times 10^{-4} \mu \mathrm{Ci}$ and a one-year dose commitment to the lungs of:

$$
\begin{gathered}
D E(\text { mrem })=\frac{2.2 \times 10^{3}\left(8.33 \times 10^{-4} \mu C i\right)}{1.82 \times 10^{-3}} \cdot \text { day } \cdot(1-\exp (-1.82 \\
\left.\left.\quad \times 10^{-3} \times 365\right)\right) \frac{(\text { mrem })}{\mu C i \cdot \text { day }}=489 \mathrm{mrem}
\end{gathered}
$$

The 50-year dose commitment to the lungs would be:

$$
D E(\text { mrem })=2.2 \times 10^{3} \frac{\left(8.33 \times 10^{-4}\right)}{1.82 \times 10^{-3}}=1001 \mathrm{mrem}
$$

The one-year dose commitment of almost 0.5 rem equals the amount of chronic exposure permitted annually to the nonoccupationally exposed public in 10 CFR 20. This dose is $10 \%$ to $50 \%$ of EPA's protective action guide of 1 - to 5-rem whole-body exposure under emergency conditions.

The assumptions used in this analysis may be overly conservative in calculating dose. Parameters such as the chemical form of DU and its actual solubility must be considered as well as the particle size distribution at the point of exposure. The use of the 0.0375 factor rather than the 0.25 for the respirable, nontransportable fraction may well be offset by the addition of assumptions of atmospheric diffusion from the the accident site to the point of exposure.

The ICRP Report 30 dosimetric model for the respiratory system breaks uranium compounds into three classes: $D$ (day) for relatively soluble compounds with half-times in the lungs of less than 10 days, $W$ (week) for compounds with half-times of 10 to 100 days, and $Y$ (year) for compounds with retention times longer than 100 days. Under this system, the highly insoluble 
uranium oxides, $\mathrm{UO}_{2}$ and $\mathrm{U}_{3} \mathrm{O}_{8}$, are assigned to inhalation class $Y$ and the fraction of material expected to enter the gastrointestinal tract following inhalation exposure is $0.002 . \quad \mathrm{UO}_{3}$ is assigned to class $W$, and it is estimated that a fraction of 0.05 reaches the GI tract. Of the quantity entering the GI tract, 0.12 ( $D$ and $W$ ) and $0.00052(Y)$ fractions are expected to reach the kidney. The effective half-lives in this case are 6 and 1500 days, respectively.

The choice of the concentration limit for exclusion boundary calculations depends on the quantity of respirable, soluble uranium postulated to be released. The most conservative calculation is to assume that if any is soluble, it is all soluble, and the chemical toxicity concentrations apply. This will protect personnel from chemical and radiological injury. If, however, the soluble portion of the respiratory uranium is only a small fraction of the uranium present, as would be expected from field data, use of the radiological concentration limits is more reasonable, especially for short-term incidents. In any case, the limit used in the calculations should be selected after consideration of the expected ratios of soluble to insoluble compounds and respirable to nonrespirable particle sizes.

Application of 1983 field data. In the 1982-83 burn tests with the M829, the DU penetrators did not follow the behavior pattern established in earlier tests due to the combustible cartridge material used in the M829. Rather than ejecting nearly undamaged penetrators from the fire as happened with the M774 in 1977, the M829 propellent fizzled and the rounds remained in the fire. The heated DU penetrators oxidized over a period of two days, and in several cases al1 that was left after the fire cooled was powdered uranium oxide. Eighty percent of the original mass was oxidized. During the April 1983 test, a containment structure (8-ft high, 30-ft by $30-\mathrm{ft}$ square) facilitiated recovery of the DU oxide. Air monitors were secured outside the structure to detect aerosolized particulates. A mass balance performed on all debris showed complete material recovery.

The containment structure prevented collection on the monitors of any DU debris temporarily suspended by local winds. Results of this test were similar to previous tests without containment structures in that the air 
monitors detected no evidence of airborne DU. Of the in situ oxidized DU collected and analyzed for its size distribution, only $0.2 \%$ to $0.65 \%$ was in the respirable size range. Furthermore, the respirable portion was $99+\%$ insoluble in synthetic lung fluid, indicating that the transfer of uranium to the kidneys would be restricted.

The extent of transfer of uranium to the kidneys of such predominantly insoluble material is not clear. The transfer coefficient of inhaled ${ }^{238} \mathrm{U}$ from the lung to the kidney is given as 0.11 in NUREG-0172 (Hoenes and Soldat 1977). Unfortunately, the assumptions of the chemical form and solubility of the uranium are not stated. McMillan used 25\% of the soluble uranium as the inhaled fraction reaching the blood. The ICRP 30 (1979) cites the percentage of uranium compounds being absorbed by the blood as a result of ingestion as 0.05 for water soluble inorganic compounds (usually hexevalent uranium) and 0.002 for relatively insoluble compounds (usually tetravalent).

Typically, a portion of particles inhaled are removed from the lungs through mucocilia action transferring them through the bronchial tubes where they are coughed up and swallowed, thus entering the GI tract. of the soluble compounds cleared from the lungs in this way, some would enter the blood by absorption through the intestines. Most of the insoluble DU cleared through the GI tract is quickly excreted, contributing little to the dose to the kidney. (In this case then, the radiological risk would be the limiting factor for determining a criteria level.)

The percentage of uranium reaching the lungs and kidneys, based on the field data and stated assumptions, is an expected transport of $0.51 \%$ to the lungs and $0.0052 \%$ to the kidneys from inhalation exposure (see Figure 4.22 ).

Other exposure pathways. The direct hazard of inhalation exposure from a passing cloud of uranium aerosols is the most significant offsite concern from a major DU fire. There are, however, additional pathways of exposure, which will be briefly discussed and dismissed from further analysis because the inhalation exposure limit is the most critical in establishing exclusion boundary areas. The first of these is the external radiation exposure. The ${ }^{238_{U}}$ is an alpha emitter and as such poses no real risk to any of the sensitive 


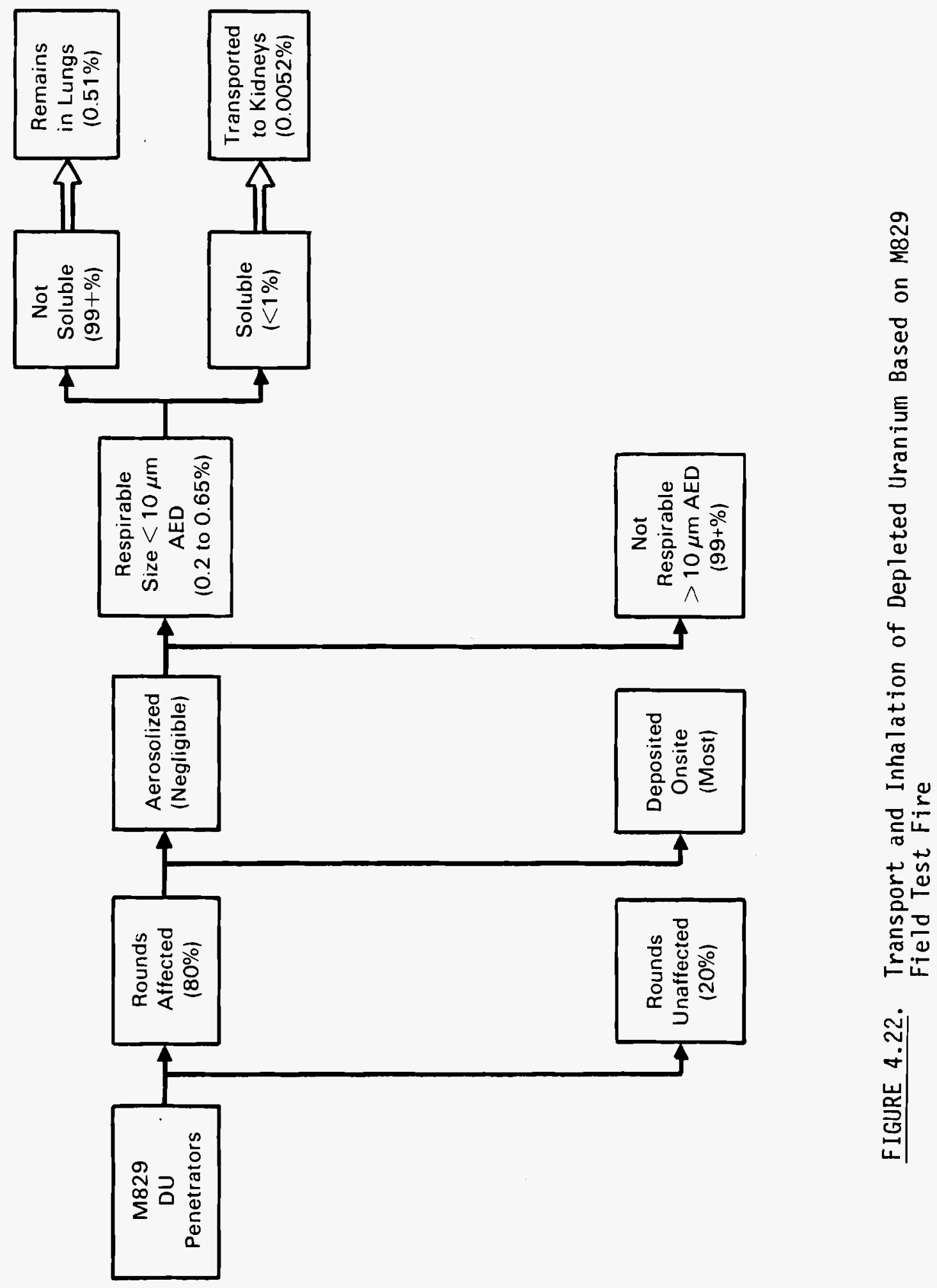


tissues of the body including the lenses of the eyes at a depth of $3 \mathrm{~mm}$ and the basal layer of the epidermis at $70 \mu \mathrm{m}$. This nonpenetrating radiation interacts only with the outer dermal layer and, at scenario atmospheric levels, would have no significant effect. The beta radiation in the plume could pose a hazard to uncovered skin, and gamma radiation would contribute to the whole-body dose. However, these dose contributions are expected to be insignificant. (a)

Deposition of the radionuclides into the local environment may provide an additional source of direct ingestion from DU clinging to or incorporated into vegetation or contaminating the potable water supplies. Release from a major fire presents a contamination source to the local environment. The extent of the area affected depends on the air circulation patterns, deposition rate and the existing background radiation levels. The long half-life of the uranium isotope enhances the potential for biological uptake through the food chain. Dilution and diffusion transport mechanisms remove some of the deposited material from the site. Environmental weathering may break DU down allowing it to leach into the soil but it tends to remain close to the soil surface (Stoetzel, Waite and Gilchrist 1983) rather than migrating into groundwater aquifers. Uptake of uranium by plants is highly variable depending on the soil chemistry and composition and the relation to the growing season. However, plants generally select against uranium uptake. Ingestion of plants that have direct foliar deposition is probably more significant in the food chain.

A release over a water body provides a mechanism of transport from the site of particles directly deposited on its surface or entering through runoff and leaching. Generally the DU particles are not carried far before they are deposited to the sediments. Most DU compounds are relatively insoluble in water though DU penetrators themselves have been shown to break down in both fresh and salt water (TASC 1979).

(a) Documented in a letter report, "Calculations of the Effects of Shipping and Bulk Storage Accidents Involving Depleted Uranium Penetrators," from R. I. Scherpelz, J. Mishima and M. A. Parkhurst (Pacific Northwest Laboratory) to the U.S. Army in 1984. 
Food chain effects should be negligible to nonexistent for this shortterm release and the radioisotopes involved. Studies of consumption of deer ingesting DU from downwind of an area periodically exposed to DU target testing showed that even under very conservative assumptions, the general populace would have been exposed to levels well below 10 CFR 20 (NRC 1983) protection standards of annual whole-body and critical-organ doses (TASC 1979).

Resuspension of deposited particles offers a secondary source of DU contamination both external and through inhalation. However, these secondary concentrations will be considerably reduced from the initial release concentration at that location and will pose a proportionate fraction of the initial hazard.

The conclusions to be made concerning the external and internal pathways (aside from inhalation) are that they are decidedly secondary in importance to the primary release. While the environment may become somewhat contaminated over its normal background readings, it also acts as a buffer mitigating the hazard by soil adsorption, which prevents leaching, and by the selective exclusion of uranium from most plants. The severity of this problem is a function of the original release concentration levels, chemical form, and particle size. The extent of contamination will depend on the particle size, deposition rate, and stability class during the initial release.

In the event that these pathway additions to the overall doses are of specific interest, numerous biological food chain modeling codes have been developed which calculate the predicted doses from each identified pathway. 


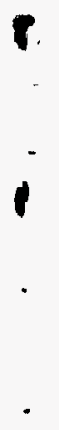

$\checkmark$ 


\section{REFERENCES}

Alexander, R. E. 1974. Application of Bioassay for Uranium. WASH-1251, U.S. Atomic Energy Commission.

Alpert, D. J., P. H. Gudiksen and K. Woodard. 1981. "Modeling Atmospheric Dispersion for Reactor Accident Consequences." Proceedings of the International ANS/ENS Topical Meeting on Probabilistic Risk Assessment, Sept. 20-24, 1981, Port Chester, New York, pp. 808-817. American NucTear Society, Inc., LaGrange Park, Illinois.

American Conference of Governmental Industrial Hygienists (ACGIH). 1983. TLVs Threshold Limit Values for Chemical Substances in Work Air Adopted by ACGIH for 1983-84. Cincinnati, Ohio.

American Society for Testing and Materials (ASTM). 1984. "Standard Test Methods for Microquantities of Uranium in Water by Fluorometry, Procedure D2907-75." In 1984 Annual Book of ASTM Standards, 11.02:479-485, Philadelphia, Pennsylvania.

Aronson, S., R. B. Roof, Jr., and J. Belle. 1957. "Kinetic Study of the Oxidation of Uranium Dioxide." The Journal of Chemical Physics, $37(1): 137-144$.

Ayotte, R. L. December 1983. $120 \mathrm{~mm}$ Cost Comparison Study. Honeywe 11 Incorporated Defence Systems Division, Minnetonka, Minnesota.

Baker, L., Jr., J. G. Schnizlein and J. D. Bingle. 1966. "The Ignition of Uranium." Journal of Nuclear Materials, 20:22-38.

Ballinger, M. Y., and P.C. Owczarski. 1985. "Radioactive Source Term Models in a Compartment Fire Code." Accepted for publication in May or June, 1985, in Nuclear Technology.

Bander, T. J. 1982. Literature Review of Models for Estimating Soil Erosion and Deposition from Wind Stresses on Uranium MilT Tailings Covers. NUREG/CR-2768 (PNL-4302), Pacific Northwest Laboratory, Richland, Washington.

Bayer, A., et al. 1982. "The German Risk Study: Accident Consequence Model and Results of the Study." Nuclear Technology, Vol. 59 (Oct. 1982), pp. $20-50$.

Bennett, M. J., and B. L. Myatt. 1977. "The Effect of Aluminum Content Upon Its Oxidation Behavior in Carbon Dioxide and Air." Journal of Nuclear Materials, $66: 37-43$.

(1) Registered trademark of the American Conference of Governmental Industrial Hygienists. 
Bennett, M. J., and J. B. Price. 1981. "The Oxidation Behavior of Uranium in Air at $348-765^{\circ} \mathrm{K} . "$ Journal of Nuclear Materials, 101:44-55.

Bloch, J., U. Atzmony, M. P. Mintz and N. Shamir. 1982. "Surface Spectroscopy Studies of the Oxidation Behavior of Uranium." Journal of Nuclear Materials, 105:196-200.

Bloch, J., and M. H. Mintz. 1982. "Types of Hydrid Phase Development in Bulk Uranium and Holmium." Journal of Nuclear Materials, 110:251-255.

Bloore, E. W., and E. F. Wilsey. November 1979. Tank Burn Test "Operation Hot-Box." DU-1, ARRADCOM DU Task Force, U.S. Army Armament Research and Development Command, Dover, New Jersey.

Briggs, G. A. 1969. Plume Rise. TID-25075, available from National Technical Information Service, Springfield, Virginia.

Briggs, G. A. 1973. Diffusion Estimation for Small Emissions, ATDL Contribution File No. 79, Atmospheric Turbulence and Diffusion Laboratory.

Briggs, G. A. 1975. "Plume Rìse Predictions." In Lectures on Air Pollution and Environmental Impact Analyses, Workshop Proceedings, Boston, Massachusetts, September 29 - October 3, 1975, pp 59-111. American Meteorological Society, Boston, Massachusetts.

Bucci, S. A., and J. Y. Nalbandian. April 1981. Sensitivity Study on Air Dispersion and Hazard Exposure Models. TR-3135-2, The Analytical Sciences Corporation, Reading, Mississippi.

Carter, R. F., and K. Stewart. 1970. "On the 0xide Fume Formed by the Combustion of Plutonium and Uranium." Inhaled Particles III, W. H. Walton, Ed., Unwin Brothers Limited, The Gresham Press, Old Working, Surrey, England.

Chan, M. K. W., and J. Mishima. July 1983. Characteristics of Combustion Product: A Review of the Literature. NUREG/CR-2658 (PNL-4174), Pacific Northwest Laboratory, Richland, Washington.

Clarke, R. K., J. T. Foley, W. F. Hartman and D. W. Larson. September 1975. Severity of Transportation Accidents, Vol III Motor Carriers. SLA-74-0001, Sandia National Laboratory, Atbuquerque, New Mexico.

Clayton, G. D., and F. E. Clayton, editors. 1978. Patty's Industrial Hygiene and Toxicology. Third Edition. John Wiley \& Sons, New York.

Colmenares, C., R. Howell and T. McCreary. 1981. Oxidation of Uranium Studied by Gravimetric and Positron Annihilation. UCRL-85549, Lawrence Livermore National Laboratory, Livermore, California.

Condon, J. B., S. S. Cristy and J. R. Kirkpatrick. 1983. Uranium Reaction with Water Vapor. V/DU-274, Oak Ridge, Y-12 Plant, Oak Ridge, Tennessee. 
Conne11, J. R., and H. W. Church. 1980. Recommended Methods for Estimating Atmospheric Concentrations of Hazardous Vapors after Accidental Release Near Nuclear Reactor Sites. NUREG/CR-1152, SAND 78-1879, Sandia Laboratories.

Egan, B. A. 1975. "Turbulent Diffusion in Complex Terrain." In Lectures on Air Pollution and Environmental Impact Analyses, D. Haugen, ed., pp. 112-135. American Meteorological Society, Boston, Massachusetts.

Egan, B. A., R. D'Errico and C. Vaudo. 1979. "Estimating Air Quality Levels in Regions of High Terrain Under Stable Atmospheric Conditions." Fourth Symposium on Turbulence, Diffusion, and Air Pollution. American Meteorological Society, Boston, Massachusetts.

Elder, J.C., and M. C. Tinkle. 1980. 0xidation of Depleted Uranium Penetrators and Aerosol Dispersal at High Temperatures. LA-8610-MS, Los A1amos, New Mexico.

Ellis, W. P. May 1981. "An Unusual Temperature Dependence in the Oxidation of 0xycarbide Layers on Uranium." Surface Sciences, 109:L567-L570.

Emmons, H. W. 1978. "The Prediction of Fires in Buildings." In 17th Symposium (International) on Combustion, The Combustion Institute, Pittsburgh, Pennsylvania.

Environmental Protection Agency. 1980. Manual of Protective Action Guides and Protective Actions for Nuclear Incidents. EPA-520/1-75-001. Washington, D.C.

Eve, I. S. 1964. "Some Suggested Maximum Permissible Single Intakes of Uranium." Health Physics, 10:773-776.

Funkhouser, M. D. 1981. "Setting Control Boundaries from Igloos Storing Pyrophoric Depleted Uranium." Letter report to Commander, U.S. Army Material Develop and Readiness Commiand, Department of the Army, Fort Belvoir, Virginia.

Gifford, F. A. 1968. "An Outline of Theories of Diffusion in the Lower Layers of the Atmosphere." In Meteorology and Atomic Energy - 1968, D. H. Slade, ed., pp. 66-116. AEC Report TID-24190. U.S. Atomic Energy Commission, National Technical Information Service, Springfield, Virginia.

Gifford, F. A. 1976. "Turbulent Diffusion - Typing Schemes: A Review." Nuclear Safety, Vol 17. pp 68-86.

Gilchrist, R. L., G. B. Parker and J. Mishima. 1978. Radiological and Toxicological Assessment of an External Heat (Burn) Test of the $105 \mathrm{~mm}$ Cartridge, APFSDS-T, XM774. PNL-2670, Pacific Northwest Laboratory, Richland, Washington. 
Gittus, J. H. 1963. "Gaseous and Aqueous Corrosion." Ch. 12 in Uranium, Butterworth's, Washington, D.C.

Glissmeyer, J. A., and J. Mishima. 1979. Characterization of Airborne Uranium from Test Firings of XM774 Ammunition. PNL-2944, Pacific Northwest Laboratory, Richland, Washington.

Goldstein, J. I., H. Yankowitz, D. F. Newbury, F. Lifshin, J. W. Colby and J. C. Coleman. 1977. "Image Formation in the Scanning Electron Microscope." Chapter IV in Practical Scanning Electron Microscope, Plenum Press, New York, New York.

Gray, G. J. January 1978. Hazard Classification Test of the Cartridge, $105 \mathrm{~mm}$, APFSDS-T, XM774. U.S. Army Armament Research and Development Command, Dover, New Jersey.

Halverson, M. A., and M. Y. Ballinger. May 1984. "Radioactive Airborne Releases From Burning Contaminated Combustibles." Presented at 1984 American Nuclear Society Annual Meeting, New Orleans, Louisiana, June 3-8, 1984.

Hanna, S. R., G. A. Briggs and R. P. Hosker, Jr. 1982. Handbook on Atmospheric Dispersion. DOE/TIC-11223.

Harmathy, T. Z. August 1972a. "A New Look at Compartment Fires, Part I." Fire Technology.

Harmathy, T. Z. November 1972b. "A New Look at Compartment Fires, Part II." Fire Technology.

Harmathy, T. Z., and J. R. Mahaffey. 1982. "Normalized Heat Load: A Key Parmaeter in Fire Safety Design." In Fire and Materials, 6:27-31.

Hilliard, R. K. 1958. Oxidation of Uranium in Air at High Temperatures. HW-58022, HAPO - GeneraT ETectric Company, Richland, Washington.

Hodge, H. C., J. N. Stannard and J. B. Hursh, Editors. 1973. Uranium, Plutonium Transplutonic Elements. Springer-Verlag, New York.

Hoenes, G. R., and J. K. Soldat. 1977. Age-Specific Radiation Dose Commitment Factors for a One-Year Chronic Intake. NUREG-0172. Prepared by the Pacific Northwest Laboratory for the U.S. Nuclear Regulatory Commission.

Hooker, C. D., D. E. Hadlock, J. Mishima and R. L. Gilchrist. 1983. Hazard Classification Test of the Cartridge, $120 \mathrm{~mm}$, APFSDS-T, XM829. PNL-4459, Pacific Northwest Laboratory, Richland, Washington.

International Commission on Radiological Protection (ICRP). 1959. Recommendations of the International Commission on Radiological Protection. Report of Committee 2 on Permissible Dose for Internal Raidation, ICRP Publication 2, Pergamon Press, London. 
International Commission on Radiological Protection (ICRP). 1966. Task Group on Lung Dynamics.

International Commission on Radiological Protection (ICRP). 1979. Limits for Intakes of Radionuclides by Workers. ICRP Publication 30, Part 1.

Iwasaki, M., and N. Ishikawa. 1970. "Air Oxidation of $\mathrm{UO}_{2}$ Pellets at $800^{\circ}$ and $900^{\circ} \mathrm{C} . "$ Journal of Nulcear Materials, 36:116-119.

Iwasaki, M., T. Sakurai, N. Ishikawa and Y. Kobayashi. 1969. Oxidative Pulverization of $\mathrm{UO}_{2}$ Pellets. JAERI-1171, Japan Atomic Energy Institute, Japan.

Jackson, R. L., J. B. Condon and L. M. Steckel. 1977. Uranium/Water Vapor Reactions in Gaseous Atmospheres. Y-2078, Oak Ridge Y-12 Plant, Oak Ridge, Tennessee.

Kalkwarf, D. R. 1982. "Dissolution Rates of Airborne Uranium in Simulated Lung Fluid." Health Phys. 43(4):587-590.

Kalkwarf, D. R. 1983. "Dissolution Rates of Uranium Compounds in Simulated Lung Fluid." The Science of the Total Environment, 28:405-414.

Leibowitz, L., J. G. Schnizlein, J. D. Bingle and R. C. Vogel. 1961. "The Kinetics of Oxidation of Uranium between $125^{\circ}$ and $250^{\circ} \mathrm{C} . "$ Journal of the Electrochemical Society, 108(12):1155-1160.

Lynch, C. T., ed. 1974. CRC Handbook of Material Sciences, Vol. 1, General Properties. CRC Press, Cleveland, Ohio.

McMillan, R. C. 1979. "Dispersal of Uranium During a Fire." Letter report, Department of the Army, Fort Belvoir, Virginia.

Mackison, F. W., R. S. Stricoff, L. J. Partridge, Jr., Editors. 1978. NIOSH/ OSHA Pocket Guide to Chemical Hazards. Prepared by A. D. Little, Inc., for the U.S. Department of Health and Human Services and the U.S. Department of Labor, Washington, D.C.

Martin, R. A., et al. 1983. Material Transport Analysis for Accident-Induced Flow in Nuclear Facilities. NUREG/CR-3527, LA-9913-MS, Los Alamos National Laboratory.

Megaw, W. J., R. C. Chadwick, A. C. Wells and J. E. Bridges. 1961. "The Oxidation and Release of Iodine-131 From Uranium Slugs Oxidizing in Air and Carbon Dioxide." Reactor Science and Technology, 15:176-184.

Mercer, T. T. 1977. "Matching Sampler Penetration Curves to Definitions of Respirable Fraction." Health Phys. 33:259-264.

MICROME. July 1975. Instruction Manual SediGraph 5000D Particle Size Analyzer. MIC $P / N: 500 / 42802$, Micromeritics Instrument Corporation, Norcross, Georgia. 
Mishima, J., and L. C. Schwendiman. Apri1 1973. Fractional Airborne Release of Uranium (Representing Plutonium) During the Burning of Contaminated Waste. BNWL-1730, Pacific Northwest Laboratory, Richland, Washington.

Mishima, J. 1976. "Potential Aerosol Generation Mechanisms From Damaged Shipping Packages." Transport Packaging for Radioactive Materials, Proceedings of a Seminar in Vienna, August 23-27, 1976, Internationa 1 Atomic Energy Agency, Vienna.

Mitler, H. E. 1978. The Physical Basis for the Harvard Computer Fire Code. Home Fire Project Technical Report Number 34, Division of Applied Sciences, Harvard University, Cambridge, Massachusetts.

Mitler, H. E., and H.W. Emmons. 1981. Documentation for CFC V, the Fifth Harvard Computer Fire Code. Home Fire Project Technical Report Number 45, Division of Applied Sciences, Harvard University, Cambridge, Massachusetts.

Morton, B. R., G. I. Taylor and J. S. Turner. 1956. "Turbulent Gravitational Convection from Maintained and Instantaneous Sources." In Proceedings Roy. Soc. (London), Ser. A, 234:1-23.

0lofson, C. T., G. E. Meyer, and A. L. Hoffmanner. 1976. Processing and Applications of Depleted Uranium Alloy Products. MCIC-76-28, Metals and Ceramics Informations Center, Battelle Columbus Laboratories.

Pasquill, F. 1961. "The Estimation of the Dispersion of Windborne Materia1." Meteorological Magazine, 90:33-49.

Pasquill, F. 1974. Atmospheric Diffusion, 2nd Edition. John Wiley \& Sons, New York.

Peakill, K. A., and J. E. Antill. 1960. "Oxidation of Uranium Dioxide in Air at $350^{\circ}-1000^{\circ} \mathrm{C} . "$ Journal of Nuclear Materials, 2:194-195.

Raabe, 0. G. 1980. "Physical Properties of Aerosols Affecting Inhalation Toxicology," in Pulmonary Toxicology of Respirable Particles, Proceedings of the Nineteenth Annual Hanford Life Sciences Sympsoium at Richland, Washington, October 22-24, 1979.

Radiological Health Handbook. 1970. U.S. Department of Health, Education and Welfare, Public Health Service. Rockville, Maryland.

Ramsde11, J. V. 1983. Evaluation of the Split-H Approach to Modeling NonBuoyant Releases from Vent Stacks. NUREG/CR-3016, PNL-4516, Pacific Northwest Laboratory, Richland, Washington.

Ramsde11, J. V., G. F. Athey and C. S. Glantz. 1983. MESOI Version 2.0: An Interactive Mesoscale Langrangian Puff Dispersion Model With Deposition and Decay. NUREG/CR-3344, PNL-4753, Pacific Northwest Laboratory, Richland, Washington. 
Ritchie, A. G. 1981. "A Review of the Rates of Reaction of Uranium with Oxygen and Water Vapor at Temperatures Up to $300^{\circ} \mathrm{C} . "$ Journal of Nuclear Materials, 102:107-182.

Robinson, R. A., W. J. Zielenback and A. A. Lawrence. August 1976. Survey of Strain Rate Effects for Some Common Structural Materials Used in Radioactive Material Packaging and Transport Systems. BMI-1954, Battelle Columbus Laboratory, Columbus, Ohio.

Rupp, A. F., et al. 1948. Dilution of Stack Gases in Cross Winds. AEC Report AECD-1811, U.S. Atomic Energy Commission.

Schmitt, C. R. May 1975. "Carbon Microspheres as Extinguishing Agents for Fissionable Material Fires." Fire Technology, 11:95-98.

Schnizlein, J. G., L. Baker, Jr., and J. D. Bingle. 1966. "The Ignition of Binary Alloys of Uranium." Journal of Nuclear Materials, 20:39-47.

Schnizlein, J. G., P. J. Pizzolato, H. A. Porte, J. D. Bingle, D. F. Fischer, L. W. Mishler and R. C. Vogel. 1959. Ignition Behavior and Kinetics of 0xidation of the Reactor Materials, Uranium, Zirconium, Plutonium and Thorium, and Binary Alloys of Each. A Status Report. ANL-5974, Chemical Engineering Division, Argonne National Laboratory, Lemont, Ill inois.

Scrpisick, R. C., K. C. Crist, M. I. Tillery and S. C. Sonderholm. (Undated) Preliminary Study of Uranium Dioxide Dissolution.

Sehme1, G. A. 1980. "Particle Resuspension: A Review." Environment Internationa 1, 4:107-127.

Sehme1, G. A., and F. D. Lloyd. 1976. "Particle Resuspension Rates." In Atmosphere - Surface Exchange of Particulate and Gaseous Pollutants, Energy Research and Development Administration, Technical Information Center, Washington, D.C.

Singer, L. A., and J. A. Fizzola. November 1964. "The Prediction of the Rise of a Hot Cloud From Field Experiments." APCA Journa 1, 11(11):455-458.

Slade, D. H. (ed.). 1968. Meteorology and Atomic Energy-1968. TID-24190, National Technical Information Service, Springfield, Virginia.

Stakebake, J. L. September 1979. "Kinetics for the Reaction of Hydrogen with Uranium Powder." Journal Electrochemical Society: Solid-State Science and Technology, 126(9):1596-1601.

Stakebake, J. L. 1979. Kinetics for the Reaction of Hydrogen with Uranium Powder. RFP-2845, Atomics International, Rocky Flats Plant, Golden, Colorado.

Stakebake, J. L., and G. E. Bixby. June 1979. Evaluation of Reaction Kinetics for Gas-Powder Systems. RFP-2849, Rockwell International Corporation, Golden, Colorado. 
Steciak, J., A. Tewarson and J. S. Newman. February 1983. Fire Properties of Combustible Materials Commonly Found in Nuclear Fuel Cycle Facilities. FMRI J.1.0G3R8.RC, Factory Mutual Research, Norwood, Mississippi.

Steindler, M. J., and W. B. Seefeldt. 1980. "A Method for Estimating the Challenge to an Air Cleaning System Resulting from an Accidental Explosive Event." In 16th DOE Air Cleaning Conference, CONF-801033, Harvard Air Cleaning Laboratory, Boston, Massachusetts.

Stinton, D. P., S. M. Tiegs, W. J. Lackey and T. B. Lindemer. December 1979. "Rate Controlling Factors in the Carbothermic Preparation of U02-UC2-C Microspheres." Journal American Ceramic Society. 62(11/12):596-599.

Stobbs, J. J., and I. Whittle. 1966. "The Influence of Impurities on the Oxidation of Uranium in Carbon Dioxide Between $450^{\circ} \mathrm{C}$ and $650^{\circ} \mathrm{C}$." Journal of Nuclear Materials, 19:160-168.

Stoetzel, G. A., D. A. Waite, and R. L. Gilchrist. 1983. Preliminary Environmental Survey of the B-3 Range and Ford's Farm Area. PNL-2976, Pacific Northwest Laboratory, Richland, Washington.

Strafford, K. N. 1979. "A Comparison of the High Temperature Nitridation and Oxidation Behavior of Metals." Corrosion Science, 19:49-62.

Sutter, S. L. 1982. Accident Generated Particulate Materials and Their Characteristics - A Review of Background Information. NUREG/CR-2651, PNL-4154, Pacific Northwest Laboratory, Richland, Washington.

Sutter, S. L. 1983. Aerosols Generated by Releases of Pressurized Powders and Solutions in Static Air. NUREG/CR-3093 (PNL-4566), Pacific Northwest. Laboratory, Richland, Washington.

Sutter, S. L., J. W. Johnston and J. Mishima. 1981. Aerosols Generated by the Free Fall Spills of Powders and Solutions in Static Air. NUREG/CR-2139 (PNL-3786), Pacific Northwest Laboratory, Richland, Washington.

Sutton, D. G. 1932. "A Theory of Eddy Diffusion in the Atmosphere." In Proceedings Roy. Soc. (London), Ser. A. 135:143.

Suzuki, Y., Y. Arai, T. Sasayama and H. Watanabe. March 1982. "Kinetics on Carbothermic Reduction of $\mathrm{UO}_{2}+\mathrm{C}$ Powders and Compacts of $\mathrm{UC}_{2} \cdot$ " Journal Nuclear Science and Technology, 19(3):22-230.

Tannenbaum, A., ed. 1951. Toxicology of Uranium. McGraw-Hill Book Company, Inc., New York.

Tewarson, A. 1972. "Some Observations on Experimental Fires in Enclosures." Combustion and Flalles, 19:101-111.

Tewarson, A. 1979. Experimental Evaluation of Flammability Parameters of Polymeric Materials. FMRC J.1.1A6R1, Factory Mutual Research, Norwood, Mississippi. 
Tewarson, A. 1980. Physio-Chemical and Combustion/Pyrolys is Properties of Polymeric Materials - Technical Report. FMRC J.1.0EON 6.RC, National Bureau of Standards, Washington, D.C.

The Analytical Sciences Corporation (TASC). 1979. Environmental Effects Summary for Cartridge, $105 \mathrm{~mm}$, APFSDS-T, XM774 and Cartridge, $105 \mathrm{~mm}$, APFSDS-T, M735A1. TR-1518-2. Prepared for the U.S. Army Armament Research and Development Command, Dover, New Jersey.

The Analytical Sciences Corporation (TASC). 1980. Procedures to Calculate Radiological and Toxicological Exposures From Airborne Releases of Depleted Uranium. TR-3135-1. Prepared for the U.S. Army Research and Development Command, Dover, New Jersey.

Tyzack, C., and H. C. Cowen. 1976. "Corrosion of Reactor Materials in Carbon Dioxide." Atomic Energy Review. 142:263-324.

U.S. Department of Army (ARMY). 1962. Uranium Properties - Processes Control. Monogram Series No. 55, Watertown Arsenal Laboratories, Watertown, Massachusetts.

U.S. Department of the Army (ARMY). 1979. Dispersal of Uranium During a Fire. 0866IRJAY-4 (Revised), U.S. Army Mobility Equipment Research and Development Command, Fort Belvior, Virginia.

U.S. Department of the Army (ARMY). 1981. Setting Control Boundaries from Igloo Storing Pyrophoric Depleted Uranium. Material Technology Laboratory, U.S. Army Mobility Equipment Research Research and Development Command, Fort Belvoir, Virginia.

U.S. Department of the Army, the Navy, the Air Force, and the Defense Logistics Agency (DOD). 1982. Department of Defense Explosives Hazard Classification Procedures. Washington, D.C.

U.S. Environmental Protection Agency (EPA). Revised 1980. Manual of Protective Action Guides and Protective Actions for Nuclear Incidents. EPA-520/1-75-001, Washington, D.C.

U.S. Nuclear Regulatory Commission (NRC). 1977. Methods for Estimating Atmospheric Dispersion of Gaseous Effluents in Routine Releases from Light-Water-Cooled Reactors. Regulatory Guide 1.111, NRC, Washington D.C.

U.S. Nuclear Regulatory Commission (NRC). 1979. Atmospheric Dispersion Models for Potential Accident Consequence Assessments at Nuclear Power Plants. Regulatory Guide 1.145, NRC, Washington, D.C.

U.S. Nuclear Regulatory Commission (NRC). 1983. Title 10, Chapter 1, Code of Federal Regulations, Part 20 - Standards for Protection Against Radiation (10 CFR 20).

Van der Hoven, I. 1982. Meteorological Considerations in the Development of a Real-Time Atmospheric Dispersion Model for Reactor Effluent Exposure Pathway. NUREG/CR-2584, NRC, Washington, D.C. 
Walters, J. 0., J. E. Elliot and E. W. Bloore. 1979. Safety and Health Considerations for Handling Staballoy Munitions. DU-2, ARRADCOM DU Task Force, U.S. Army Armament Research and Development Command, Dover, New Jersey. 
ACGIH - American Conference of Governmental Industrial Hygienists

AED - aerodynamic equivalent diameter, the diameter of a sphere of unit density exhibiting the aerodynamic behavior of the stated size

AMAD - activity median aerodynamic diameter, the aerodynamic equivalent diameter at which half the radioactivity is from particles larger and half is from particles smaller than the stated diameter

break weight - the weight of uranium reacted or the weight gain at which the rate of reaction/oxidation changes

char - the component of wood that does not volatilize at temperatures normally found in fires but does oxidize

chromel alumel - a metal couple used to measure temperature in the upper temperature range

cooked off - the reaction of munitions to high temperature resulting in the dissassembly of the round

crib - a method of stacking wood that allows good ventilation between individual pieces and assures good combustion

DOD - U.S. Department of Defense

DU - depleted uranium

enclosure/compartment fire - a fire occurring inside the confines of a single, open space, totally enclosed but communicating with a source of oxidant

EPA - Environmental Protection Agency

feedback - the transmission of energy back to the fuel surface resulting in continuing vaporization and further combustion

fines collector - a rubber sack used as a last stage in a sonic sieve stack to collect "fines" passing through the last sieve

fire-loading concept - the concept that fire damage is equated to the amount of combustible material per unit area at a location

flashover - the point in an enclosure fire when all the combustible materials are involved and the flames "flashover" the assembly

flaring - the combustion of unconfined propellant that occurs over a very short period of time, seconds 
geometry, internal - the physical parameters within a crib that are

influential in controlling the rate of combustion (e.g., dimensions of the wood pieces/free surface area, porosity of the pile or fractional voidage, air permeability in the horizontal and vertical directions, etc.)

HEAT (rounds) - high explosive anti-tank

HEP (rounds) - high explosive plastic

hyperstoichiometric $\left(\mathrm{UO}_{2}\right)$ - containing more than the quantity of oxygen in the molecule to constitute a stoichiometric (the proportion in which chemical elements combine to form stable molecules) mixture

ICRP - International Commission on Radiological Protection

LLD - least linear diameter, the smallest geometric dimension of a particle (the orientation that allows a particle to pass through a standard mesh in a sieve) expressed as the diameter of a sphere with the same dimension

M774 round - 105-mm round with a DU penetrator and a solid case

M829 round - 120-mm round with a DU penetrator and a combustible case

MICROME - Micromeritic Instrument Corporation

MMAD - mass median aerodynamic diameter, half the mass of particles are associated with particles greater than and half less than the stated AED

MMD - mass median diameter, half the mass of particles are associated with particles greater than and half less than the stated geometric diameter

MPC - maximum permissible concentration

NRC - U.S. Nuclear Regulatory Commission

NTIS - National Technical Information Service

PAG - protective action guides (EPA)

penetrator - the monolithic metal component of a projectile from kinetic rounds

PNL - Pacific Northwest Laboratory, operated by the Battelle Memorial Institute under contract with the U.S. Department of Energy

RH - relative humidity

respirable fraction - a fraction of the particles airborne that could be inhaled into the human respiratory system (conservatively estimated to be all particles less than $10 \mu \mathrm{m}$ AED) 
SED - spherical equivalent diameter, exhibiting the same aerodynamic behavior as a sphere of the stated diameter

SEM - scanning electron microscope

staballoy - an alloy composed of $0.75 \%$ titanium and $99.25 \%$ depleted uranium

STEL - short-term exposure limit (ACGIH)

TASC - The Analytical Sciences Corporation

thermophoresis - the deposition of particles upon surfaces due to the thermal flux from a hot to cold surface

TWA - time-weighted average (ACGIH)

two-phase flow - a condition occurring in enclosure fires where the combustion products/flames come out the upper portion of an opening and cold air enters through the lower portion of the opening

up-loaded tank - a tank carrying an operational load and mixture of munitions volatiles - a combustible component of wood that is vaporized by temperatures normally in fires

wt\% - percent by weight

zonal - burning in discrete physical layers or zones 


\section{DISTRIBUTION}

No. of

Copies

OFFSITE

30 DOE Technical Information Center

AFMCO (OCSA)

Headquarters Dept. of the Army

ATTN: DACS-FM

Washington, DC 20310

4 CDR, DARCOM

ATTN: AMCSF-P (3)

AMCSG-R (1)

5001 Eisenhower Avenue

Alexandria, VA 22333

Office of the Project Manager

Tank Main Armament System

ATTN: DRCPM-TMA-120

Dover, NJ 07801

2 CDR, USAEHA

ATTN: HSE-R

MSE-0

Aberdeen Proving Ground

Aberdeen, MD 21010

2 CDR, USAARMC

ATTN: $\quad$ ATZK-CD

ATZK-CG

Fort Knox, KY 40121

CMDT USAMMCS

ATTN: ATSK-CD-CS

Redstone Arenal, AL 35800

Inspector General

Headquarters Dept. of the Army

DAIG-SD

Washington, DC 20310

2 CDR, AMCCOM

ATTN: AMSMC-ASR

AMSMC-SF

Rock Island, IL 61202
No. of

Copies

2 OASA

Headquarters Dept. of the Army

ATTN: SAIL-FM

SARDA

Washington, DC 20310

Commander

Aberdeen Proving Ground

ATTN: STEAP-TL

Aberdeen Proving Ground

Aberdeen, MD 21010

Commander

U.S. Army Materials \& Mechanics Research Center

ATTN: DRXMR-X

Watertown, MA 02172

Commander

U.S. Army Research Office

P.0. Box 12211

Research Triangle Park, NC 27709

Commander

U.S. Army Foreign Science \& Technical Center

220 7th Street NE

Charlottesville, VA 22901

Commander

U.S. Army Tank-Automotive Material Readiness Command ATTN: DRSTA-E

Warren, MI 48090

Commander

U.S. Naval Ordinance Laboratory

ATTN: CODE WM

Silver Springs, MD 20910

Director

Air Force Materials Laboratory

ATTN: AFML Technical Library

Wright-Patterson AFB

Dayton, OH 45433 
No. of

Copies

\section{OFFSITE}

ODSRDA

Headquarters Dept. of the Army

ATTN: DAMA-CMS

Washington, DC 20310

ODPAE

Headquarters Dept. of the Army ATTN: ACS-DPA.

Washington, DC 20310

Surgeon Genera?

Headquarters Dept. of the Army

ATTN: DASG-PSP-0

Washington, DC 20310

5 CDR, TRADOC

ATTN: ATPR-HR-S

ATEN-FF-NR

ATCD-S

ATCD-M-A

ATEN-FE

Ft. Monroe, VA 23651

Chief

Bureau of Weapons

Dept. of Navy

ATTN: Technical Information Division

Washington, DC 20025

Deputy Chief of Staff for Research Development and Acquisition

Dept. of the Army

ATTN: DAMA-ARZ-D

Washington, DC 20310

2 Ballistic Research Laboratory

ATTN: AMXBR-VLD-R

$A M X B R-S F$

Aberdeen Proving Ground

Aberdeen, MD 21005
No. of

Copies

29 CDR, ARDC

ATTN: SMCAR-LCU-CT (10)

SMCAR-SF (15)

SMCAR-SCM

SMCAR-TDS (2)

SMCAR-TSS

Dover, NJ 07801

3 ODCSLOG

Headquarters Dept. of the Army

ATTN: DALO-SMD

DALO-SMS

DALO-TSP

Washington, DC 20310

Chief of Public Affairs

Headquarters Dept. of the Army (SAPA-PP)

Washington, DC 20310

6 ODCSOPS

Headquarters Dept. of the Army

ATTN: DAMC-RQD

DAMO-SSM

DAMO-ODO

DAMO-TRS

DAMO-TRI

DAMO-SSA

Washington, DC 20310

General Counse?

Headquarters Dept. of the Army

SAGC

Washington, DC 20310

Director

Defense Ammunition Center and School

ATTN: SARAC-AS

Savanna, IL 61074

CDR, MERADCOM

ATTN: DRME-VR

Ft. Belvoir, VA 22060 


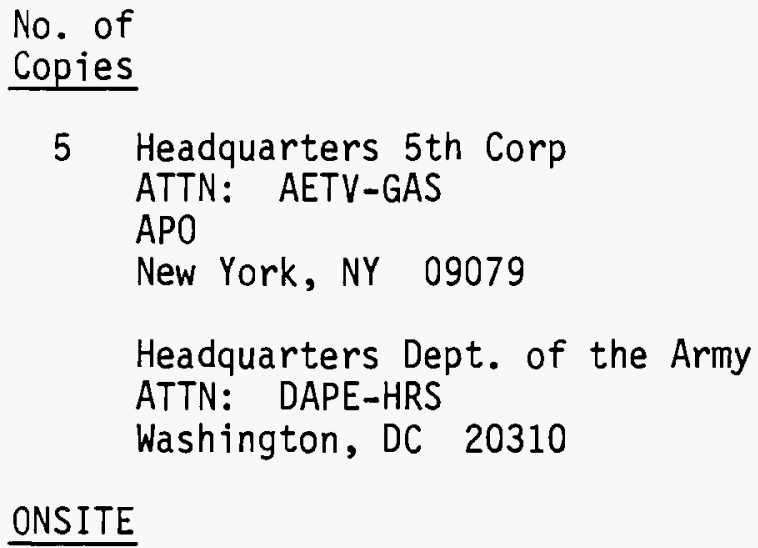

3 DOE Richland Operations Office

P. K. Clark

R. E. Gerton

H. E. Ransom
No. of

Copies

51 Pacific Northwest Laboratory

G. W. R. Endres

T. H. Essig

L. G. Faust

W. A. Glass

D. E. Hadlock (25)

D. L. Haggard

W. N. Herrington, II I

G. R. Hoenes

C. D. Hooker

A. Marshall

J. Mishima (2)

L. H. Munson

M. A. Parkhurst (2)

R. I. Scherpelz (2)

J. M. Selby

K. L. Soldat

C. M. Unruh

Technical Information Center (5)

Publishing Coordination (2) 

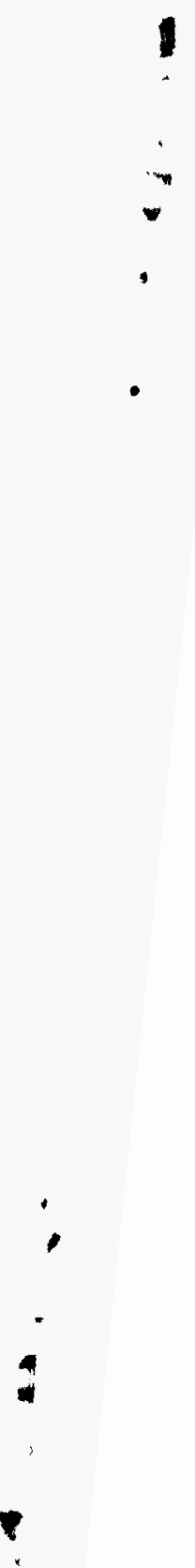